\title{
PRETARGETED CANCER RADIOIMMUNOTHERAPY AND RADIOIMAGING USING ANTIBODIES AND ANTIBODY FRAGMENTS
}

\author{
A Dissertation \\ Presented to \\ The Faculty of the Graduate School \\ At the University of Missouri \\ In Partial Fulfillment \\ of the Requirements for the Degree \\ Doctor of Philosophy

\section{By} \\ MANANKUMAR SHAH \\ Dr. Thomas P. Quinn, Dissertation Supervisor \\ December 2018
}


The undersigned, appointed by the dean of the Graduate School, have examined the dissertation entitled

\section{PRETARGETED CANCER RADIOIMMUNOTHERAPY AND RADIOIMAGING USING ANTIBODIES AND ANTIBODY FRAGMENTS}

Presented by Manankumar Shah

A candidate for the degree of

Doctor of Philosophy in Biochemistry

And hereby certify that, in their opinion, it is worthy of acceptance.

Dr. Thomas P. Quinn

Dr. Susan Deutscher

Dr. George Smith

Dr. Silvia Jurisson

Dr. Frank Schmidt 


\section{ACKNOWLEDGMENTS}

First and foremost, I would like to convey my deepest gratitude to my research advisor Dr. Thomas Quinn. I am immensely thankful for his guidance, support, and mentorship. Tom has been instrumental in my development as a scientist, and I would not be where I am today without him. I cannot thank him enough for the constant encouragement and his willingness to allow me to pursue scientific projects of my interests. Tom has been extremely patient with me throughout the course of my study and at the same time pushed me just enough and on the right moments to keep me on track, and for that I will be forever grateful. I would also like to thank my committee members Dr. Susan Deutscher, Dr. George Smith, Dr. Silvia Jurisson, and Dr. Frank Schmidt for providing valuable feedbacks and direction for my research. I would like to especially thank Dr. Susan Deutscher for all of her guidance and encouragement for last five and half years.

I would like to thank and dedicate this dissertation to my parents, Anilkumar and Darshnaben Shah. They have been incredible role models and have instilled me with great life lessons to make me a better person. Throughout my whole life, they have been incredibly supportive and have encouraged me to chase my dreams. No amount of words can express how indebted I am to them. I am also thankful to my brother, Zubin Shah, who has always given me his honest opinions on everything in life and has inspired me to work hard with dedication

and passion. I would like to say a big thank you to my cousin Parag Shah and my 
sister in-law Arpita Shah. They are the bedrock of my life away from India. I cannot imagine my life in the United States without their love and support.

I would like to thank everyone in the lab as well. Xiuli has played an integral role in my training in radiochemistry, while Marie has provided invaluable help with tissue culture and other day to day lab activities. I have to give a shout out to Austin Prater. Austin has been a great company in the lab to share the highs and the lows of the graduate school. I will miss our conversations on sports, politics, and pretty much on any topic! Last but not least, I am extremely thankful to my fellow graduate students Ryan Harvey, Dr. Widler Casey, Dr. Megan Sheridan, Dr. Erica LaMontagne, and Emily Armbruster. Thank you for being an awesome bunch of friends. I will always cherish the memories we shared including group lunches, study sessions and even studying for 20 questions! I am glad I got to share my graduate school experience with you all. 


\section{TABLE OF CONTENTS}

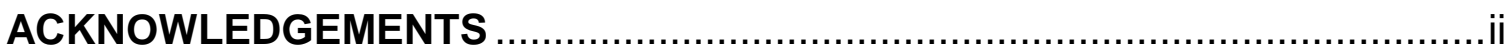

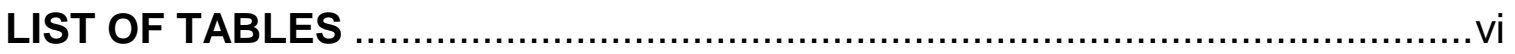

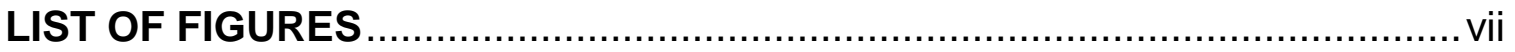

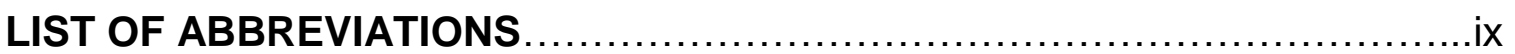

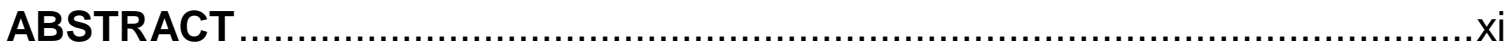

\section{Chapter 1}

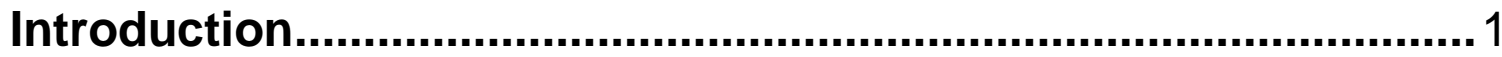

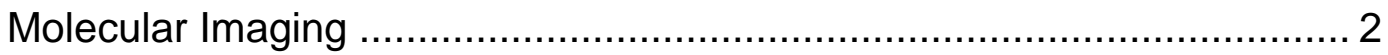

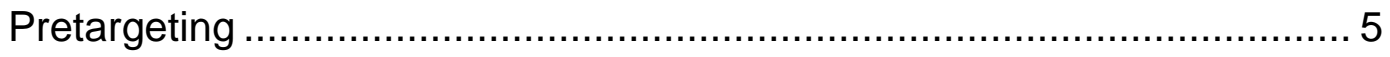

Alpha Particle Based Therapy $\ldots \ldots \ldots \ldots \ldots \ldots \ldots \ldots \ldots \ldots \ldots \ldots \ldots \ldots \ldots \ldots \ldots \ldots$

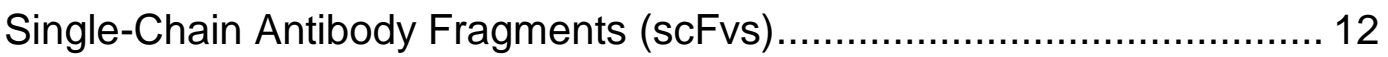

Phage Display of Antibodies ................................................. 15

Matrix Metalloproteinases (MMPs) ........................................ 21

\section{Chapter 2}

Metal-Free Cycloaddition Chemistry Driven Pretargeted

Radioimmunotherapy Using $\boldsymbol{\alpha - P a r t i c l e ~ R a d i a t i o n ~ . . . . . . . . . . . . . . . . . . . . . . . . . . . . . . . ~} 23$

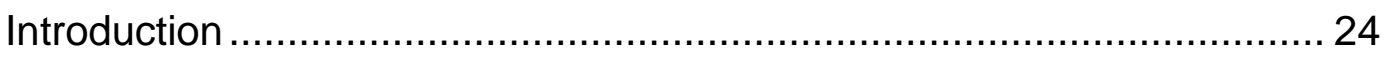

Materials and Methods........................................................ 29

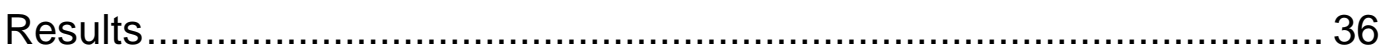

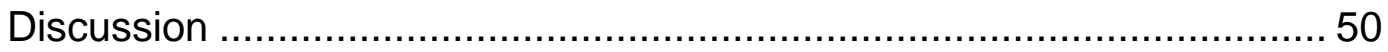


Conclusions

\section{Chapter 3}

MMP-12 As a Novel Tumor Target for PET/CT Imaging Using Phage Display Derived Antibody Fragments and Ultrasmall Silica Nanoparticles ............. 55

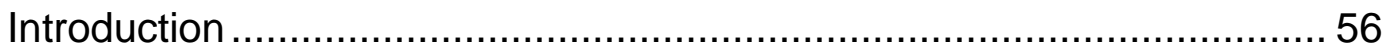

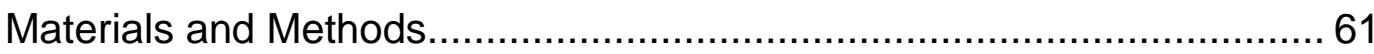

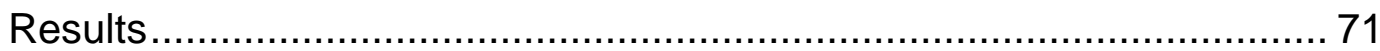

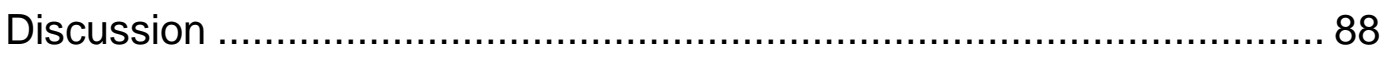

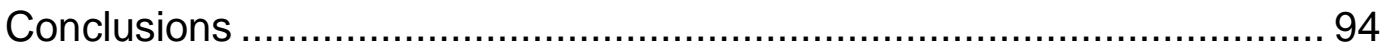

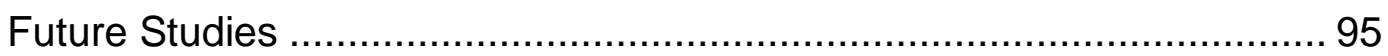

\section{Chapter 4}

Phage Display Selection of Single-Chain Antibody Fragments Against Thomsen-Friedenreich Antigen (TF-Antigen) …..................................... 96

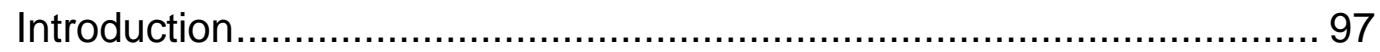

Materials and Methods …......................................................... 100

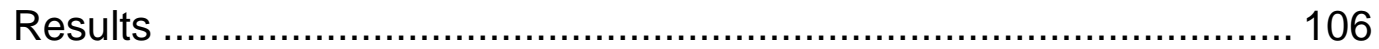

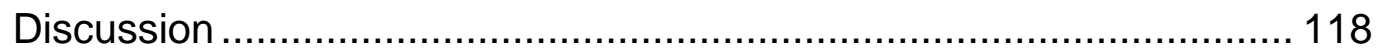

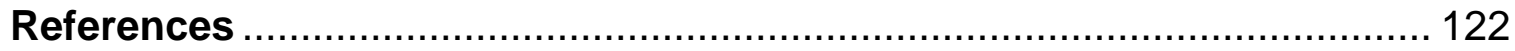

VITA 


\section{LIST OF TABLES}

Table

Page

\section{Chapter 2}

Table 2.1 Biodistribution of ${ }^{212} \mathrm{~Pb}-\mathrm{DOTA}-\mathrm{Tz}$ and ${ }^{212} \mathrm{~Pb}-\mathrm{TCMC}-\mathrm{Tz}$ in LS174T tumor bearing nude mice pretargeted with CC49-TCO mAb........ 40

Table 2.2 Absorbed radiation doses from ${ }^{212} \mathrm{~Pb}-\mathrm{DOTA}-\mathrm{Tz}$ and ${ }^{212} \mathrm{~Pb}-\mathrm{TCMC}$ Tz in mice bearing LS174T colon carcinoma tumors 42

\section{Chapter 3}

Table 3.1 Sequence analysis of MMP-12 specific antibody fragments 74

\section{Chapter 4}

Table 4.1 Stability of ${ }^{99 \mathrm{~m}} \mathrm{Tc}$-labeled $9 \mathrm{C}-\mathrm{scFv}$ 115 


\section{LIST OF FIGURES}

Chapter

Page

\section{Chapter 1}

Figure 1.1 Schematics of full length IgG monoclonal antibody and single-chain fragment (scFv) ............................................................... 16

Figure 1.2 Schematic of phage display selection process...........................20

Figure 1.3 Principle of trypsin based elution...............................22

\section{Chapter 2}

Figure 2.1 Structures of pretargeting reagents used in the study. A) TCO-NHS, B) DOTA-PEG $10^{-T e t r a z i n e ~ a n d, ~ C) ~ T C M C-B n-S C N-P E G ~}{ }_{10}^{-}$ Tetrazine, and D) Galactose-albumin-Tetrazine based clearing agent..........35

Figure 2.2 Pharmacokinetics of ${ }^{212} \mathrm{~Pb}$-labeled tetrazines (without the pretargeted $\mathrm{mAb}$ ) in mice bearing LS174T human colon carcinoma

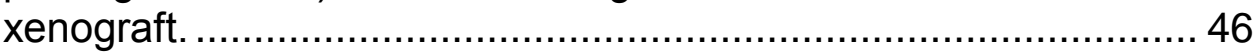

Figure 2.3 Schematic of the pretargeting protocol used in this study ............. 48

Figure 2.4 Plots of average tumor volumes and average body weights of each group of mice during first 21 days of the PRIT studies................. 54

Figure 2.5 Kaplan-Meier survival curves ….......................................... 56

Figure 2.6 The effects of radiation-induced toxicity on white blood cell counts,

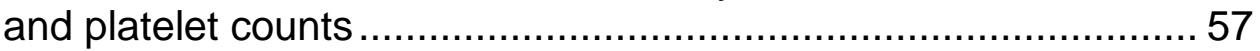

Figure 2.7 Kidney histology sections from untreated mice (PBS), and pretargeted mice treated with $200 \mu \mathrm{Ci}$, and $75 \mu \mathrm{Ci}$ of ${ }^{212} \mathrm{~Pb}$-DOTA-

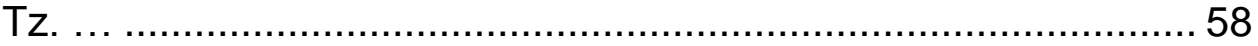




\section{Chapter 3}

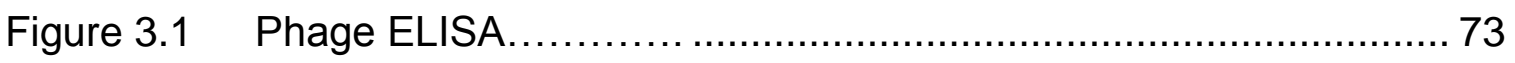

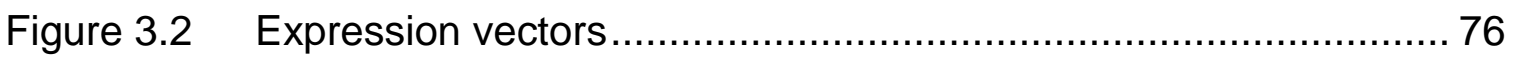

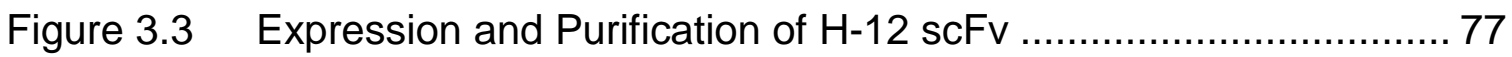

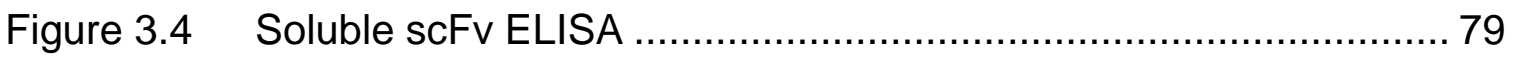

Figure 3.5 Binding affinity of $\mathrm{H} 12$ scFv towards MMP-12 protein was determined by microscale thermophoresis (MST) ....................... 80

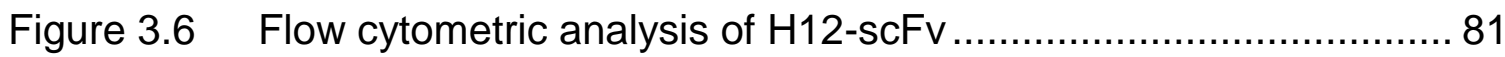

Figure 3.7 Fluorescence microscopy analysis of cell binding....................... 83

Figure 3.8 A schematic of the Cornell prime (C' dot) nanoparticles .............. 84

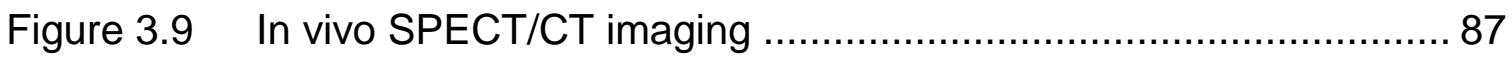

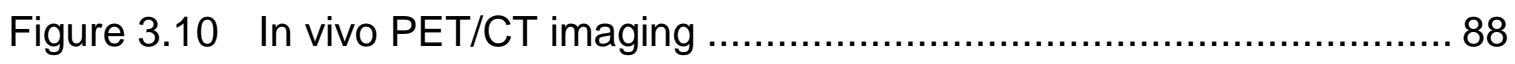

\section{Chapter 4}

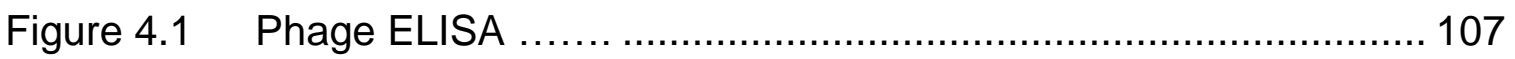

Figure 4.2 Expression and purification of 9C-scFv................................. 109

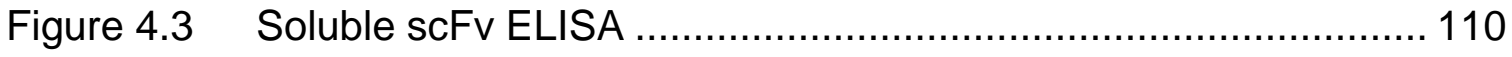

Figure 4.4 Binding affinity determination of the TF-specific 9C-scFv .......... 111

Figure 4.5 Flow cytometry analysis of 9C-scFv ................................ 114

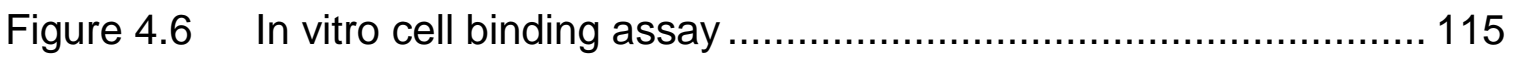

Figure 4.7 In vivo SPECT/CT imaging …............................................ 117 


\section{LIST OF ABBREVIATIONS}

$\%$ ID/g: Percent injected dose/gram

BSA: Bovine serum albumin

EDTA: Ethylenediaminetetraacetic acid

C' dot: Cornell prime ultrasmall silica nanoparticles

CDR: Complementarity Determining Regions

DBCO: Dibenzocyclootyne

DOF: Desferoxamine

DOTA: 1,4,7,10-tetraazacyclododecane-1,4,7,10-tetraacetic acid

ECM: Extra Cellular Matrix

EDTA: Ethylenediaminetetraacetic acid

ELISA: Enzyme-linked immnunosorbent assay

IEDDA: Inverse Electron Demand Diels-Alder

ITLC: Instant Thin Layer Chromatography

mAb: Monoclonal Antibody

MFI: Mean Fluorescence Intensity

MMP: Matrix Metalloproteinases

MST: Microscale thermophoresis

NOTA: 1,4,7-triazacyclononane-1,4,7-triacetic acid

PBS: Phosphate Buffer Solution

PET: Positron Emission Tomography

PRIT: Pretargeted Radioimmunotherapy 
RIT: Radioimmunotherapy

scFv: Single-chain variable antibody fragment

SDS-PAGE: Sodium dodecyl sulfate polyacrylamide gel electrophoresis

SPECT: Single-Photon Emission Computed Tomography

T/NT: Tumor-to-Non-tumor ratio

TBS: Tris buffer saline

TBST: Tris buffer saline with tween-20

TCMC: 1,4,7,10-tetra-(2-carbamonyl methyl)-cyclododecane

TCO: trans-cyclooctene

TF: Thomsen-Friedenreich

Tz: Tetrazine

VH: Variable Heavy chain

VL: Variable Light chain 


\title{
PRETARGETED CANCER RADIOIMMUNOTHERAPY AND RADIOIMAGING USING ANTIBODIES AND ANTIBODY FRAGMENTS
}

\author{
By: Manankumar Shah \\ Dr. Thomas P. Quinn, Dissertation Advisor
}

\begin{abstract}
Over the last few decades, antibodies have become the mainstay of cancer diagnosis and therapeutics. In traditional radioimmunotherapy (RIT), tumor targeting antibodies are directly conjugated with radioisotopes and depending on the radionuclides's properties, the direct labeled antibodies can be used for diagnostic or therapeutic purposes. However, one of the major challenges of using radiolabeled antibodies for therapy is their long serum halflives. It generally takes 5-7 days for antibodies to achieve maximum tumor binding. This slow blood clearance results in high normal tissue irradiation and a poor therapeutic index. This is exemplified by the fact that to date, only two radiolabeled antibodies have been approved by the FDA for radioimmunotherapy


of cancer. In order to overcome this obstacle, several pretargeting strategies have been developed and investigated. The pretargeted radioimmunotherapy approach (PRIT) decouples the administration of tumor targeting monoclonal antibodies (mAbs) from that of the radiolabeled ligand. This multi-step strategy allows delivery of high doses of radiation to tumor cells while minimizing nonspecific normal tissue irradiation. In this study, we evaluated the potential of pretargeted a-particle radioimmunotherapy based on inverse electron demand Diels-Alder reaction (IEDDA) between trans-cyclooctene (TCO) and tetrazine (Tz). Two tetrazine based chelators, DOTA-Tz and TCMC-Tz, were synthesized and compared for their radiolabeling efficiency with ${ }^{212} \mathrm{~Pb}$, radiochemical stability and in vivo pharmacokinetics. Dosimetry was determined from pretargeted biodistribution studies. The PRIT study was carried out in LS174T tumor bearing mice pretargeted with CC49-TCO mAbs. After removing unbound mAbs from the blood using two doses of clearing agent, mice were treated with various doses of $(0,75,125,200$, and $2 \times 75 \mu \mathrm{Ci})$ of ${ }^{212} \mathrm{~Pb}-\mathrm{DOTA}-\mathrm{Tz} .{ }^{212} \mathrm{~Pb}-\mathrm{DOTA}-\mathrm{Tz}$ displayed better in vivo biodistribution than ${ }^{212} \mathrm{~Pb}-\mathrm{TCMC}-\mathrm{Tz}$ and was selected for PRIT study. All the mouse groups receiving treatment displayed dose dependent reduction in tumor size, while the control groups showed exponential tumor growth. Groups receiving $200 \mu \mathrm{Ci}$ of ${ }^{212} \mathrm{~Pb}-\mathrm{DOTA}-\mathrm{Tz}$ and $15 \mu \mathrm{Ci}$ of direct labeled CC49 exhibited acute radiation associated toxicity. Treatment with 75, 125, and 2 x $75 \mu \mathrm{Ci}$ of ${ }^{212} \mathrm{~Pb}-\mathrm{DOTA}-\mathrm{Tz}$ resulted in statistically significant improvement in median survival (26, 35 and 39 days respectively). This study successfully demonstrated that pretargeted ${ }^{212} \mathrm{~Pb} \alpha$-particle therapy resulted in reduced tumor 
growth rates and improved survival with minimal normal tissue toxicity, as detailed in Chapter 2.

Lung cancer is the leading cause of the cancer related deaths in the United States and world-wide. In 2018, it is estimated that about 234,030 new patients will be diagnosed and 154,050 will die of lung cancer in the United States. Once the cancer is metastasized, the 5 -year survival rate is reduced to less than $5 \%$. Matrix metalloproteinase-12 (MMP-12) is a member of family of zinc dependent endopeptidase enzymes that are involved in extracellular matrix (ECM) remodeling. MMP-12 is generally expressed by macrophages and is associated with degradation of elastin in ECM. A growing body of evidence suggests that MMP-12 plays a key role in lung cancer proliferation and metastasis. Single-chain antibody fragments (scFv) were selected against MMP12 using phage display methodology to develop target vectors for lung cancer radioimaging. The McCafferty scFv library was screened to isolate MMP-12 specific antibodies. Two rounds of selection against purified MMP-12 resulted in 8 unique ScFv clones which showed MMP-12 specific binding. The selected clones were successfully expressed in E.coli and their binding to MMP-12 was confirmed by ELISA assay. Flow-cytometry and fluorescence microscopy demonstrated the specific binding of the selected scFv clone to the MMP-12 on human lung adenocarcinoma cells A549. The selected scFv was conjugated with ultrasmall silica nanoparticles and the resulting nano-conjugate was radiolabeled with ${ }^{89} \mathrm{Zr}$. The ${ }^{89} \mathrm{Zr}$-labeled scFv-nanoparicles were injected in mice bearing A549 tumors for in vivo PET/CT imaging. The whole-body images revealed a tumor 
specific uptake of ${ }^{89} \mathrm{Zr}$-labeled scFv-nanoparicles with minimum non-target accumulation. The data from this study clearly demonstrated the potential of MMP-12 as a novel diagnostic marker for lung adenocarcinoma and that MMP12 specific scFv-nanoparticle conjugates can be used for non-invasive in vivo imaging. This project is detailed in Chapter 3.

Thomsen-Friedenreich (TF) is a disaccharide (Galactose $\beta 1-3 \mathrm{~N}$ acetylgalactosamine) antigen, which is present on about $\sim 90 \%$ of carcinomas. The TF expression on the tumor cell is correlated with poor prognosis and tumor propagation. TF antigen is also involved in cell to cell adhesion and metastasis, making it a very good target for cancer imaging and therapy. Using phage display technology, TF binding scFv fragments were selected from the McCafferty antibody library. The selected ScFv clones were characterized in vitro for their TF specificity and cell binding properties by ELISA and flow-cytometry assay. The selected TF specific clone (9C-scFv) was radiolabeled with ${ }^{99 m} \mathrm{Tc}$ by directly conjugating ${ }^{99 \mathrm{~m}} \mathrm{Tc}$ to the $\mathrm{C}$-terminal $6 \mathrm{x}$ His-tag. The ${ }^{99 \mathrm{~m}} \mathrm{Tc}$-labeled $9 \mathrm{C}$-scFv was injected in mice bearing MDA-MB-231 human breast cancer xenografts. The SPECT/CT images, acquired 4 hours post injection, revealed a moderate tumor uptake of radiolabeled scFvs with significant accumulation in the liver and kidneys. The phage display derived single-chain scFv fragments against the TF antigen demonstrated potential for development as an imaging agent but requires more work to achieve favorable pharmacokinetics. 
CHAPTER 1

INTRODUCTION 


\section{Molecular Imaging}

Molecular imaging not only provides means for non-invasive cancer diagnosis and staging but also plays an important role for treatment planning, treatment response assessment, surgical management, and post treatment evaluation for cancer relapse.(1) Traditionally, physicians have relied upon the classical imaging modalities like X-ray tests, computed topography (CT) scans, ultrasound, and magnetic resonance imaging (MRI). Even though these techniques are the backbone of current diagnostic medicine, they are largely restricted to providing anatomical and physiological information.(2) With the advent of the personalized medicine, there is a growing need to analyze specific targets and biomarkers in vivo. Nuclear imaging methodologies like single-photon emission computed tomography (SPECT) and positron emission tomography (PET) allow detection and functional evaluation of specific targets via the use of radioactive probes. Tumor targeting vectors such as various antibody forms, peptides, and nanoparticles can be conjugated with radioisotopes to provide a powerful tool for imaging specific targets with nanomolar or picomolar affinities. $(3,4)$

SPECT imaging involves radiolabeling tissue targeting constructs with radionuclides that emit $y$-rays. Some of the commonly used SPECT radionuclides include ${ }^{99 \mathrm{~m}} \mathrm{Tc}\left(\mathrm{t}_{1 / 2}=6 \mathrm{~h}\right),{ }^{67} \mathrm{Ga}\left(\mathrm{t}_{1 / 2}=78.3 \mathrm{~h}\right),{ }^{111} \mathrm{In}\left(\mathrm{t}_{1 / 2}=67 \mathrm{~h}\right)$, and ${ }^{203} \mathrm{~Pb}$ $\left(\mathrm{t}_{1 / 2}=52 \mathrm{~h}\right) .(5)^{99 \mathrm{~m}} \mathrm{Tc}$ is one of the most widely available and least expensive radioisotopes for SPECT imaging. ${ }^{99 m}$ Tc-labeled radioimaging agents are thus 
the mainstay of nuclear imaging worldwide. $(6,7)$ SPECT has traditionally been regarded as a nonquantitative imaging method. However, advancements in detector cameras, algorithms for image reconstructions, and sophisticated compensation techniques have now made SPECT viable for quantitative imaging.(8)

PET imaging involves the use of positron emitting radionuclides. Positrons emitted from decaying radionuclides collide with electrons in nearby tissue resulting in annihilation and emission of two $511 \mathrm{keV}$ photons oriented at 180 degree from each other. Detectors, arranged in a ring configuration detect the emitted photons and the data are reconstructed into a whole-body image to map the distribution and concentration of the radionuclide in the body.(9) Typical clinical PET scanners have roughly 10 -fold greater sensitivity than the SPECT instruments, facilitating the detection of radiotracers at picomolar concentrations. Because of the advances in genomic and proteomic sciences, several new cancer biomarkers were discovered in the last decade. This coupled with more availability of radionuclides and a myriad of different conjugation and chelation strategies have fueled the interest in PET imaging. Positron emitting radiometals such as ${ }^{18} \mathrm{~F}\left(\mathrm{t}_{1 / 2}=1.8 \mathrm{~h}\right),{ }^{64} \mathrm{Cu}\left(\mathrm{t}_{1 / 2}=12.7 \mathrm{~h}\right),{ }^{68} \mathrm{Ga}\left(\mathrm{t}_{1 / 2}=1.1 \mathrm{~h}\right),{ }^{86} \mathrm{Y}\left(\mathrm{t}_{1 / 2}=14.7 \mathrm{~h}\right)$, and ${ }^{89} \mathrm{Zr}\left(\mathrm{t}_{1 / 2}=78.4 \mathrm{~h}\right)$ are increasingly used for PET imaging due to favorable halflives and the availability of a number of metal chelators and prosthetic groups.(10-12)

Intact antibodies have long been used for targeted therapeutics due to their specificities and target affinities. However, their long serum half-lives and 
poor biodistribution profiles hamper their use as imaging agents.(13) Many of these issues can be overcome by the use of smaller tumor targeting vectors such as peptides, and various antibody fragments like single-chain variable fragments (scFvs), Fab domains, and nanobodies. These constructs display improved pharmacokinetic properties such as better tissue penetration and rapid blood clearance without compromising binding specificities. This allows the imaging studies to be performed on the same day after injection of radiolabeled ScFv rather than waiting for $1-3$ days in the case of an intact antibody. $(14,15)$ The choice of PET and SPECT imaging can be made based upon the availability of radionuclide, cost, half-life of the isotope and the intended use. Typically, the decay half-life of the radioisotope is matched with the serum half-life of the targeting agent. Both imaging methods provide several options for non-invasive ways for cancer detection and characterization. 


\section{Pretargeting}

The success of any cancer diagnostic or therapeutic strategy relies upon the selective uptake of the targeting agent in the tumor. Because of their high binding affinities and specificities, monoclonal antibodies have long been used as targeting vehicles for delivering radionuclides for imaging as well as therapeutic applications. Even though radiolabeled antibodies have been investigated since 1950 , to date only ${ }^{90} \mathrm{Y}$-labeled ibritumonomab and ${ }^{131} \mathrm{I}$-labeled tositumomab have been approved by the FDA for non-Hodgkin's lymphoma therapy.(16,17) The major hindrance in the success of the radioimmunotherapy (RIT) is the poor pharmacokinetics of the full length monoclonal antibodies (mAbs). Because of their larger size (150 kDa), mAbs have a long serum half-life and it may take 5-7 days for antibodies to achieve maximum tumor accumulation. The prolonged circulation of radiolabeled antibodies leads to high tumor accumulation, however at the cost of excessive normal tissue irradiation. This is especially detrimental in radioimmunotherapy as it significantly limits the amount of dose administered and reduces the therapeutic effectiveness. To overcome the drawbacks of conventional RIT, several pretargeted radioimmunotherapy (PRIT) strategies have been developed and investigated.(18)

Pretargeting strategies generally involve three steps: 1) Administration of highly tumor specific antibodies and their accumulation at the target site, 2) Following maximum tumor uptake, freely circulating antibodies are removed from the blood using a clearing agent, 3) After sufficient time, a fast clearing radiolabeled species is injected which has high specificity and affinity towards 
tumor bound antibodies.(19) Because of their small size, any unbound radiolabeled effector molecules are rapidly excreted out of body via the kidneys. As a result, high tumor-to-nontumor (T/NT) ratios can be achieved resulting in an improved therapeutic index compared to the conventional RIT. Some of the earlier classes of pretargeting strategies include biotin/avidin systems, bispecific antibodies, and complementary oligonucleotides. Even though these approaches displayed some promise, they have had limited success due to several disadvantages like immunogenicity, slow reaction rates, and low binding constants. Over the past decade, a new class of biorthogonal click-chemistry reactions has been increasingly investigated and has shown great promise in cancer radioimaging and radiotherapy.(20)

According to Bertozzi et al., for a chemical reaction to be termed as biorthogonal, it must be very selective, high yielding, have very fast reaction kinetics, have biologically inert components, and produce non-toxic byproducts. (21) $\mathrm{Cu}(\mathrm{I})$-catalyzed azide-alkyne click chemistry (CuAAC) is one of the most prominent examples of biorthogonal reactions. It is an extremely efficient reaction between azide and alkyne functionalized molecules forming a stable conjugate via a triazole moiety. Over the years, a number of imaging probes have been designed and investigated for in vivo radioimaging using this strategy.(22-24) However, the necessity of cytotoxic copper as a catalyst for the CUAAC reaction would severely limit its application in a clinical setting. As a result, metal-free click-chemistry reactions have attracted significant interest in 
recent times for radioimaging as well as therapeutic applications in living systems.

The Staudinger ligation is one of the earliest metal-free click chemistry reactions investigated.(25) It involves a highly selective reaction between azide and phosphine groups resulting in formation of an amide bond. In 2011, Van Dongen and co-workers functionalized an anti-CD44v6 mAbs with azide groups and synthesized phosphine containing small radiolabeled effector moieties for in vivo tumor radioimaging. Unfortunately, there was no in vivo Staudinger reaction detected. It was mainly because of slow reaction rates $\left(k_{2}=2 \times 10^{-3} \mathrm{M}^{-1} \mathrm{~s}^{-1}\right)$ as well as oxidation of the phosphine group which made it unreactive.(26)

Strain promoted alkyne-azide cycloaddition (SPAAC) represents another class of copper-free biorthogonal reactions. It relies upon the use of strained cyclootyne and azide moieties and can achieve up to 3 orders of magnitude faster reaction kinetics $\left(k_{2}=0.31 \mathrm{M}^{-1} \mathrm{~s}^{-1}\right) \cdot(27)$ In 2013 , Lee et al. successfully displayed the potential of SPACC reaction for in vivo tumor PET imaging using cyclootyne modified nanoparticles and ${ }^{18} \mathrm{~F}$-labeled azide ligands.(28) Even though SPAAC has much faster reaction kinetics, it is still not fast enough to be used in low enough concentrations typically used in in vivo applications.

The discovery of the inverse electron-demand Diels-Alder cycloaddition (IEDDA) reaction between trans-cyclootene (TCO) and tetrazine (Tz) by Fox and coworkers was the turning point in terms of in vivo application of biorthogonal reactions. This is a highly specific and rapid reaction with reaction rates of up to 
$2.5 \times 10^{5} \mathrm{M}^{-1} \mathrm{~s}^{-1} .(27,29)$ In their landmark study in 2010 , Rossin et al. demonstrated for the first time, the application of IEDDA-based click-chemistry approach for SPECT imaging in a mouse tumor model.(30) In this study, mice bearing LS174T xenografts were pretargeted with TCO modified CC49 mAbs. ${ }^{111}$ In-DOTA labeled tetrazine was injected 24 hours after the CC49-TCO mAb administration for SPECT imaging. Following a similar approach, Lewis and Zegils developed PET imaging strategies using ${ }^{64} \mathrm{Cu}$-labeled tetrazine species.(31) Since then, there have been numerous IEDDA-based studies that have been conducted using various tumor targeting vectors such as diabodies, affibodies, and nanoparticles. The application of TCO-tetrazine based clickchemistry is not only limited to imaging studies. Recently, Houghton et al. demonstrated the feasibility of pretargeted radioimmunotherapy (PRTI) using TCO conjugated antibodies and ${ }^{177}$ Lu-DOTA labeled tetrazine.(32) 


\section{Alpha Particle Based Therapy}

Nuclear decay occurs as a result of spontaneous disintegration of atomic nuclei resulting in more stable nuclei. The three major types of radiation include alpha particles, beta particles, and gamma rays. All of these radiations differ in their physical characteristics and thus in their intended use.(33) Alpha radiation is made up of charged particles composed of two protons and two neutrons. They are essentially ${ }^{4} \mathrm{He}$ nucleus with +2 net charge. Alpha emission usually occurs in elements of high atomic number $(Z>82)$ and is an example of ionizing radiation. The emitted alpha particle, due to its mass and energy, can knock an orbital electron from the interacting atom creating a positively charged ion. This pair of negatively charged electrons and positively charged ions can then go on to cause further ionization reactions in their paths. Alpha particles move relatively slowly and deposit large amounts of energy per unit path length (100 keV/ $\mu \mathrm{m})$. Alpha particles offer several advantages over beta particles and gamma radiation for use in targeted radiotherapy. First, alpha particles have a very short tissue path length of around 50-100 $\mu \mathrm{m}$. When combined with its high linear energy transfer (LET), they can deposit a therapeutic dose in a highly localized manner with negligible damage to normal tissue. They induce double stranded DNA damage which is irreparable and produce nucleotide modifications that cause apoptosis, cell cycle-arrest and autophagy. Moreover, these cytotoxic damages are independent of the tissue oxygen level and can thus be effective in a hypoxic tumor microenvironment.(34) These properties make alpha particles an attractive 
choice for the use in radioimmunotherapy, especially in the treatment of micrometastatic and disseminated tumors.

The fundamental goal of any cancer radioimmunotherapy is to deliver a cytotoxic radiation dose to the tumor with minimum irradiation to the surrounding healthy tissue. Alpha particle based therapy offers a decisive advantage towards this goal due to its intense ionizing track over a very short path length in tissues. Several alpha emitting radioisotopes have been investigated over the years for their potential therapeutic application. These include ${ }^{211} \mathrm{At},{ }^{212} \mathrm{Bi},{ }^{213} \mathrm{Bi},{ }^{225} \mathrm{Ac}$, ${ }^{212} \mathrm{~Pb},{ }^{227} \mathrm{Th}$, and ${ }^{223} \mathrm{Ra}$.(35) Pretargeted radioimmunotherapy (PRIT) described in Chapter 2 of this dissertation was carried out using ${ }^{212} \mathrm{~Pb}$. It is important to note here that ${ }^{212} \mathrm{~Pb}$ is not an alpha emitter but decays to ${ }^{212} \mathrm{Bi}$, which actually emits alpha particles. The short half-life of ${ }^{212} \mathrm{Bi}\left(\mathrm{t}_{1 / 2}=60 \mathrm{~min}\right)$ presents a challenge in dose preparation and delivery. By using ${ }^{212} \mathrm{~Pb}$ as an in vivo generator for ${ }^{212} \mathrm{Bi}$, it is possible to deliver more than 10 times the administered dose compared to ${ }^{212} \mathrm{Bi}$ while overcoming the time constraints of ${ }^{212} \mathrm{Bi} .(36,37){ }^{212} \mathrm{~Pb}$ is a product of ${ }^{228} \mathrm{Th}$ decay chain and can be produced from the ${ }^{224} \mathrm{Ra} /{ }^{212} \mathrm{~Pb}$ generator. Traditionally, the bifunctional chelator 1,4,7,10-tetraazacyclododecane-1,4,7,10tetraacetic acid (DOTA) has been used to radiolabel mAbs, peptides, and other molecules with ${ }^{212} \mathrm{~Pb} .(38-40)$ Although DOTA has been used successfully to radiolabel ${ }^{212} \mathrm{~Pb}$ with a high labeling yield, around $30 \%$ of ${ }^{212} \mathrm{Bi}$ is released from the complex during ${ }^{212} \mathrm{~Pb}$ to ${ }^{212} \mathrm{Bi}$ decay.(41) Also, DOTA requires heating the reaction mixture to $>80^{\circ} \mathrm{C}$ which is not ideal for labeling thermolabile proteins like antibodies. To overcome this issue, Brechbiel and coworkers have developed 
1,4,7,10-tetra-(2-carbamonyl methyl)-cyclododecane (TCMC) as a novel chelator to stably chelate ${ }^{212} \mathrm{~Pb}$ at $37^{\circ} \mathrm{C}$.(41) Preclinical studies with ${ }^{212} \mathrm{~Pb}-\mathrm{TCMC}$ Trastuzumab demonstrated an improvement in median survival of mice from 19 days to 56 days.(38) ${ }^{212} \mathrm{~Pb}$-labeled peptides in a melanoma tumor model have shown the improvement in survival from 15 to 50 days. (39) Combination therapy studies of ${ }^{212} \mathrm{~Pb}$-labeled trastuzumab with gemcitabine or paclitaxel have successfully showed the therapeutic efficacy of this approach where the median survival of animals receiving treatment were improved significantly. $(42,43)$ Because of its success in animal models, ${ }^{212} \mathrm{~Pb}-\mathrm{TCMC}$-Trastuzumab was recently approved for phase I clinical studies at the University of Alabama. The results of this study have clearly demonstrated the potential and feasibility of alpha particle based therapeutic approaches. $(44,45)$ Combining the benefits of superior pharmacokinetics of the PRIT approach with alpha emitters may produce even better results and thus requires further investigation. 


\section{Single-Chain Antibody Fragments (scFvs)}

Monoclonal antibodies (mAbs) are a major weapon of the body's immune system against foreign antigens derived from bacterial and viral infections. In 1975, Kohler and Milstein demonstrated for the first time the ability to generate antibodies in vitro by cell fusion between antibody generating B cells and immortal myeloma cells.(46) Since then monoclonal antibodies have transformed cancer diagnostics and therapeutics due to their excellent specificity and binding affinities. The $\lg G$ antibody molecule is made up of 4 chains, 2 heavy chains and 2 light chains, arranged in a "Y" shaped structure. (Fig. 1.1) The antigen binding domains, which are specific for each antigen, are located on the tips of Fab domains. The fragment crystalline domain (Fc), which binds to the Fc receptors, is involved in recruitment of cytotoxic effector molecules and is responsible for long serum half-lives (> 10 days) of the antibodies. The IgG class of antibodies are $150,000 \mathrm{kDa}$ in size and are bivalent in nature.(47) Even though full length mAbs have been invaluable in recent decades as therapeutics as well as diagnostic agents in a number of diseases, there are instances where Fcmediated effects are not desirable. For example, the long serum half-life of full length antibodies results in high background noise and poor contrast in imaging applications. The unwanted activation of Fc-mediated activation of Fc-receptors may lead to massive cytokine release and associated cell toxicities.(48) Thus, antibodies have been modified either enzymatically or genetically engineered to be expressed in various monovalent or multivalent forms. 


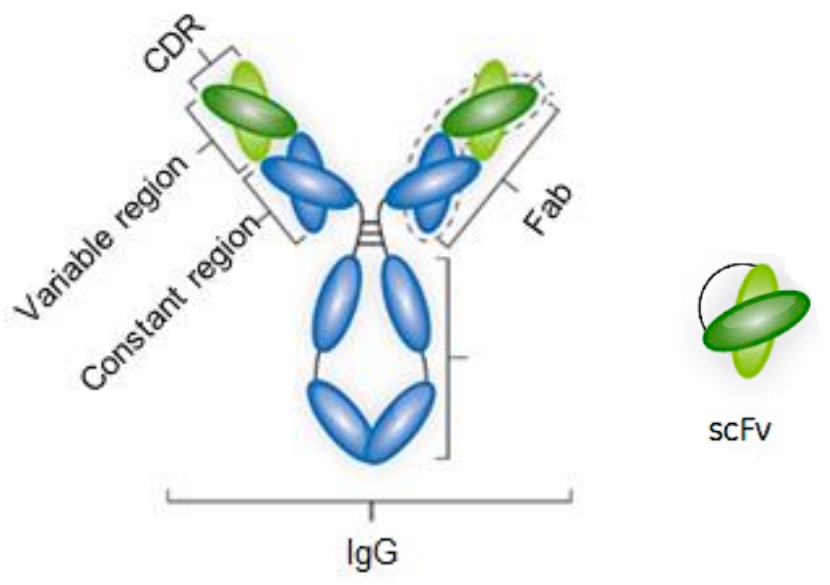

Fig: 1.1 Schematics of full length IgG monoclonal antibody and singlechain fragment (scFv)

Single-chain variable fragments $(\mathrm{scFv})$ consist of the smallest stabilized antigen binding domain where variable heavy chain $(\mathrm{VH})$ and variable light chain $(\mathrm{VL})$ domains are joined by a flexible peptide linker. (Fig.1.1) Each $V$ domain contains three hypervariable loops, which form the antigen-binding site, and are referred to as complementarity determining regions (CDRs). The amino acid sequences of these CDRs are specific for individual antigens. The peptide linker joining $\mathrm{VH}$ and $\mathrm{VL}$ domains is usually $10-25$ amino acids long. The ScFv fragments are around $30 \mathrm{KDa}$ in size with each variable domain containing roughly 110 amino acids. $(49,50)$

The scFv fragments retain the antigen binding specificity of the parent mAbs and offer several advantages over full length antibodies. Due to lack of the 
Fc domain, scFvs are devoid of immunogenicity. They can be expressed and purified in large quantities in bacterial as well as mammalian systems. Because of their smaller size, scFvs offer superior pharmacokinetic properties such as higher tissue penetration and rapid whole-body clearance.(51) This is important in the in vivo radioimaging applications where a reduction in background noise is as important as target recognition for attainment of high contrast images. The radiolabeled scFv fragments quickly bind to their tumor targets and any unbound scFvs are excreted out of the body via kidneys within a few hours. These properties have made scFvs one of the most used agents for molecular imaging. So far scFvs have been labeled with several radionuclides $\left({ }^{111} \mathrm{In},{ }^{64} \mathrm{Cu},{ }^{68} \mathrm{Ga}\right.$, ${ }^{99 \mathrm{~m}} \mathrm{Tc}$ ) for successful in vivo PET and SPECT imaging.(52-55)

Although scFvs offer several advantages they are not without their drawbacks. Due to their monovalent nature, scFvs have lower binding affinities and higher target off rates than the full length antibodies. Combined with their rapid blood clearance rates, this generally impairs the tumor uptake of scFvs. These drawbacks have been remedied by genetically engineering antibodies into various multi-valent forms, which offer higher avidity without compromising fast blood clearance compared to monovalent scFv fragments. 


\section{Phage Display of Antibodies}

Phage display technology, first described by Dr. George Smith in 1985, allows insertion of foreign amino acids into phage coat proteins and creating phage display libraries.(56) McCafferty and co-workers reported the display of single-chain antibody fragments (scFvs) on the phage surface in 1990.(57) Since then, phage display has been successfully used to display peptides, various forms of antibodies, receptors, and enzymes.(58-60) The most commonly used phages are the filamentous single-stranded DNA phages (M13, fd and f1) and two of the most common sites for insertion of foreign sequences are coat proteins plll and pVIII.(61-64) The power of the phage display technology comes from the ability to co-select peptides/proteins and their genes using a large and diverse library. The term antibody phage display library refers to the collection of phage particles that displays antibody fragments on their surfaces. The McCafferty phage display library was created by sequentially cloning a repertoire of human light chain variable regions (VL) followed by human heavy chain regions $(\mathrm{VH})$ in the pSANG4 phagemid. The $\mathrm{VH}$ and $\mathrm{VL}$ pools were created by PCR amplification of non-immunized human lymphocytes. $(57,65)$ This results in a naïve or non-immunized ScFv antibody library that can be used to isolate antibodies against a range of different antigens, including antibodies recognizing "self" proteins or toxic antigens. 


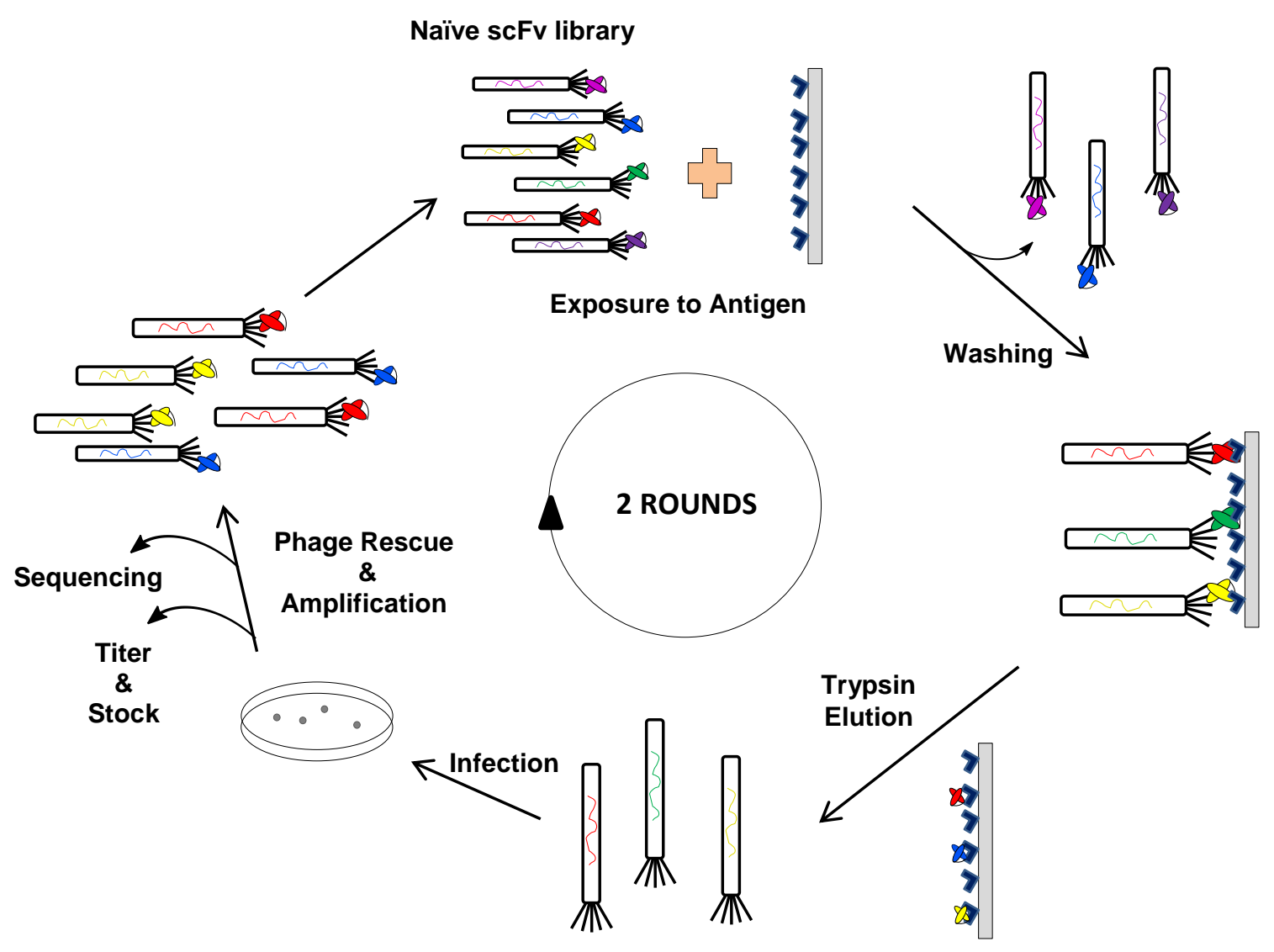

Figure: 1.2 Schematic of phage display selection process 
The goal of an antibody phage display selection process is to isolate a subpopulation of antibodies against a specific biomarker from a large and diverse library. The McCafferty library has a diversity of $1.1 \times 10^{10}$ unique scFv clones with each clone having around 100 copies.(65) The general scheme of phage display selection involves incubating an entire library with an immobilized target. Phages are allowed to bind to the target and non-specifically bound phages are washed away. The target bound phages are eluted using trypsin mediated proteolyic cleavage and are amplified in TG1 E.coli cells. These amplified phages are then rescued by helper phage superinfection and the resulting subset of phage population is used for the next round of selection (Fig. 1.2). The antibody library is subjected to multiple rounds of selection with each round being more stringent than the previous one in order to isolate high affinity antibodies aginst a target of interest. One has to be careful though as excessive rounds of selection can lead to enrichment of so-called "bald" phages which do not display any scFv but have a signifcantly higher growth advantage.

The use of trypsin-cleavable KM13 helper phage ensures that only 2 rounds of selection are required instead of the usual 3-4 rounds. This helper phage was engineered with modified plll protein which has a trypsin-sensitive site in plll protein (Fig. 1.3).(66,67) During phagemid rescue and phage assembly, both plll protein from helper phage and pllI-scFv fusion protein from phagemid compete for packaging into phage particles. In fact, approximately $90 \%$ of all phage particles produced have only plll protein from the helper phage and do not display scFv on their surfaces. The remaining $10 \%$ phages carry at 
least one phagemid derived recombinant plII-scFv fusion protein and thus display antibody fragments on their tips. During trypsin elution, plll-scFv fusion protein is cleaved between ScFv domain and plll leaving the phage particle with at least one intact plll protein and their infectivity. Meanwhile trypsin treatment also cleaves helper phage derived plll proteins resulting in truncated phage particles with defective plll protein. Because of the loss of D1 and D2 domains in these "bald" particles, they lose their bacterial infectivity. Thus, the use of genetically modified M13 helper phage and trypsin treatment make all particles (phagemid and helper) that do not have at least one phagemid-encoded recombinant pllIscFv protein non-infective and reduces the population these "bald" phages from the selection process. 


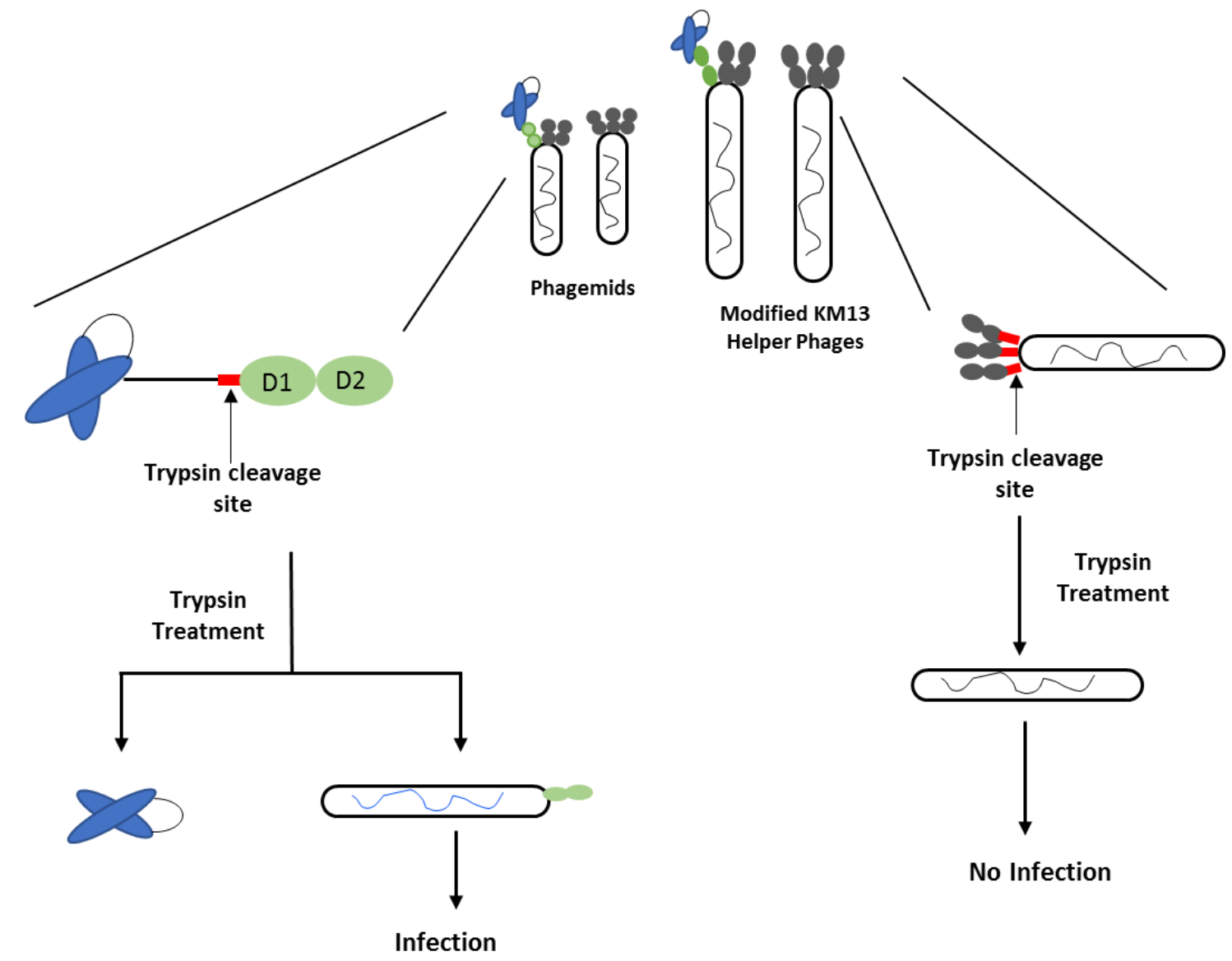

Fig 1.3: Principle of trypsin based elution 
Isolation of antibody fragments against a specific target can be accomplished using purified protein or directly on the cells expressing a particular target. Phage display can also be used to identify antibodies against non-protein targets like small moelcules which is very difficult to achieve using immunization. The scFvs isolated from phage display have binding affinities in the micromolar to nanomolar range. $(68,69)$ This can be further increased by affinity maturation where the sequence of initial lead scFv is used to create a sub-library, which is screened again to enrich for binders with higer binidng affinities.(70) Apart from directly selecting human antibodies against a target protein with nanomolar affinities, it is also possible to tailor the selection and screening techniques to isolate antibodies with many other attributes like agonistic or antagonistic properties, potency, specificity, stability, and cross-reactivity.(87-89) Antibody fragments isolated from phage libraries can be readily reformatted into full length IgG format without the loss of function. All of these in vitro flexibilities and advantages make phage display technology very attractive for the discovery of new therapeutics. As of 2017, more than 60 phage display-derived drug candidates are in various stages of clinical trials. So far, US FDA has approved 6 antibodies and 1 peptide based drugs discovered by phage display.(90) Adalimumab (Humira), the first fully human monoclonal antibody drug approved by US FDA, was discovered from phage display using the McCafferty library. Humira had sales of $\$ 18.9$ billon worldwide in 2017.(91) This demonstrates the potential and power of phage display technology as rapid, efficient, and relatively inexpensive way of generating biological agents. 


\section{Matrix Metalloproteinases (MMPs)}

Matrix metalloproteinases (MMPs) are a family of 25 zinc-containing protease enzymes that are involved in degradation of extra cellular matrix (ECM) and basement membrane components. MMPs are structurally related: they all have a propeptide domain, a zinc-containing catalytic domain, and a hemopexinlike domain. The propeptide domain gets cleaved during the activation leaving a truncated active enzyme, while the hemopexin domain is involved in proteinprotein interaction and substrate specificity.(71) The ECM is a complex and dynamic network that is made up various macromolecules such as collagens, fibronectins, proteoglycans, glycosaminoglycans, and other glycoproteins. It acts as a glue to keep cells together and functions as a pool of various growth factors and signaling molecules. In normal physiological condition, the ECM plays an important role in embryonic development, morphogenesis, tissue resorption and remodeling, cell differentiation, growth, migration, and apoptosis.(72) The degradation of ECM by MMPs can thus have a profound impact on tissue structure, function, and remodeling.(73) The uninhibited activities of MMPs have been implicated in various pathological conditions like inflammation, arthritis, fibrosis, and cancer.(74-77) Because MMPs are involved in degradation of ECM components, they are known to help cancer cells in detachment from the primary tumor cells, allowing them to escape into blood vessels for metastasis. Several MMPs are implicated in their role in cancer metastasis and it is possible that they work in tandem. $(78,79)$ 
MMP-12 is a $54 \mathrm{kDa}$ proteolytic enzyme which is mainly secreted by macrophages.(80) MMP-12 is implicated in numerous diseases like atherosclerosis, aortic aneurysm, chronic obstructive pulmonary disease (COPD), and rheumatoid arthritis.(81-84) Recently, more and more evidences are emerging which suggest that MMP-12 plays important role in lung cancer. MMP-12 overexpression by lung tissues has been correlated with lung cancer propagation.(85) At the same time, knockdown of MMP-12 from lung adenocarcinoma cells suppresses the cell growth and invasiveness of the tumor cells.(86) This body of evidences suggests that MMP-12 might be a potential target for lung cancer diagnosis as well as for therapy.

Due to advantages offered by phage display, we decided to identify MMP-12 specific scFvs and investigate if MMP-12 can be used as a novel biomarker for lung cancer detection. This project is detailed in Chapter 3. 


\section{CHAPTER 2}

\section{Metal-Free Cycloaddition Chemistry Driven Pretargeted Radioimmunotherapy Using a-Particle Radiation}

This work has been published in Bioconjugate Chemistry, Volume 28.11, Pages 3007-3015 in 2017 under the title "Metal-Free Cycloaddition Chemistry Driven Pretargeted Radioimmunotherapy Using a-Particle Radiation" It is reprinted with permission (@ American Chemical Society 2018).

Manankumar A. Shah, Xiuli Zhang, Raffaella Rossin, Marc S. Robillard, Darrell R. Fisher, Tyler Bueltmann, Freek J. M. Hoeben, and Thomas P. Quinn are co-authors of this work 


\section{Introduction}

Conventional radioimmunotherapy (RIT) involves a single step approach in which a tumor targeting monoclonal antibody $(\mathrm{mAb})$ is directly radiolabeled. Once injected, the radiolabeled mAb circulates throughout the body and ultimately binds to its target on tumor cells. The radiation emitting from the radionuclide delivers the therapeutic dose to tumor cells. $(92,93)$ However, the success of RIT has been limited due to poor pharmacokinetic properties of antibodies. The large molecular weight of the radiolabeled mAb results in extended biodistribution and whole-body clearance. This prolonged blood circulation of radiolabeled mAbs results in lengthy radiation exposure to nontarget normal tissues, which in turn limits the amount of radiation dose administered and reduces the therapeutic efficacy.(94-96)

Pretargeted radioimmunotherapy (PRIT) is an alternative strategy developed to address the drawbacks associated with conventional RIT. Pretargeting is a multistep approach which essentially separates the delivery of the tumor targeting molecule from the delivery of the radionuclides. The general scheme of pretargeting involves administration of tumor targeting mAb, which has been modified with a specific tag. This modified mAb is allowed to circulate throughout the body and accumulate on the tumor. The unbound $m A b$ is cleared from the blood usually via liver and GI tract. The clearance of unbound mAb from the blood can be accelerated by administration of a clearing agent. This is followed by the administration of low molecular weight radioactive effector molecules, which have a very high affinity and specificity for the tag on the 
modified mAb. Due to their small size and fast pharmacokinetics, radiolabeled effector molecules bind rapidly to the pretargeted mAb on the tumor and any unbound radioactive effector molecules are quickly cleared out of the blood via kidneys. As a result, PRIT achieves a high tumor/non-tumor (T/NT) ratio allowing administration of high radiation doses with minimal exposure to normal tissues. $(97,98)$ Several pretargeting approaches have been investigated extensively in preclinical studies, which include bispecific antibodies (bsAb), avidin/streptavidin- biotin based systems, mAb conjugated to oligonucleotides and mAb conjugated to enzymes.(99-103) Although these strategies have shown some success over the years, their effectiveness is limited because of some limitations. For example, streptavidin-biotin system causes induction of adverse immune reactions, while bispecific antibodies suffer from complexity and high production costs as well as moderate biomarker binding constants.(20) Novel bioorthogonal chemical reactions that do not suffer from these limitations have increasingly been investigated over the last decade.(104) The widely evaluated bioorthogonal reactions include the Staudinger ligation, the strain promoted alkyne-azide cycloaddition (SPAAC) and the inverse electron demand DielsAlder reaction (IEDDA).(26-31) In 2010, Robillard et al. demonstrated the first successful in vivo application of an IEDDA reaction between trans-cyclooctene (TCO) and tetrazine (Tz) for SPECT imaging using CC49-TCO mAb and ${ }^{111} \mathrm{In}$ DOTA-Tz. In subsequent studies, a clearing agent was developed to reduce circulating unbound antibody prior to radiolabeled tetrazine administration. Dosimetry studies demonstrated that the use of clearing agent resulted in an 8- 
fold increased dose to the tumor. Moreover, they showed the potential and feasibility of an IEDDA based pretargeting approach for in vivo PRIT using ${ }^{177} \mathrm{Lu}$ DOTA-Tz.(105-107) Recently, Houghton et al. showed that a pretargeted approach can reduce total body dose and demonstrated the in vivo efficacy of a PRIT regimen using a $\beta$-emitters ${ }^{177} \mathrm{Lu}$ labeled tetrazine and TCO modified mAb. $(32,108)$

Alpha-particles are charged $\mathrm{He}^{+2}$ nuclei with radionuclide energies ranging from 2 to $10 \mathrm{MeV}$. The linear energy transfer of $\alpha$-particles, typically $\sim 100 \mathrm{keV} /$ $\mu \mathrm{m}$, is significantly higher than that of $\beta$-particles $(\sim 0.2 \mathrm{keV} / \mu \mathrm{m})$. Furthermore, a-particles have a very short tissue path length of $\sim 100 \mu \mathrm{m}$ and can deposit $\sim 1500$ times more energy per unit path length than $\beta$-particles. The cytotoxic effects of $\alpha$-particles resulting from irreversible double strand DNA damage are independent of dose rate, dose fractionation, or tissue oxygen levels. These properties make $\alpha$-particle based therapeutic approaches attractive for targeted treatment strategies. The most widely studied radionuclides for targeted $\alpha$ radiotherapy include ${ }^{225} \mathrm{Ac}\left(\mathrm{t}_{1 / 2} \sim 10.0\right.$ days), ${ }^{211} \mathrm{At}\left(\mathrm{t}_{1 / 2} \sim 7.2\right.$ days), ${ }^{212} \mathrm{Bi}\left(\mathrm{t}_{1 / 2} \sim\right.$ 60.5 minutes), ${ }^{213} \mathrm{Bi}$ ( $\mathrm{t}_{1 / 2} \sim 45.6$ minutes), and ${ }^{212} \mathrm{~Pb}$ ( $\mathrm{t}_{1 / 2} \sim 10.6$ hours).(34$36,109,111)$ Moreover, the use of parent radionuclides as an in vivo generator of short half-life a-emitters has also been successfully employed.(37-39) In this report ${ }^{212} \mathrm{~Pb}$, parent of the $\alpha$-emitter ${ }^{212} \mathrm{Bi}$, was used to overcome difficulties associated with short half-life of ${ }^{212} \mathrm{Bi}\left(\mathrm{t}_{1 / 2} \sim 60 \mathrm{~min}\right)$. Our laboratory has successfully demonstrated the use of ${ }^{212} \mathrm{~Pb}$ in a peptide targeted $\alpha$-particle therapy on melanoma tumors.(39) Over the years, Brechbiel et al. and others 
have shown the feasibility and therapeutic efficacy of targeted RIT using ${ }^{212} \mathrm{~Pb}$ Transtuzumab. $(40,112,113)$ Recently, the results of the first clinical trial employing ${ }^{212} \mathrm{~Pb}$-Transtuzumab have further confirmed the safety and suitability of ${ }^{212} \mathrm{~Pb}$ in radioimmunotherapy. $(44,45)$

In this study, we investigated the feasibility and effectiveness of pretargeted ${ }^{212} \mathrm{~Pb}$ a-particle radioimmunotherapy using in vivo IEDDA chemistry in mice bearing LS174T human colon carcinoma xenografts. We compared and evaluated two tetrazine-PEG conjugated chelators 1,4,7,10tetraazacyclododecane-1,4,7,10-tetraacetic acid (DOTA) and 1,4,7,10-tetra-(2carbamonyl methyl)-cyclododecane (TCMC) (Fig. 2.1) for their ${ }^{212} \mathrm{~Pb}$ radiolabeling efficiencies and in vivo pharmacokinetic properties. CC49, a mouse IgG mAb which binds to the tumor-associated glycoprotein (TAG-72) antigen, was used as the tumor targeting molecule. A three step pretargeting protocol involving pretargeted CC49-TCO mAb, administration of a clearing agent and ${ }^{212} \mathrm{~Pb}$-DOTA-Tz was carried out for radioimmunotherapy. The results of the IEDDA based $\alpha$-PRIT therapy regimen yielded dose-dependent reductions in tumor growth with improved survival, highlighting the clinical potential of the $\alpha$ particle based PRIT. 
A<smiles>O=C(COC1CC/C=C/CCC1)CN1C(=O)CCC1=O</smiles>

B<smiles>CNCCN(CC(=O)O)CC(C)(C)OCC(C)(C)OCCNC(=O)CCCC(=O)Nc1ccc(-c2nnc(-c3ccccn3)nn2)nc1</smiles>

C<smiles>CC(C)(CNC(=O)CCCC(=O)Nc1ccc(-c2nnc(-c3ccccn3)nn2)nc1)COCCNC(=S)Nc1ccc(CC(CC(C)(C)OCCN2CCN(CC(N)=O)CCN(CC(N)=O)CC2)N2CCN(CC(N)=O)CC2)cc1</smiles>

D

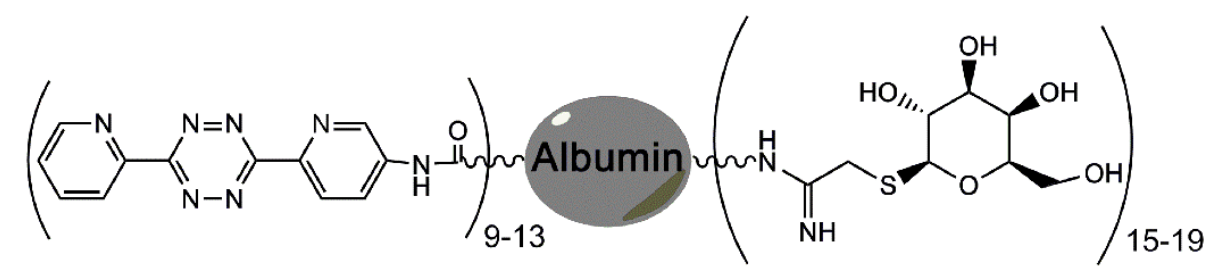

Figure 2.1: Structures of pretargeting reagents used in the study. A) TCO-NHS, B) DOTA-PEG 10 -Tetrazine and, C) TCMC-Bn-SCN-PEG 10 -Tetrazine, and D) Galactose-albumin-Tetrazine based clearing agent. 


\section{Materials and Methods}

\section{Antibody Preparation and TCO conjugation:}

CC49 mAb was purified from the supernatant of its hybridoma cell line (American Type Culture collection, VA) using protein G affinity column chromatography (GE Healthcare, NJ) as per the manufacturer's instructions. Rituximab (Genentech Inc.), a human mAb which targets CD20 on the surface of B-cells, was used in therapy as a non-targeting control antibody.

\section{CC49-TCO Conjugation:}

To modify CC49 mAb with TCO, $2 \mathrm{mg}$ of CC49 $(8 \mathrm{mg} / \mathrm{ml}$ in PBS) was incubated with 10 molar equivalent excess of TCO-NHS ( $1 \mathrm{mg} / \mathrm{ml}$ in dry DMSO). The $\mathrm{pH}$ was adjusted to 9.0 with $1 \mathrm{M}$ carbonate buffer and the reaction was carried out for 30 minutes at room temperature with agitation. The TCO modified CC49 was purified using PD-10 desalting columns (GE healthcare, NJ) and the concentration was measured by NanoDrop (Thermo Scientific). The average number of TCO molecules per antibody was calculated by titrating CC49-TCO with radiolabeled Tz as previously reported (data not shown). ${ }^{21}$

\section{Radiolabeling:}

${ }^{224} \mathrm{Ra} /{ }^{212} \mathrm{~Pb}$ radionuclide generators were purchased from the US Department of Energy, Oak Ridge National Laboratory (Oak Ridge, Tennessee). Preferential elution of ${ }^{212} \mathrm{~Pb}$ was carried out by rinsing the generator column with $0.5 \mathrm{~N} \mathrm{HCl}$ to remove ${ }^{212} \mathrm{Bi}$ and its daughters. Subsequently, the generator column 
was rinsed with $2 \mathrm{~N} \mathrm{HCl}$ to elute ${ }^{212} \mathrm{~Pb}$. The eluent was mixed with $2 \mathrm{M} \mathrm{HNO}_{3}$ in a glass vial and the resulting solution was heated to dryness on a hot plate. The ${ }^{212} \mathrm{~Pb}-\mathrm{Pb}\left(\mathrm{NO}_{3}\right)_{2}$ residues were dissolved in $0.5 \mathrm{M}$ ammonium acetate buffer $(\mathrm{pH}$ 5.5) and used for radiolabeling.

DOTA-PEG $10^{-}$Tz was synthesized as previously reported. ${ }^{22}$ Synthesis of TCMC-PEG ${ }_{10}-\mathrm{Tz}$ is described in the supporting information (Scheme S1). For radiolabeling, DOTA-Tz or TCMC-Tz (2 mg/ml in $\left.0.5 \mathrm{M} \mathrm{NH} \mathrm{NAc}_{4} \mathrm{pH} 7.0\right)$ was combined with an appropriate amount of ${ }^{212} \mathrm{~Pb}-\mathrm{Pb}\left(\mathrm{NO}_{3}\right)_{2}$ solution. The $\mathrm{pH}$ was adjusted to 5.5 and the reaction mixture was incubated at $60^{\circ} \mathrm{C}$ for 20 minutes. Unbound ${ }^{212} \mathrm{~Pb}$ was removed using a PD-10 column. Fractions containing ${ }^{212} \mathrm{~Pb}$ were pooled and mixed with $10 \mathrm{mM}$ diethylenetriaminepentaacetic acid DTPA (5 $\mu \mathrm{L})$ and gentisic acid (20 mg/ml, $100 \mu \mathrm{g} /$ mouse dose; $\mathrm{pH}$ 5.5). The radiolabeling yield was measured by instant thin layer chromatography (ITLC) using 200 mM ethylenediaminetetraacetic acid (EDTA) as mobile phase. To determine the stability of radiolabeled complexes, an aliquot of ${ }^{212} \mathrm{~Pb}-\mathrm{DOTA}-\mathrm{Tz}$ and ${ }^{212} \mathrm{~Pb}$ TCMC-Tz was diluted in PBS, added to serum and incubated at $37^{\circ} \mathrm{C}$. Samples were taken at various time points and analyzed by ITLC. The effective specific activity of ${ }^{212} \mathrm{~Pb}$-Labeled $\mathrm{Tz}$ used for biodistribution was approximately 0.8 $\mu \mathrm{Ci} / \mathrm{nmol}$ of the tetrazine chelator. 


\section{Tumor Model:}

All animal experiments were carried out in compliance with the Institutional Animal Care and Use committee approval. The pharmacokinetic and therapy studies were carried out in athymic female BALB/C (nu/nu) mice (Envigo, USA). The human colon carcinoma cell line LS174T was obtained from ATCC and was maintained in RPMI 1640 medium supplemented with 1\% L-glutamine, 10\% FBS and $1 \%$ penicillin/streptomycin. Mice were inoculated subcutaneously (s.c.) with $4 \times 10^{6}$ LS174T cells in $100 \mu \mathrm{L}$ sterile PBS in the right flank and used when tumors were clearly visible, palpable and measureable.

\section{Blood Clearance and Biodistribution of DOTA-Tz and TCMC-Tz:}

Two groups of 3 tumor bearing mice were injected intravenously via tail vein with ${ }^{212} \mathrm{~Pb}-\mathrm{DOTA}-\mathrm{Tz}$ and ${ }^{212} \mathrm{~Pb}-\mathrm{TCMC}-\mathrm{Tz}(100 \mu \mathrm{L} /$ mouse, $\sim 10 \mu \mathrm{Ci})$ to examine blood clearance. The mice were serially bled and blood samples were collected at 10, 20, 30, 60 minutes and 24 hours. The blood samples were weighed and counted for radioactivity. In a separate experiment, two groups of LS174T tumor mice $(n=3)$ were injected intravenously with ${ }^{212} \mathrm{~Pb}-\mathrm{DOTA}-\mathrm{Tz}$ and ${ }^{212} \mathrm{~Pb}-\mathrm{TCMC}-\mathrm{Tz}(100 \mu \mathrm{L} /$ mouse, $\sim 10 \mu \mathrm{Ci})$ to study the biodistribution profile of the compounds. The mice were sacrificed at 30 minutes, 3 and 6 hours post injection (p.i.), and tumors and organs of interest were harvested, weighed, and counted to measure radioactivity. The radioactive tissue samples were counted using gamma counter and the results were expressed as a percentage of injected dose per gram (\% ID/g) and as a percentage injected dose (\% ID). 


\section{Pretargeted Biodistribution:}

Mice with visible and palpable tumors ( $\mathrm{n}=3$ mice per group) were selected for biodistribution studies and were injected with CC49-TCO via tail vein (100 $\mu \mathrm{g} / 100 \mu \mathrm{L}$ per mouse). Unbound, freely circulating antibodies were removed from circulation by administration of two doses of a galactose- albumin-Tz based clearing agent $(120 \mu \mathrm{g} / 100 \mu \mathrm{L}$ per mouse) $30 \mathrm{~h}$ and $48 \mathrm{~h}$ post CC49-TCO injection. The clearing agent should capture any unbound mAb in the blood and remove it from the circulation to the liver via Ashwell receptors on hepatocytes. ${ }^{21}$ Two hours after the last dose of clearing agent, mice were injected with a 10 molar excess to CC49-TCO of either ${ }^{212} \mathrm{~Pb}-\mathrm{DOTA}-\mathrm{Tz}$ or ${ }^{212} \mathrm{~Pb}-\mathrm{TCMC}-\mathrm{Tz}(\sim 5 \mu \mathrm{Ci}$ per mouse containing $100 \mu \mathrm{g}$ of gentisic acid and $50 \mathrm{nmol}$ of DTPA). The mice were sacrificed $3 \mathrm{~h}, 24 \mathrm{~h}$ and $48 \mathrm{~h}$ after the injection of radiolabeled-tetrazine. Tumors and other major organs were harvested, weighed and counted for radioactivity. Blood values were assumed to be $6.5 \%$ of whole body weight. Radioactivity in the remainder of the carcasses was also counted to determine the whole body retention and clearance by accounting for all the activity in the mice. 


\section{Dosimetry Studies:}

Dosimetry calculations were based on total radiation energy deposited per unit mass, as determined for the $\beta$-decay of ${ }^{212} \mathrm{~Pb}$ as well as $\alpha, \beta$ and $y$ radiations emitted for ${ }^{212} \mathrm{Bi}^{43}$ The biodistribution profiles of ${ }^{212} \mathrm{~Pb}-\mathrm{DOTA}-\mathrm{Tz}$ and ${ }^{212} \mathrm{~Pb}$ TCMC-Tz for the organ and tissues in the LS174T tumor-bearing mice pretargeted with CC49-TCO were used to calculate radiation absorbed doses to the tumors and also to the mouse normal organs and tissues using methods described previously. $(39,116-118)$ Similar methods were previously used to calculate alpha-particle radiation doses in mice from ${ }^{213} \mathrm{Bi}$ and ${ }^{211} \mathrm{At} .(119,120)$ For each tumor, organ, or tissue, the time-activity measurement data were plotted, and a time-activity function was fitted to the plotted data by least-squares regression analysis; these included time-activity data generated for 14 organs (blood, brain, heart, lung, liver, spleen, stomach, kidneys, small intestine, large intestine, muscle, skin, bone and tumor). Integration of the time activity curves yielded the cumulative number of radioactive disintegrations for ${ }^{212} \mathrm{~Pb}$ and ${ }^{212} \mathrm{Bi}$ in each organ. The cumulative activities associated with each organ or tissue were then multiplied by the equilibrium dose constants for each of the alpha- and betaemissions to yield the cumulative absorbed dose, integrated to infinity (for complete biological clearance or radioactive decay), together with an accounting for beta-particle absorbed fractions. Cross-organ beta doses for these organs were negligible compared to the radiation self-organ-dose imparted by alpha particles, and were not included. 


\section{Pretargeted Therapy:}

Pretargeted radioimmunotherapy was performed in mice bearing LS147T human colon carcinoma xenografts. Tumor bearing mice were randomized into study groups ( $\mathrm{n}=8$ mice per group) 4 days post LS174T cell inoculation ensuring that all study groups have approximately equal tumor volumes. Initially, four groups of tumor bearing animals $(n=8)$ were injected with $100 \mu \mathrm{g}$ of CC49-TCO, followed by two doses of clearing agent at $30 \mathrm{~h}$ and $48 \mathrm{~h}$. These mice were treated with $75 \mu \mathrm{Ci}, 125 \mu \mathrm{Ci}$ and $200 \mu \mathrm{Ci}$ of ${ }^{212} \mathrm{~Pb}-\mathrm{DOTA}-\mathrm{Tz}$ (10 molar equivalents to CC49-TCO) two hours after the last dose of clearing agent (Fig. 2.3). To determine the efficacy of a multi-dose regimen, one group of mice $(n=8)$ was pretargeted with CC49-TCO and two doses of clearing agent, followed by two doses of $75 \mu \mathrm{Ci}$ of ${ }^{212} \mathrm{~Pb}-\mathrm{DOTA}-\mathrm{Tz}$ at a 7 day interval. Two non-treatment control groups of mice $(n=8)$ were injected with $100 \mu \mathrm{L}$ of PBS and $100 \mu \mathrm{g}$ of CC49-TCO. As a non-specific control, a group of 8 mice was injected with rituximab-TCO (RTX-TCO) and received $200 \mu \mathrm{Ci}$ of ${ }^{212} \mathrm{~Pb}$-DOTA-Tz. To compare the therapeutic efficacy of PRIT vs. RIT regimen, one group of mice $(n=8)$ was treated with $15 \mu \mathrm{Ci}$ of direct labeled ${ }^{212} \mathrm{~Pb}-\mathrm{TCMC}-\mathrm{CC} 49$, which was reported to be the maximum tolerated dose.(111) All injections were carried out i.v. through tail vein and mice were monitored for tumor size, body weight and body score twice a week. Tumor volume was calculated by measuring length, width and depth of the tumors with digital caliper and using the following formula: Tumor volume $=$ length $\mathrm{x}$ width $\mathrm{x}$ depth. Mice were removed from the therapy study and sacrificed if weight loss was $>20 \%$ of initial weight, tumor volume exceeded 1.0 
$\mathrm{cm}^{3}$, or the appearance of skin ulceration on the tumor. To determine the hematological toxicity, blood samples were collected at the time of animal sacrifice. White Blood Count (WBC), total and differential leukocyte count, Red Blood Cell (RBC) count and platelet counts were performed for each tumor bearing mouse group and compared with a non-tumor bearing control mouse group. Histopathological studies were performed on tumor and kidney tissue samples from the PBS, $75 \mu \mathrm{Ci}$, and $200 \mu \mathrm{Ci}$ treatment groups.

\section{Statistical Analysis:}

The values for all samples in the different experimental conditions were averaged, and the standard error or standard deviation of the mean was calculated. All values were expressed as mean $\pm s d$. Differences between means were determined using the unpaired Student's $t$-tests. Kaplan-Meier survival curves were generated using Graph Pad Prism software and curve comparison was done using Lon-rank (Mantel-Cox) test model. $\quad\left({ }^{\star} P<0.05,{ }^{* *} P<0.01\right.$, $\left.{ }^{* * *} P<0.001\right)$ 


\section{Results}

\section{Radiolabeling and Pharmacokinetics of ${ }^{212} \mathrm{~Pb}$ Labeled Tetrazine Conjugates:}

The radiolabeling efficiencies for both ${ }^{212} \mathrm{~Pb}$-DOTA-Tz and ${ }^{212} \mathrm{~Pb}-\mathrm{TCMC}-\mathrm{Tz}$ (Fig. 2.1) were found to be $\geq 95 \%$. Both compounds also exhibited high serum stability with $>85 \%$ of ${ }^{212} \mathrm{~Pb}$-DOTA-Tz and $>91 \%$ of ${ }^{212} \mathrm{~Pb}-\mathrm{TCMC}-\mathrm{Tz}$ remaining intact after 24 hours incubation.

The blood clearance of ${ }^{212} \mathrm{~Pb}-\mathrm{DOTA}-\mathrm{Tz}$ and ${ }^{212} \mathrm{~Pb}-\mathrm{TCMC}-\mathrm{Tz}$ was very rapid with $\sim 95 \%$ of activity cleared out of blood within first 3 hours p.i. (Fig. 2.2AB). The $t_{1 / 2}$ values for ${ }^{212} \mathrm{~Pb}-$ DOTA-Tz and ${ }^{212} \mathrm{~Pb}-\mathrm{TCMC}-\mathrm{Tz}$ were found to be $<60$ minutes. Further, the pharmacokinetic profiles of the two radiolabeled tetrazine compounds were evaluated for their tissue uptake and whole body clearance (Fig. 2.2C-D). Both ${ }^{212} \mathrm{~Pb}-\mathrm{DOTA}-\mathrm{Tz}$ and ${ }^{212} \mathrm{~Pb}-\mathrm{TCMC}-\mathrm{Tz}$ exhibited rapid tissue and whole body clearance with $\sim 77 \%$ and $\sim 74 \%$ of injected dose cleared through urine by 3 hours p.i., respectively. At 24 hours, there was no uptake of ${ }^{212} \mathrm{~Pb}$ DOTA-Tz in any of major organs except for kidneys $(2.3 \% \mathrm{ID} / \mathrm{g})$, which was the primary route of excretion. In contrast, the biodistribution of ${ }^{212} \mathrm{~Pb}-\mathrm{TCMC}-\mathrm{Tz}$ at 24 hours showed significant uptake in liver $(\sim 15.6 \% \mathrm{ID} / \mathrm{g})$, spleen $(3.2 \% \mathrm{ID} / \mathrm{g})$, lung $(2.0 \% \mathrm{ID} / \mathrm{g})$ and kidneys $(3.0 \% \mathrm{ID} / \mathrm{g})$. 
$\mathbf{A}$

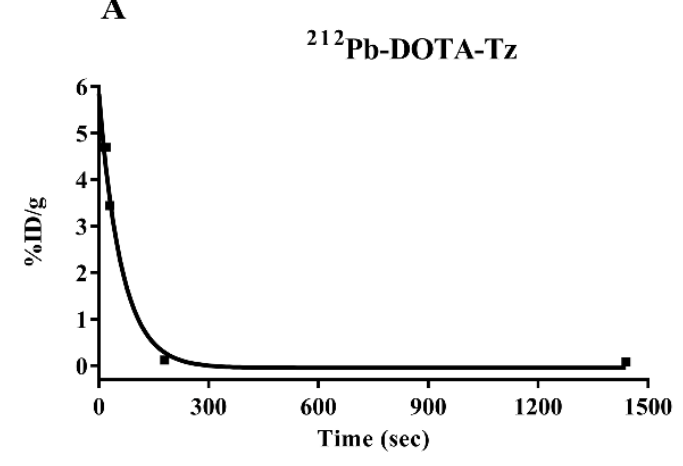

C

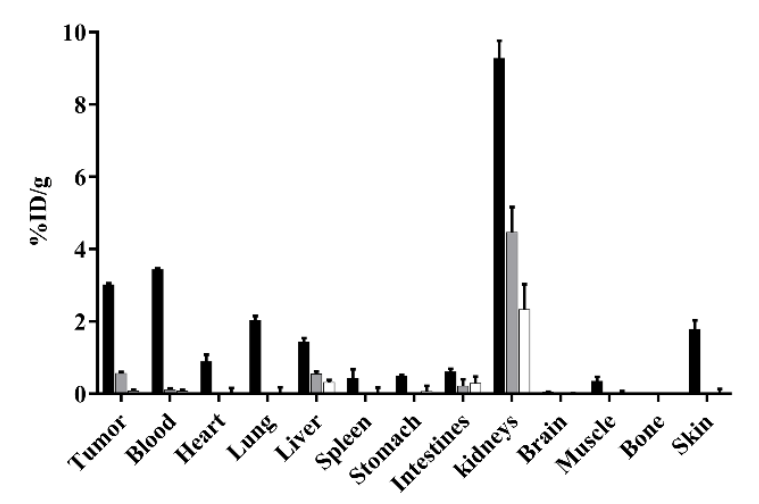

B

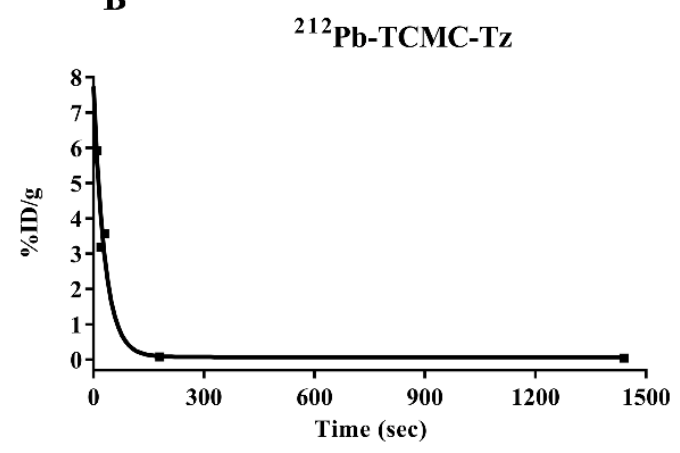

D

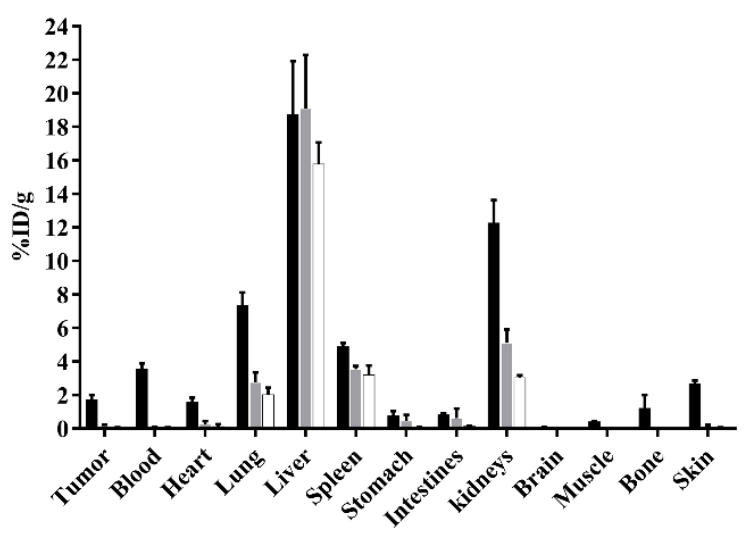

Figure 2.2: Pharmacokinetics of ${ }^{212} \mathrm{~Pb}$-labeled tetrazines (without the pretargeted mAb) in mice bearing LS174T human colon carcinoma xenograft. Blood Clearance of A) ${ }^{212} \mathrm{~Pb}-\mathrm{DOTA}-\mathrm{Tz}$ and $\left.\mathrm{B}\right){ }^{212} \mathrm{~Pb}-\mathrm{TCMC}-\mathrm{Tz}$. Biodistribution of C) ${ }^{212} \mathrm{~Pb}-\mathrm{DOTA}-\mathrm{Tz}$ and D) ${ }^{212} \mathrm{~Pb}-\mathrm{TCMC}-\mathrm{Tz}$ in LS174T tumor bearing mice at 30 minutes $(\square)$, 3 hours $(\square)$, and 24 hours $(\square)$ post injection (n=3). 


\section{Pretargeted Biodistribution:}

The biodistribution and tumor-targeting properties of ${ }^{212} \mathrm{~Pb}-\mathrm{DOTA}-\mathrm{Tz}$ and ${ }^{212} \mathrm{~Pb}-\mathrm{TCMC}-\mathrm{Tz}$ were evaluated in LS174T tumor bearing mice pretargeted with CC49-TCO mAb (Table 2.1). ${ }^{212} \mathrm{~Pb}$-DOTA-Tz showed rapid tumor uptake and minimum accumulation in other major body tissues. The tumor uptake value for ${ }^{212} \mathrm{~Pb}-\mathrm{DOTA}$-Tz reached $0.94 \pm 0.47 \% \mathrm{ID} / \mathrm{g}$ by 3 hours p.i. and then decreased to $0.66 \pm 0.11 \% \mathrm{ID} / \mathrm{g}$ by 24 hours p.i. Clearance from blood $(0.1 \pm 0.02 \% \mathrm{ID} / \mathrm{g}$ at 3 hours and $0.04 \pm 0.02 \% \mathrm{ID} / \mathrm{g}$ at 24 hours) and other major organs was rapid and no non-specific uptake was observed except for the kidneys $(2.53 \pm 0.23 \% \mathrm{ID} / \mathrm{g}$ at 3 hours and $1.33 \pm 0.16 \% \mathrm{ID} / \mathrm{g}$ at 24 hours). Given that $\mathrm{t}_{1 / 2}$ of ${ }^{212} \mathrm{~Pb}$ is $\sim 10.6$ hours, almost no tissue activity was measured at 48 hours p.i. In comparison, ${ }^{212} \mathrm{~Pb}-\mathrm{TCMC}-\mathrm{Tz}$ also displayed rapid tumor accumulation with a higher uptake value of $1.64 \pm 1.22 \% \mathrm{ID} / \mathrm{g}$ at 3 hours p.i. which dropped to $0.50 \pm 0.17 \% \mathrm{ID} / \mathrm{g}$ by 24 hours p.i. While ${ }^{212} \mathrm{~Pb}-\mathrm{TCMC}-\mathrm{Tz}$ cleared out of blood rapidly $(0.12 \pm 0.09 \%$ $\mathrm{ID} / \mathrm{g}$ at 3 hours and $0.01 \pm 0.04 \% \mathrm{ID} / \mathrm{g}$ at 24 hours p.i.), a significant uptake in the liver was observed. The liver accumulation of ${ }^{212} \mathrm{~Pb}-\mathrm{TCMC}-\mathrm{Tz}$ at 3 hours and 24 hours was $5.39 \pm 1.31 \% \mathrm{ID} / \mathrm{g}$ and $2.49 \pm 0.35 \% \mathrm{ID} / \mathrm{g}$, respectively. The high liver uptake of ${ }^{212} \mathrm{~Pb}-\mathrm{TCMC}-\mathrm{Tz}$ in the pretargeting study was consistent with tissue distribution of ${ }^{212} \mathrm{~Pb}-\mathrm{TCMC}-\mathrm{Tz}$ alone as described above. 


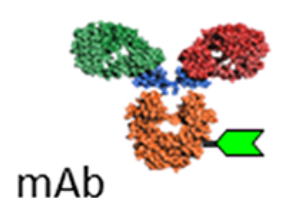

$\mathrm{mAb}$

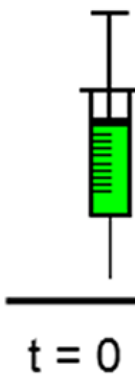

Clearing Agent

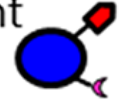

Clearing

$$
\text { Agent }
$$
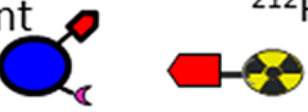

${ }^{212} \mathrm{~Pb}-\mathrm{Tz}$

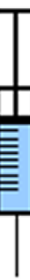

$48 \mathrm{~h} \quad 50 \mathrm{~h}$

Figure 2.3: Schematic of the pretargeting protocol used in this study. Tumor bearing mice were first injected with TCO modified mAb. To remove circulating antibodies from the blood, two doses of clearing agent were administered at $30 \mathrm{~h}$ and $48 \mathrm{~h}$ post mAb injections. Two hours after the last dose of clearing agent, mice were injected with ${ }^{212} \mathrm{~Pb}$-labeled tetrazine probes. 
Table 2.1: Biodistribution of ${ }^{212} \mathrm{~Pb}-\mathrm{DOTA}-\mathrm{Tz}$ and ${ }^{212} \mathrm{~Pb}-\mathrm{TCMC}-\mathrm{Tz}$ in LS174T tumor bearing nude mice pretargeted with CC49-TCO mAb.

\begin{tabular}{|c|c|c|c|c|c|c|}
\hline \multirow[b]{2}{*}{ Tissues } & \multicolumn{3}{|c|}{${ }^{212} \mathrm{~Pb}-\mathrm{DOTA}-\mathrm{Tz}(\% \mathrm{ID} / \mathrm{g})$} & \multicolumn{3}{|c|}{${ }^{212} \mathrm{~Pb}-\mathrm{TCMC}-\mathrm{Tz}(\% \mathrm{ID} / \mathrm{g})$} \\
\hline & 3 Hours & 24 Hours & 48 Hours & 3 Hours & 24 Hours & 48 Hours \\
\hline Tumor & $0.94 \pm 0.47$ & $0.66 \pm 0.11$ & $0.00 \pm 0.00$ & $1.64 \pm 1.22$ & $0.50 \pm 0.17$ & $0.58 \pm 0.05$ \\
\hline Blood & $0.10 \pm 0.02$ & $0.04 \pm 0.02$ & $0.00 \pm 0.00$ & $0.12 \pm 0.09$ & $0.01 \pm 0.04$ & $0.12 \pm 0.01$ \\
\hline Heart & $0.03 \pm 0.03$ & $0.00 \pm 0.00$ & $0.00 \pm 0.00$ & $0.00 \pm 0.00$ & $0.00 \pm 0.00$ & $0.14 \pm 0.22$ \\
\hline Lung & $0.20 \pm 0.04$ & $0.09 \pm 0.06$ & $0.00 \pm 0.00$ & $0.41 \pm 0.28$ & $0.13 \pm 0.23$ & $0.28 \pm 0.15$ \\
\hline Liver & $0.28 \pm 0.03$ & $0.21 \pm 0.05$ & $0.17 \pm 0.11$ & $5.39 \pm 1.31$ & $2.49 \pm 0.35$ & $2.53 \pm 0.30$ \\
\hline Spleen & $0.01 \pm 0.00$ & $0.00 \pm 0.00$ & $0.00 \pm 0.00$ & $0.19 \pm 0.24$ & $0.05 \pm 0.14$ & $0.54 \pm 0.11$ \\
\hline Stomach & $0.25 \pm 0.13$ & $0.08 \pm 0.11$ & $0.00 \pm 0.00$ & $0.48 \pm 0.23$ & $0.06 \pm 0.10$ & $0.12 \pm 0.05$ \\
\hline Intestines & $0.44 \pm 0.12$ & $0.12 \pm 0.14$ & $0.01 \pm 0.01$ & $0.70 \pm 0.02$ & $0.08 \pm 0.03$ & $0.19 \pm 0.15$ \\
\hline Kidneys & $2.53 \pm 0.23$ & $1.33 \pm 0.16$ & $0.47 \pm 0.20$ & $4.07 \pm 0.93$ & $2.46 \pm 0.44$ & $1.79 \pm 0.18$ \\
\hline Brain & $0.00 \pm 0.00$ & $0.00 \pm 0.00$ & $0.00 \pm 0.00$ & $0.00 \pm 0.00$ & $0.00 \pm 0.00$ & $0.03 \pm 0.01$ \\
\hline Muscle & $0.00 \pm 0.00$ & $0.00 \pm 0.00$ & $0.00 \pm 0.00$ & $0.00 \pm 0.00$ & $0.00 \pm 0.00$ & $0.00 \pm 0.00$ \\
\hline Bone & $0.00 \pm 0.00$ & $0.00 \pm 0.00$ & $0.00 \pm 0.00$ & $0.00 \pm 0.00$ & $0.00 \pm 0.00$ & $0.89 \pm 0.78$ \\
\hline Skin & $0.17 \pm 0.17$ & $0.12 \pm 0.06$ & $0.00 \pm 0.00$ & $0.07 \pm 0.05$ & $0.00 \pm 0.00$ & $0.16 \pm 0.09$ \\
\hline
\end{tabular}




\section{Dosimetry:}

The mean organ absorbed doses to tumors, organs, and tissues per unit administered activity for ${ }^{212} \mathrm{~Pb}-\mathrm{DOTA}-\mathrm{Tz}$ and ${ }^{212} \mathrm{~Pb}-\mathrm{TCMC}-\mathrm{Tz}$ were calculated using the measured biodistribution data in mice bearing LS174T tumors (Table 2.2). The absorbed doses to tumor tissue from ${ }^{212} \mathrm{~Pb}-\mathrm{DOTA}-\mathrm{Tz}$ and ${ }^{212} \mathrm{~Pb}$ TCMC-Tz were found to be $4.83 \mathrm{cGy} / \mu \mathrm{Ci}$ and $9.42 \mathrm{cGy} / \mu \mathrm{Ci}$ respectively. Normal organ doses for ${ }^{212} \mathrm{~Pb}$-DOTA-Tz were comparatively low except for the kidneys, which were calculated to be $12.6 \mathrm{cGy} / \mu \mathrm{Ci}$. The absorbed doses to kidneys and liver for ${ }^{212} \mathrm{~Pb}-\mathrm{TCMC}-\mathrm{Tz}$ were $34.4 \mathrm{cGy} / \mu \mathrm{Ci}$ and $43.7 \mathrm{cGy} / \mu \mathrm{Ci}$, respectively. 
Table 2.2: Absorbed radiation doses from ${ }^{212} \mathrm{~Pb}-\mathrm{DOTA}-\mathrm{Tz}$ and ${ }^{212} \mathrm{~Pb}-\mathrm{TCMC}-\mathrm{Tz}$ in mice bearing LS174T colon carcinoma tumors.

\begin{tabular}{|l|c|c|}
\hline & ${ }^{212} \mathbf{P b}-\mathbf{D O T A}-\mathbf{T z}$ & ${ }^{212} \mathbf{P b}-\mathbf{T C M C}-\mathbf{T z}$ \\
\hline Tissue & $\mathbf{c G y} / \mathbf{\mu C i}$ & $\mathbf{c G y} / \mathbf{\mu C i}$ \\
\hline Tumor & 4.83 & 9.42 \\
\hline Blood & 0.937 & 2.47 \\
\hline Heart & 0.0867 & $\mathrm{~N} / \mathrm{A}$ \\
\hline Lung & 0.789 & 3.74 \\
\hline Liver & 2.44 & 43.7 \\
\hline Spleen & 0.0746 & $\mathrm{~N} / \mathrm{A}$ \\
\hline Stomach & 0.584 & 1.8 \\
\hline L. Intestine & 1.63 & 3.55 \\
\hline S. Intestine & 0.884 & 1.44 \\
\hline Kidneys & 12.6 & 34.4 \\
\hline Brain & 0.0181 & $\mathrm{~N} / \mathrm{A}$ \\
\hline Muscle & 0.0489 & $\mathrm{~N} / \mathrm{A}$ \\
\hline Carcass & 0.943 & 2.65 \\
\hline Bone & 0.329 & $\mathrm{~N} / \mathrm{A}$ \\
\hline Skin & 0.991 & $\mathrm{~N} / \mathrm{A}$ \\
\hline
\end{tabular}




\section{Pretargeted Therapy:}

The pretargeted radioimmunotherapy studies were carried out in LS147T tumor bearing mice following the protocol depicted in Fig. 2.3. The effects of ${ }^{212} \mathrm{~Pb}-\mathrm{DOTA}-\mathrm{Tz}$ treatment on tumor growth rate as well as body weight are shown in Fig. 2.4. Mouse groups receiving the single dose of $75 \mu \mathrm{Ci}$ and $200 \mu \mathrm{Ci}$ of ${ }^{212} \mathrm{~Pb}-\mathrm{DOTA}-\mathrm{Tz}$ exhibited substantial tumor growth inhibition over the study period with mean tumor volume of $0.14 \pm 0.13 \mathrm{~cm}^{3}$ and $0.06 \pm 0.06 \mathrm{~cm}^{3}$ respectively, on day 20. By comparison, tumors in the non- treatment control groups, which received PBS and CC49-TCO, grew rapidly and had to be sacrificed on day 20 due to large tumor volume (mean tumor volume $>0.6 \mathrm{~cm}^{3}$ ) and over-all poor body condition. Mice which received a single $15 \mu \mathrm{Ci}$ dose of directly labeled ${ }^{212} \mathrm{~Pb}-\mathrm{TCMC}-\mathrm{CC} 49$ or pretargeted RTX-TCO and $200 \mu \mathrm{Ci}$ of ${ }^{212} \mathrm{~Pb}-\mathrm{DOTA}-\mathrm{Tz}$ exhibited slower tumor growth rate than that of the non-treated control groups but faster than the mice in the PRIT regimen (Fig. 2.4A). Mice that received either $200 \mu \mathrm{Ci}$ of ${ }^{212} \mathrm{~Pb}-\mathrm{DOTA}-\mathrm{Tz}$ or $15 \mu \mathrm{Ci}$ of ${ }^{212} \mathrm{~Pb}-\mathrm{TCMC}-\mathrm{CC} 49$ were sacrificed on day 20 due to acute radiation toxicity and poor body score.

In a second therapy study, a multi-dose therapy regimen (2 doses of 75 $\mu \mathrm{Ci}$ at 7 days interval) was compared with an intermediated dose of $125 \mu \mathrm{Ci}$. The results showed that both treatment groups exhibited substantial inhibition of tumor growth over time compared to non-treatment group (Fig. 2.4C). In addition to tumor volume, animal weights were also monitored following the administration of the dose (Fig. 2.4B, D). Although mice receiving high dose of radiation (125 $\mu \mathrm{Ci}$ and $200 \mu \mathrm{Ci}$ therapy groups) showed a temporary loss in body weight, they 
recovered and maintained an acceptable level ( $>80 \%$ original body weight) throughout the course of study.

Based on the Kaplan-Meier analyses, the median survival of treatment groups receiving $75 \mu \mathrm{Ci}, 125 \mu \mathrm{Ci}$ and $2 \times 75 \mu \mathrm{Ci}$ of pretargeted ${ }^{212} \mathrm{~Pb}-\mathrm{DOTA}-\mathrm{Tz}$ were 26, 28 and 31 days, respectively (Fig. 2.5). The median survival of groups receiving $200 \mu \mathrm{Ci}$ dose and $15 \mu \mathrm{Ci}$ of directly labeled antibody were same as the control groups receiving no treatment at day 20. This was supported by hematological studies that clearly showed the negative effects of radiation on WBC and platelets counts in the $200 \mu \mathrm{Ci}$ group. Moreover, mice in the $125 \mu \mathrm{Ci}$ and $2 \times 75 \mu$ Ci pretargeted treatment groups showed reduced WBC and platelet counts, however they were less severe than the $200 \mu \mathrm{Ci}$ dose. At the same time, the $75 \mu \mathrm{Ci}$ dose was well tolerated and did not induce any blood toxicity (Fig. 2.6). Even though the kidneys received the highest organ dose, histopathological analysis of the kidneys revealed no acute tissue damage in $200 \mu \mathrm{Ci}$ and $75 \mu \mathrm{Ci}$ ${ }^{212} \mathrm{~Pb}-\mathrm{DOT} A-\mathrm{Tz}$ pretargeted therapy groups (Fig. 2.7). 
A

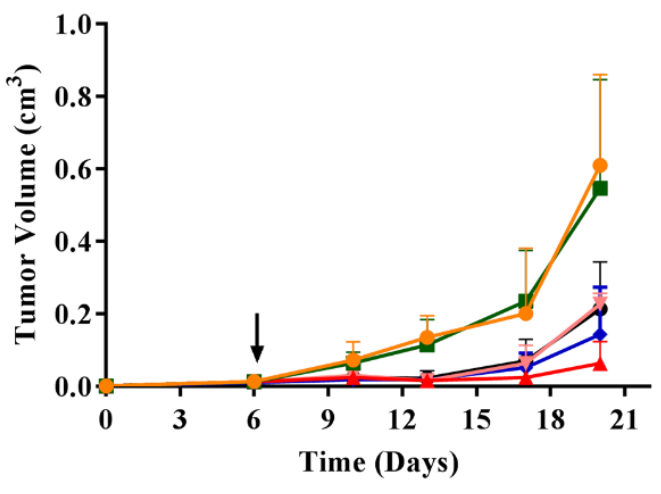

C

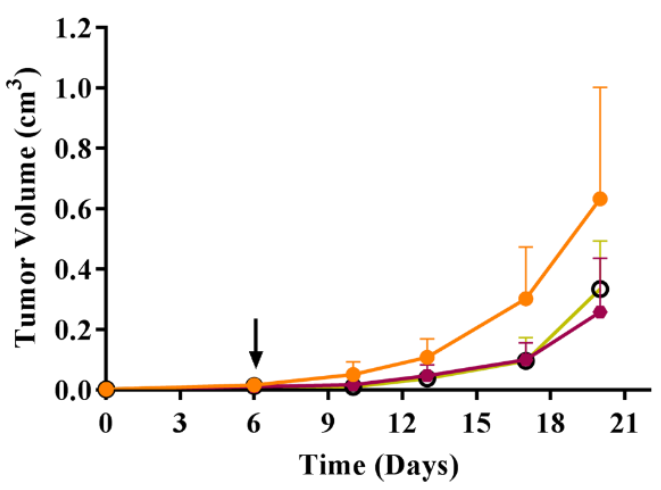

B

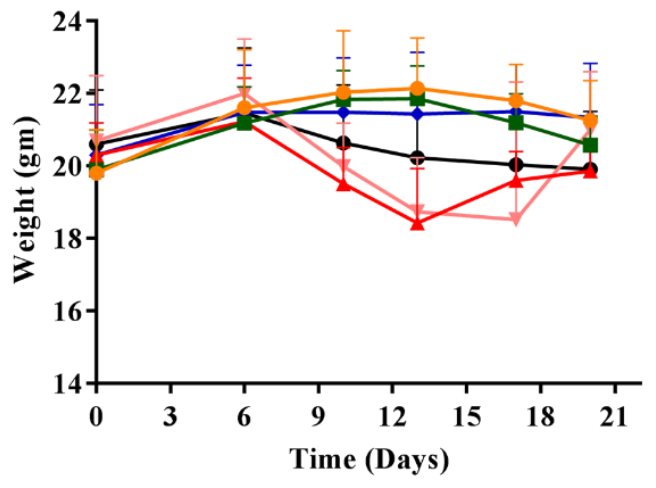

D

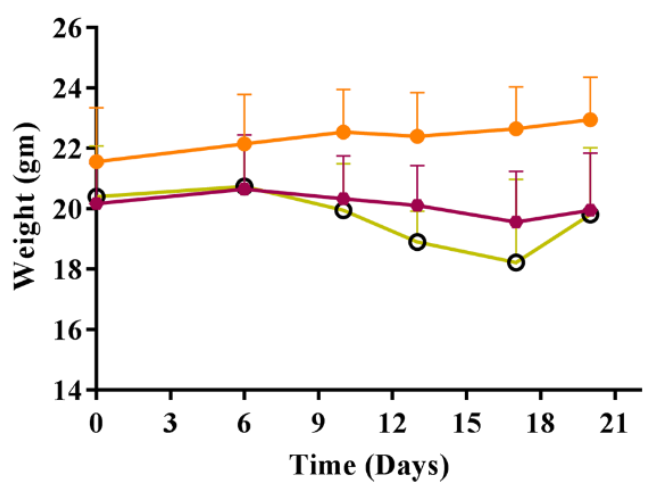


Figure 2.4: Plots of average tumor volumes $(A, C)$ and average body weights $(B$, D) of each group of mice $(n=8)$ during first 21 days of the PRIT studies. Mice bearing LS174T human colon carcinoma tumors were pretargeted with CC49TCO mAb or RTX-TCO, two doses of clearing agent and ${ }^{212} \mathrm{~Pb}-\mathrm{DOTA}-\mathrm{Tz}$. A ${ }^{212} \mathrm{~Pb}-\mathrm{TCMC}-\mathrm{CC} 49$ direct labeled mAb group was also included. In the first pretargeted therapy study, tumor volumes (A) and mouse weights (B) are reported for mice administered with PBS (-๑), CC49-TCO (-๑), CC49-TCO + 75 $\mu \mathrm{Ci}{ }^{212} \mathrm{~Pb}-\mathrm{DOTA}-\mathrm{Tz}(\rightarrow-)$, CC49-TCO $+200 \mu \mathrm{Ci}{ }^{212} \mathrm{~Pb}-\mathrm{DOTA}-\mathrm{Tz}(\neg), \mathrm{RTX}-\mathrm{TCO}$ $+200 \mu \mathrm{Ci}{ }^{212} \mathrm{~Pb}-$ DOTA-Tz $(--)$ and a direct labeled ${ }^{212} \mathrm{~Pb}-\mathrm{TCMC}-\mathrm{CC} 49(15 \mu \mathrm{Ci})$ mAb control ( $\rightarrow-)$. In a second pretargeted therapy study, tumor volumes (C) and mouse weights (D) are reported for mice injected with PBS (-o), CC49-TCO + $125 \mu \mathrm{Ci}^{212} \mathrm{~Pb}-\mathrm{DOTA}-\mathrm{Tz}(-\mathrm{-})$ and CC49-TCO $+2 \times 75 \mu \mathrm{Ci}{ }^{212} \mathrm{~Pb}-\mathrm{DOTA}-\mathrm{Tz}(\rightarrow-)$. Radioactive doses were administered $(\downarrow) 6$ days post tumor inoculation, with an additional dose on day 13 for the multi-dose therapy group. 


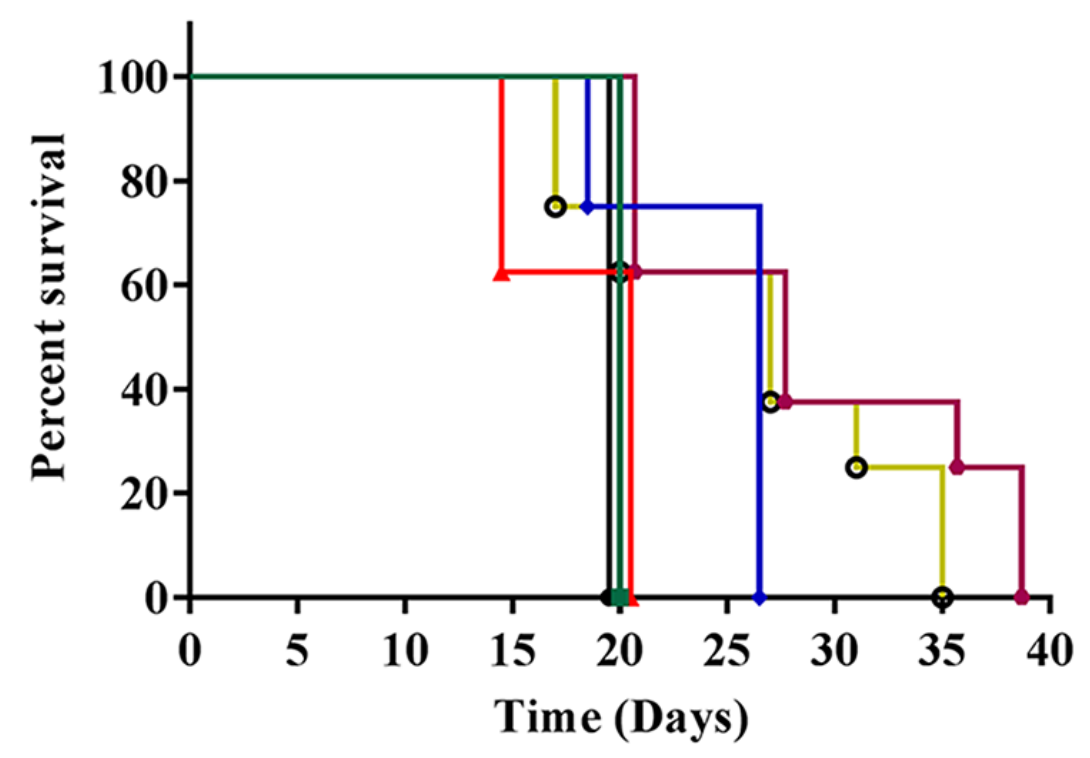

Figure 2.5: Kaplan-Meier survival curves. Mice bearing LS174T human colon carcinoma tumors were pretargeted with CC49-TCO mAb and treated with

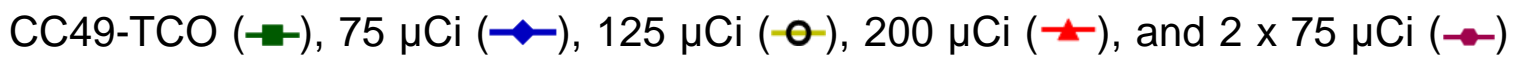
of ${ }^{212} \mathrm{~Pb}-\mathrm{DOTA}-\mathrm{Tz}$. One group of mice was treated with directly labeled ${ }^{212} \mathrm{~Pb}$ TCMC-CC49 mAb (- - -). The PBS vehicle and non-radiolabeled CC49-TCO control groups were sacrificed on day 20 (data not shown). Treatment groups receiving $75 \mu \mathrm{Ci}(P=0.03), 125 \mu \mathrm{Ci}(P=0.02)$, and $2 \times 75 \mu \mathrm{Ci}(P=0.001)$ showed significant survival over vehicle control and direct labeled mAb 

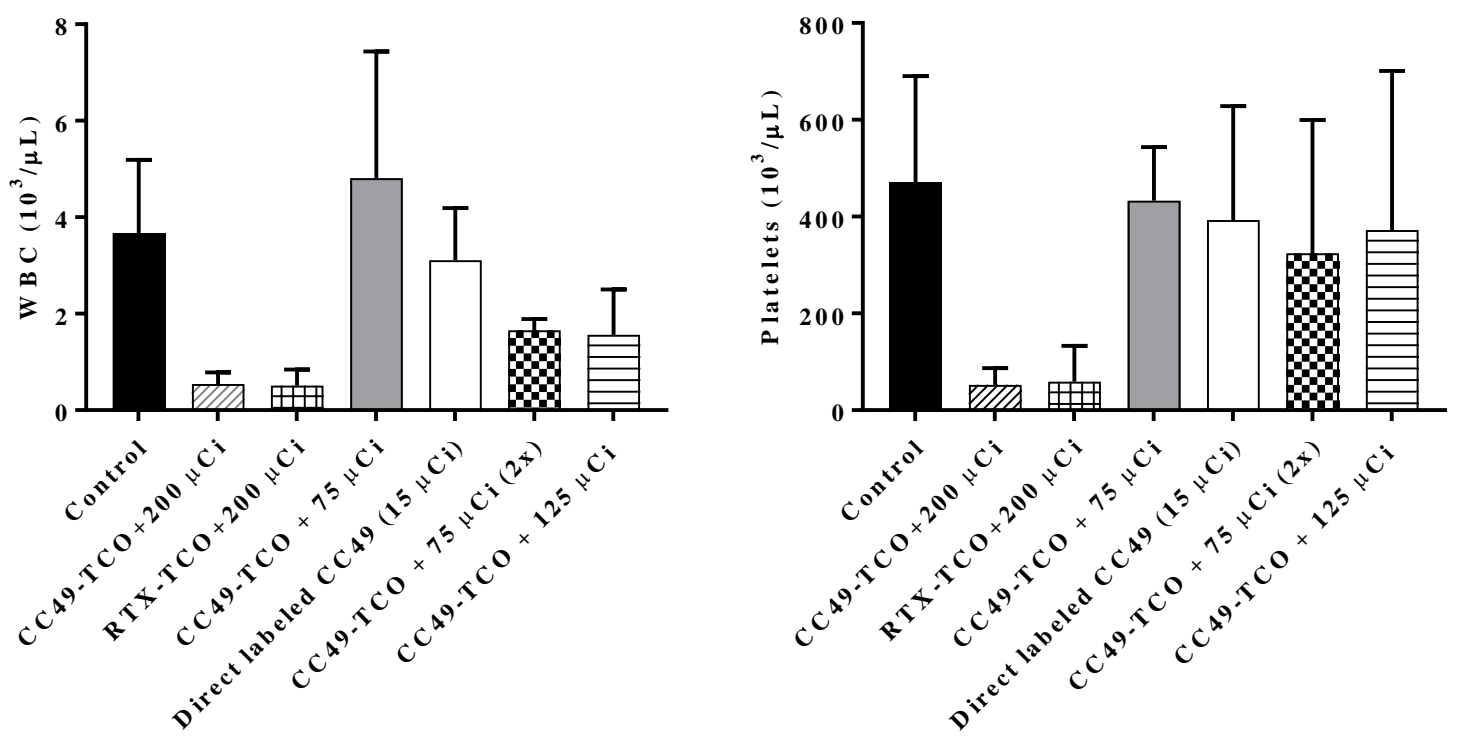

Figure 2.6: The effects of radiation-induced toxicity on (A) white blood cell counts, and (B) platelet counts. 

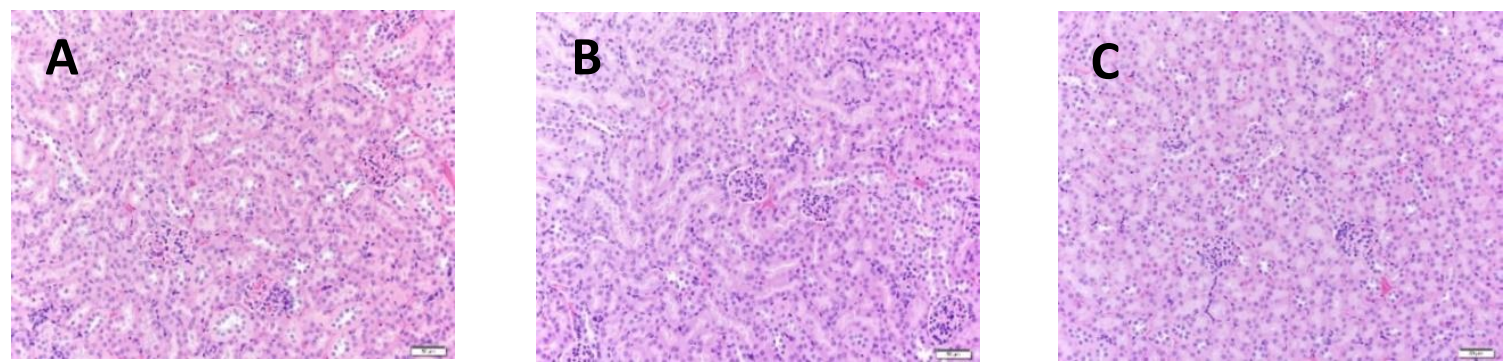

Figure 2.7: Kidney histology sections from (A) Untreated mice (PBS), and pretargeted mice treated with (B) $200 \mu \mathrm{Ci}$ and (C) $75 \mu \mathrm{Ci}$ of ${ }^{212} \mathrm{~Pb}$-DOTA-Tz. 


\section{DISCUSSION}

Two Tz based chelating systems, DOTA-Tz and TCMC-Tz (Fig. 2.1), were evaluated for their ${ }^{212} \mathrm{~Pb}$ radiolabeling efficiency, stability and tissue biodistribution. DOTA is one of the most widely used chelators and has been used in the clinical setting for number of radiometals.(114) TCMC was specifically designed to stably coordinate ${ }^{212} \mathrm{~Pb} /{ }^{203} \mathrm{~Pb}$ under mild conditions necessary for labeling antibodies.(41) TCMC has shown favorable radiolabeling kinetics and in vivo stability with radiolabeled antibodies and was successfully used in a phase 1 clinical trial with trastuzumab. $(44,45)$ Both DOTA-Tz and TCMC-Tz were radiolabeled with identical efficiencies and there was no significant difference in their serum stabilities. Similarly, both radiolabeled complexes exhibited rapid blood clearance with $\sim 95 \%$ of the injected dose being cleared from the blood within 3 hours of injection (Fig. 2.2A-B). In contrast, the tissue distribution of ${ }^{212} \mathrm{~Pb}-\mathrm{DOTA}-\mathrm{Tz}$ and ${ }^{212} \mathrm{~Pb}-\mathrm{TCMC}-\mathrm{Tz}$ showed a marked difference in that there was a significant liver uptake of ${ }^{212} \mathrm{~Pb}-\mathrm{TCMC}-\mathrm{Tz}$ at 24 hours p.i. (Fig. 2.2C-D). This suggested that in addition to the kidneys, a significant portion of the ${ }^{212} \mathrm{~Pb}-\mathrm{TCMC}-\mathrm{Tz}$ dose was also excreted via hepatobiliary/gastrointestinal tract. This difference in liver uptake of two compounds was likely due to differences in charge and hydrophobicity of the two complexes. A slight increase in hydrophobicity due to the isothiocyanotobenzyl (SCN-Bz) group may have been responsible for the Tz-PEG ${ }_{10}-\mathrm{SCN}-\mathrm{Bn}-{ }^{212} \mathrm{~Pb}$ $(\mathrm{TCMC})^{2+}$ liver uptake. The positive charge of ${ }^{212} \mathrm{~Pb}(\mathrm{TCMC})^{2+}$ would likely 
contribute to increased non-specific kidney retention compared to the negative net charge of $\mathrm{Pb}(\mathrm{DOTA})^{1-}$ complex.(41)

The biodistribution results in mice bearing LS174T color carcinoma tumors showed targeted tumor uptake and rapid clearance from the normal organs for both ${ }^{212} \mathrm{~Pb}-\mathrm{DOTA}-\mathrm{Tz}$ and ${ }^{212} \mathrm{~Pb}-\mathrm{TCMC}-\mathrm{Tz}$ (Table 2.1). The rapid clearance from the blood and normal organs led to moderately high tumor-tonormal tissue activity at 24 hours. This is particularly important in therapy as it allows administering higher radiation dose with minimal normal tissue toxicity. It is anticipated that greater tumor uptake and tumor/non-tumor ratios can be achieved by administering higher specific activity ${ }^{212} \mathrm{~Pb}-\mathrm{DOTA}-\mathrm{Tz}$ preparations. Purification of ${ }^{212} \mathrm{~Pb}-\mathrm{DOTA}-\mathrm{Tz}$ coupled with decreasing the mAb:Tz ratio from 1:10 to $1: 2$ as reported by Houston et al. should improve tumor localization and therapeutic efficacy.(32) ${ }^{212} \mathrm{~Pb}-\mathrm{TCMC}-\mathrm{Tz}$ was expected to have an equally favorable pharmacokinetic profile and in vivo stability in PRIT studies as well due to the success of ${ }^{212} \mathrm{~Pb}-\mathrm{TCMC}$-trastuzumab in clinical trials. ${ }^{212} \mathrm{~Pb}-\mathrm{TCMC}-\mathrm{Tz}$ showed almost double the tumor uptake than that of ${ }^{212} \mathrm{~Pb}-\mathrm{DOTA}-\mathrm{Tz}$ at 3 hours, however, tumor uptake was lower at 24 hours than ${ }^{212} \mathrm{~Pb}-\mathrm{DOTA}-\mathrm{Tz}$. In addition, there was also a significantly higher liver and kidney uptake for ${ }^{212} \mathrm{~Pb}-\mathrm{TCMC}-\mathrm{Tz}$ at all times points compared to ${ }^{212} \mathrm{~Pb}-\mathrm{DOTA}-\mathrm{Tz}$.

Apart from the tumor, the kidneys received the highest organ dose from ${ }^{212} \mathrm{~Pb}-\mathrm{DOTA}-\mathrm{Tz}$ (Table 2.2). A moderate dose to the kidneys was expected as ${ }^{212} \mathrm{~Pb}-\mathrm{DOT} A-\mathrm{Tz}$ clears from the body through kidneys. Moreover, it has been reported that approximately $30 \%$ of the ${ }^{212} \mathrm{Bi}$ is released from the DOTA chelator 
during decay from ${ }^{212} \mathrm{~Pb}$ to ${ }^{212} \mathrm{Bi} .(115)$ The free ${ }^{212} \mathrm{Bi}$ released from the tumor and other organs during this transition may also contribute to the kidney dose values. However, the rapid pharmacokinetics of ${ }^{212} \mathrm{~Pb}-\mathrm{DOTA}-\mathrm{Tz}$ yielded reduced residence time the kidneys, which minimized the total dose to the kidneys. This was further confirmed by the histopathological examination of kidneys, which showed no observable acute radiation toxicity in groups receiving $75 \mu \mathrm{Ci}$ and 200 $\mu \mathrm{Ci}$ of ${ }^{212} \mathrm{~Pb}-\mathrm{DOTA}-\mathrm{Tz}$ (Fig. 2.6).

Based on radiation dose to tumor, liver and kidneys (Table 2.2), ${ }^{212} \mathrm{~Pb}$ DOTA-Tz was selected as a choice of chelator system for the pretargeted therapy study. The pretargeted radioimmunotherapy studies were carried out according to the protocol described in Fig. 2.3 where mice were treated with various doses $(0,75,125,200$ and $2 \times 75 \mu \mathrm{Ci})$ of ${ }^{212} \mathrm{~Pb}-\mathrm{DOTA}-\mathrm{Tz}$. All the groups receiving PRIT displayed dose-dependent reductions in tumor growth rate, while the non-treatment control groups showed exponential tumor growth (Fig. 2.4A, C). All the treatment groups maintained an acceptable level of body weight ( $>80 \%$ of initial body weight) throughout the course of the study (Fig. 2.4B, D). Even though the $200 \mu \mathrm{Ci}$ therapy group showed the highest reduction in tumor growth rate, all the mice in that group were sacrificed on day 20 due to poor body score index and hematological radiation toxicity. This group displayed $\sim 86 \%$ reduction in the WBC and platelets counts compared to the control group. Similar results were also observed in the group which was pretargeted with RTX-TCO and received a $200 \mu \mathrm{Ci}$ dose of ${ }^{212} \mathrm{~Pb}-\mathrm{DOTA}-\mathrm{Tz}$. This indicated severe bone marrow toxicity due to the high radiation dose. Treatment groups receiving 125 
$\mu \mathrm{Ci}$ and $2 \times 75 \mu \mathrm{Ci}$ doses of ${ }^{212} \mathrm{~Pb}-\mathrm{DOTA}-\mathrm{Tz}$ also displayed a drop in leukocyte counts, $\sim 57 \%$ and $\sim 55 \%$ respectively, indicating moderate acute blood toxicity. In comparison, $75 \mu \mathrm{Ci}{ }^{212} \mathrm{~Pb}-\mathrm{DOTA}-\mathrm{Tz}$ dose was very well tolerated (Fig. 2.6) with little radiation associated toxicity.

A comparison of the treatment group receiving $75 \mu \mathrm{Ci}{ }^{212} \mathrm{~Pb}-\mathrm{DOTA}-\mathrm{Tz}$ dose in PRIT protocol to that of group receiving $15 \mu \mathrm{Ci}$ of directly labeled ${ }^{212} \mathrm{~Pb}$ TCMC-CC49 in RIT protocol clearly displayed the advantages of the pretargeting therapy regimen. Pretargeting allowed at least 5 times higher dose administration with better tumor growth rate reduction and lower blood toxicity. The median survival of mice in the $75 \mu \mathrm{Ci}$ PRIT group (26 days) was statistically significantly higher $(P=0.05)$ than control groups (20 days) (Fig. 2.5). The mice in the 125 $\mu \mathrm{Ci}$ and $2 \times 75 \mu \mathrm{Ci}$ therapy groups achieved better median survival times of 28 days $(P=0.02)$ and 31 days $(P=0.001)$ however they also exhibited transient hematological toxicity. Pretargeted $\alpha$-therapy's ability to control tumor growth is due to the radionuclide's decay properties, tumor marker heterogeneity and tumor size. LS174T is an aggressive tumor model with rapid tumor growth. However, the path length of $\alpha$ - particle is very short and is not an ideal match for treating large solid tumors. Higher energy $\beta$-emitters, such as ${ }^{90} \mathrm{Y}\left(\mathrm{t}_{1 / 2} \sim 2.7\right.$ days $)$ or moderate energy emitter ${ }^{177} \mathrm{Lu}\left(\mathrm{t}_{1 / 2} \sim 6.6\right.$ days) are likely to be better suited to treat large volume tumors. $\alpha$-particle radiation therapy is expected to be more effective in treating disseminated disease and micrometastatic disease. 


\section{CONCLUSION}

In summary, this study successfully establishes the therapeutic potential of in vivo pretargeted radioimmunotherapy employing ${ }^{212} \mathrm{~Pb}$-labeled Tz-chelators and TCO-modified tumor targeting mAbs. The PRIT protocol allowed administration of 5-10 times the dose of the direct labeled RIT approach. Despite its complexities, pretargeted $\alpha$-particle therapy utilizing ${ }^{212} \mathrm{~Pb}-\mathrm{DOTA}-\mathrm{Tz}$ was effective in reducing tumor growth rate and reducing normal tissue toxicity, resulting in improved survival. These preclinical results underscore the potential use of the IEDDA pretargeted $\alpha$-therapy in the clinic. 


\title{
CHAPTER 3
}

\author{
MMP-12 As a Novel Tumor Target for PET/CT Imaging Using \\ Phage Display Derived Antibody Fragments and Ultrasmall Silica \\ Nanoparticles.
}




\section{Introduction}

Lung cancer remains the deadliest of all cancers for both men and women world-wide. The number of people dying of lung cancer is more than breast, prostate, and colon cancers combined. Lung cancer accounts for roughly $25 \%$ of all cancer related deaths in the Unites States. More than half of patients with lung cancer die within one year of diagnosis and the 5-year survival rate remains less than $20 \%$. One of the main reasons for the high mortality rate associated with lung cancer is that by the time the disease is diagnosed, it is already metastasized and is at an advanced stage. Around $40 \%$ of newly diagnosed patients have a stage IV lung cancer.(121) The conventional methods for screening lung cancer include chest X-rays, low-dose computed tomography (LDCT), MRI scans, and FDG PET/CT scans. These methods are the mainstay of lung cancer detection and provide a non-invasive means for tumor detection. However, chest X-rays are not sensitive enough to detect lung cancer in early stages. While CT and MRI scans are more sensitive and can detect much smaller tumors, they have their own limitations. CT and MRI scans simply identify a structural abnormality and cannot differentiate between a benign mass and a malignant tumor. In almost all cases, further testing such as tissue biopsy is required to make the diagnosis. According to a recent large randomized trial, almost $96 \%$ of patients who tested positive by a CT scan screening exam did not result in lung cancer.(181) This significantly high false positive testing results in unnecessary, expensive, and more invasive tests. These findings indicate that 
there is an urgent need to develop new biomarkers and diagnosis methods for early detection of lung cancer.

Matrix metalloproteinase-12 (MMP-12), which is also referred to as macrophage elastase or macrophage metalloelastase, was originally identified as elastase and is secreted by activated macrophages.(122) As the name suggests, MMP-12 mainly cleaves elastin in the extra cellular matrix (ECM), but it also degrades other ECM components like type IV collagen, fibronectin, fibrillin-1, laminin, entactin, vitronectin, chondroitin sulfate, and heparin sulfate proteoglycans.(123-125) It is secreted as a $54 \mathrm{kDa}$ pro-enzyme which is subsequently activated by auto-cleavage of its $9 \mathrm{kDa}$ propeptide domain. The role of MMP-12 has been clearly established in various lung diseases like chronic obstructive pulmonary disease (COPD) and emphysema, especially in response to cigarette smoking.(126) MMP-12 expression has also been associated with development, progression, and instability of atherosclerotic plaques.(127) Because of its role in inflammation, aneurism, and atherosclerosis, MMP-12 has been evaluated as a target for in vivo imaging using various molecular probes.(128-130)

Apart from macrophages, MMP-12 is also overexpressed by epithelial cells in lung adenocarcinoma and squamous cell carcinomas. $(131,132)$ The overexpression of MMP-12 by epithelial tumor cells is correlated with more aggressive and invasive disease.(133) MMP-12 overexpression in non-small cell lung cancer (NSCLC) is associated with higher relapse rates and reduced patient survival.(134,135) MMP-12 up-regulation also promotes an emphysema 
to lung adenocarcinoma transition.(136) The role of MMP-12 in lung cancer was further confirmed when Lv and coworkers showed that knockdown of MMP-12 inhibits cell proliferation and invasiveness of lung adenocarcinoma.(86). More recently, Ella et al. demonstrated that tumor-derived MMP-12 promoted tumor proliferation in the lungs. They also showed that MMP-12 secreted by tumor epithelial cells, not by activated macrophages, was responsible for cancer propagation.(85) All these findings suggest the potential of MMP-12 as a novel target for lung cancer diagnosis and treatment.

Phage display is a robust and proven technique that allows researchers to select target-specific antibodies against a variety of clinically relevant antigens from large antibody libraries. It involves incubating the antibody library with an immobilized target of interest, washing away unbound phages, and eluting the target bound phages. This process is repeated for a number of rounds to enrich for antibodies with high affinity for a specific target. Single-chain antibody fragments (scFvs), which consist of variable heavy (VH) and variable light (VL) chain domains linked by flexible linker, are powerful tools in research and clinical settings due to their superior pharmacokinetic properties compared to full-length mAbs. ScFvs retain the binding specificity of the parent full-length antibody while offering rapid blood clearance and better tissue penetration.

Even though small antibody fragments can achieve high-contrast imaging, they often suffer from poor tumor uptake and higher kidney and liver uptakes. This is mainly due to their very short in vivo half-lives and rapid whole-body clearance. One way to counter this problem is to conjugate scFv fragments to 
nanoparticles to generate nano-immunoconjugates. Over the years, a diverse group of nanoparticles made up of various materials like silica, gold, magnetic or colloidal metals, liposomes, carbon nanotubes, and polymeric nanoparticles have been investigated for tumor targeting. These nanoparticles can be functionalized with various tumor specific ligands such as peptides, chemotherapeutic drugs, DNA/RNA aptamers, and small antibody fragments.(137-140) Because of their multivalent formats and longer biological half-lives, these nanoimmunoconjugates often display better tumor uptake and tissue penetration compared to monovalent scFvs.

It was hypothesized that due to its role in lung cancer propagation, MMP12 may serve as a novel diagnostic marker for lung cancer using in vivo PET imaging. In this study, antibody phage display methodology was used to identify MMP-12 specific scFv fragments. The antibody fragments would not only serve as imaging vectors but could also validate MMP-12 as a biomarker for lung adenocarcinoma. In order to identify MMP-12 specific antibody fragments, two rounds of scFv phage display selections were carried out against purified MMP12 protein. The selected subpopulation of scFv library was further screened in vitro for MMP-12 specificity by ELISA, flow-cytometry, and fluorescence microscopy using MMP-12 expressing A549 human lung adenocarcinoma cells. The selected MMP-12 specific scFv clone with high binding affinity was subsequently conjugated with ultrasmall silica Cornell prime dot (or C' dot) nanoparticles using azide-DBCO click-chemistry. The C' dot-scFv construct was radiolabeled with ${ }^{89} \mathrm{Zr}$ and injected in mice bearing A549 human lung 
adenocarcinoma xenografts. The whole-body in vivo PET/CT images revealed that there was a specific and high accumulation of ${ }^{89} \mathrm{Zr}-\mathrm{C}$ 'dot-scFv nanoimmunoconjugate in the tumor with no kidney uptake at 48 hours post injection. Here, we clearly demonstrated the potential of MMP-12 as a novel diagnostic marker for lung adenocarcinoma and that MMP-12 specific scFv-nanoparticle conjugates could be used for non-invasive in vivo tumor imaging. 


\section{Materials and Methods}

\section{Phage Display Selection}

Two rounds of solid-phase selections were carried out using the ScFv library provided by Dr. John McCafferty.(65) For the first round of selection, 100 ng $(100 \mu l)$ of purified MMP-12 was coated onto the surface of a microtiter plate well (Nunc MaxiSorp ${ }^{\mathrm{TM}}$ plate) and blocked with $5 \%(\mathrm{w} / \mathrm{v})$ skim milk powder in TBS. An aliquot of the McCafferty library (50 $\mu$ l, $10^{12}$ phages), pre-blocked in $3 \%$ $(w / v)$ skimmed milk in TBS, was added to the coated well and incubated for 1 hour at room temperature. Unbound phages were washed away by rinsing the well 5 times with $0.1 \%$ Tween 20 (TBST) and 5 times with TBS. Bound phages were eluted in $100 \mu \mathrm{g} / \mathrm{ml}$ TPCK-treated trypsin for 15 minutes at room temperature. A mid-log culture of E.coli TG1 cells ( $5 \mathrm{ml}$ ) was added to the eluted phage and incubated for 1 hour at $37^{\circ} \mathrm{C}(250 \mathrm{rpm})$. Cells were centrifuged at $3000 \times \mathrm{g}$ for 10 minutes, resuspended in $200 \mu \mathrm{l}$ of $2 \times \mathrm{TY}$ media containing ampicillin and $2 \%$ glucose (2xTYAG), plated on 2xTYAG agar plates, and incubated at $30^{\circ} \mathrm{C}$ overnight. The next day, positively infected TG1 cells were scrapped from the surface of agar dishes, resuspended in 2xTYAG media, and incubated at $37^{\circ} \mathrm{C}$ in a shaker incubator until the $\mathrm{OD}_{600}$ reached 0.5 . Helper phage M13KO7 were added at a multiplicity of infection (MOI) of around 10 and incubated at $37^{\circ} \mathrm{C}$ for 1 hour. Cells were centrifuged at $4500 \times \mathrm{g}$ for 10 minutes, resuspended in 2xTYAK media (2xTY with ampicillin and kanamycin), and incubated at $30^{\circ} \mathrm{C}$ overnight in a shaking incubator (250 rpm). The following day, cells were spun down at $27000 \times \mathrm{g}$ for 15 minutes. The supernatant, which 
contained secreted phages, was then used for the second round of the selection. To increase the stringency of the selection, the second round was carried out with a 10 times lower amount of MMP-12 protein (10 ng) than the first round. At the end of the second round, individual phage colonies were picked for screening by phage ELISA.

\section{Primary Screening by Individual Phage ELISA}

Individual colonies picked after the selection were grown in 2xTYAG media at $37^{\circ} \mathrm{C}$ for $5-6$ hours in a shaker incubator (120 rpm) in a 96 well plate. Once the $\mathrm{OD}_{600}$ reached $\sim 0.5$, cultures were superinfected with helper phage at $\mathrm{MOI}$ of 10 and incubated $a 7^{\circ} \mathrm{C}$ for 1 hour. Following incubation, the plate was centrifuged at $4500 \times \mathrm{g}$ for 10 minutes and supernatant was collected. Three Nunc MaxiSorp ${ }^{\text {TM }}$ 96-well plates were coated with $10 \mu \mathrm{g} / \mathrm{ml}(100 \mu \mathrm{l})$ of MMP-12 protein and blocked with Rockland blocking buffer (Rockland Inc., PA) for 1 hour at room temperature. A separate set of three 96-well pates were coated with bovine serum albumin (BSA) as a negative control. Supernatants containing individual phage-scFvs were added to the MMP-12 and BSA coated plates and incubated for 1 hour at room temperature. After washing plates with $0.1 \%$ TBST for 5 times, an anti-M13-HRP conjugated antibody (1:2000 dilution) was added to the wells. This was followed by addition of HRP substrate 2,2'-Azino-bis(3ethylbenzothiazoline-6-sulfonic acid) (ABTS) and the absorbance was measured at $405 \mathrm{~nm}$ using UV-Vis spectrophotometer plate reader. The scFv clones with highest signal-to-background ratios (MMP-12 : BSA) were selected for further analysis. 


\section{Sequence Analysis of Positive Clones}

A total of 23 phage clones with highest binding ratios of MMP-12 : BSA in the phage ELISA were selected for sequence analysis. These clones in pSANG4 phagemid were sequenced using forward primer M13 LeadSeq (5'AAATTATTATTCGCAATTCCTTTGGTTGTTCCT) and reverse primer NotMycSeq (5'-GGCCCCATTCAGATCCTCTTCTGAGATGAG). The clones were analyzed for the presence of full-length $\mathrm{VH}$ and VL inserts and their sequence similarities using Serial Cloner $^{\mathrm{TM}}$ software. After sequence alignment, duplicate clones were removed and the remaining unique scFv clones were subcloned into the pSANG10-3F PET expression vector for soluble antibody production. The scFv genes were also analyzed for identification of complementarity determining regions (CDR), framework regions (FWRs), and immunoglobulin families using Kabat and Chothia databases.

\section{Expression and Purification of Selected scFv Fragments}

The selected MMP-12 specific scFv clones with unique sequences were amplified by PCR using M13 LeadSeq and NotMycSeq primers. Purified PCR products were digested with $\mathrm{Ncol}$ and Notl restriction enzymes and subsequently ligated into the Ncol/Notl digested pSANG10-3F expression vector.(30) The ligated vector was used to transform chemically competent E.coli BL21 (DE3) cells by the heat shock method.

For the expression of scFv fragments, a single colony of transformed E.coli cells was picked and grown in $10 \mathrm{ml}$ of 2xTYKG media (2xTY media with 
kanamycin and $2 \%$ glucose) at $37^{\circ} \mathrm{C}$ overnight in a shaker incubator. The next day, $1 \mathrm{~L}$ of 2 XYYKG media was inoculated with the overnight culture and incubated at $37^{\circ} \mathrm{C}$ for $2.5-3$ hours until the $\mathrm{OD}_{600}$ reached $0.5-0.7$. To induce the scFv expression, cells were pelleted at $4500 \mathrm{xg}$ for 20 minutes, resuspended in 2xTY media (containing kanamycin and $1 \mathrm{mM}$ IPTG), and incubated at $30^{\circ} \mathrm{C}$ overnight (250 rpm). After overnight induction, cells were centrifuged at $4500 \times \mathrm{g}$ for 30 minutes, resuspended in $50 \mathrm{ml}$ of ice-cold buffer $1(100 \mathrm{mM}$ Tris $\mathrm{HCl} \mathrm{pH}$ 8.0, $20 \%(\mathrm{w} / \mathrm{v})$ sucrose, and $0.5 \mathrm{mM}$ EDTA), and incubated on ice for 30 minutes. The supernatant (periplasmic fraction) was collected after spinning down the cells at $27000 \times \mathrm{g}$ for 30 minutes. To initiate osmotic shock, the pellet was resuspended in buffer $2(5 \mathrm{mM} \mathrm{MgCl}$, benzonase, and protease inhibitor cocktail) and incubated on ice for 20 minutes. Cells were pelleted at $27000 \times \mathrm{g}$ for 30 minutes and the supernatant (osmotic shock fraction) was collected. At this stage, both the periplasmic fraction and the osmotic shock fraction were pooled together and passed through a $0.2 \mu \mathrm{m}$ filter.

Single-chain scFv fragments were purified by immobilized metal affinity chromatography (IMAC). Using a GE AKTA start FPLC system, a sample containing scFv was loaded on a $5 \mathrm{ml}$ HisTrap ${ }^{\mathrm{TM}} \mathrm{HP}$ Ni-column at a $3 \mathrm{ml} /$ minute flow rate. Unbound impurities were removed with 10 column volumes of washing buffer (20 mM Tris- $\mathrm{HCl}, 500 \mathrm{mM} \mathrm{NaCl}$, and $40 \mathrm{mM}$ Imidazole; $\mathrm{pH}$ 8.0). The scFv was eluted by washing the column with elution buffer $(20 \mathrm{mM}$ Tris- $\mathrm{HCl}, 500 \mathrm{mM}$ $\mathrm{NaCl}$, and $250 \mathrm{mM}$ Imidazole; $\mathrm{pH}$ 8.0). The scFv containing fractions were 
pooled and the purity of the purified $\mathrm{ScFv}$ was analyzed by SDS-PAGE and immunoblot.

\section{ScFv-ELISA}

A Nunc MaxiSorp ${ }^{\text {TM }}$ plate was coated with $100 \mu \mathrm{l}(10 \mu \mathrm{g} / \mathrm{ml})$ of MMP-12 protein overnight and blocked with Rockland blocking buffer for 1 hour at room temperature. The purified ScFv antibodies (100 ng) were added to the blocked wells and incubated for 1 hour at room temperature. The plate was washed 5 times with $0.1 \%$ TBST before incubating with an anti-FLAG-HRP conjugated antibody for 1 hour at room temperature. After washing 5 times with $0.1 \%$ TBST, the binding was detected by addition of ABTS substrate and measuring the absorbance at $405 \mathrm{~nm}$ using a UV-Visible spectrophotometer plate reader. A plate coated with BSA was used as a negative control.

\section{In Vitro Cell Binding Studies}

The A549 human lung adenocarcinoma cells and MDA-MB-231 human breast cancer cells were acquired from American Type Culture Collection. A549 cells were grown and maintained in $\mathrm{F}-12 \mathrm{~K}$ medium supplemented with $10 \%$ fetal bovine serum, L-glutamine, and gentamycin. MDA-MB-231 cells were grown as a monolayer in RPMI 1640 media supplemented with $10 \%$ fetal bovine serum, Lglutamine, and gentamycin. Cell cultures were maintained at $37^{\circ} \mathrm{C}$ in a $5 \% \mathrm{CO}_{2}$ humidified incubator. For in vitro fluorescent cell binding studies, MMP-12 specific H12 scFv was conjugated with FITC-NHS dye using manufacturer's 
instruction. An Anti-MMP-12 antibody conjugated to Alexa Fluor (ab200409, Abcam) was used as a positive control.

The binding characteristics of the purified H12-scFv to MMP-12 overexpressing A549 cells were assessed by flow cytometry. Cells $\left(2 \times 10^{5}\right.$ cells/ tube) were fixed with $80 \%$ methanol for 5 minutes and permeabilized with $0.1 \%$ TBST for 20 minutes. Cells were then blocked with 5\% BSA/TBS for 1 hour at room temperature. After washing 3 times with 1\% BSA/TBS buffer, cells were incubated with FITC-labeled $\mathrm{H} 12-\mathrm{scFv}$ at $4^{\circ} \mathrm{C}$ for 1 hour in the dark. The binding was determined by measuring relative fluorescence intensities of the stained cells by CyAn ADP flow cytometer (Beckman Coulter) using the FITC channel. MDA-MB-231 cells, which do not express MMP-12, were used as a negative control.

For the fluorescence confocal microscopy, A549 and MDA-MB-231 cells were grown in chamber slides, fixed with 100\% methanol (5 minutes), and permeabilized with $0.1 \%$ Triton X-100 for 5 minutes. The slides were blocked with $5 \%$ BSA/TBS for 1 hour at room temperature and subsequently washed with $1 \%$ BSA/TBS. This was followed by incubating slides with FITC-labeled H12scFv at $4^{\circ} \mathrm{C}$ overnight. Next day, slides were washed and incubated with 4'-6diamidino-2-phenylindole (DAPI) for 15 minutes at room temperature for nuclear staining. After additional washes, the samples were mounted under a cover-glass and analyzed on a Keyence fluorescent microscope. 


\section{Microscale Thermophoresis}

To determine the binding affinity of the H12-scFv towards purified MMP-12 protein, microscale thermophoresis (MST) technique was used. Here, $200 \mathrm{nM}$ of H12-scFv $(100 \mu \mathrm{l})$ was incubated with $100 \mathrm{nM}$ of NT-647 dye $(100 \mu \mathrm{l})$ for 30 minutes. The NTA containing dye binds specifically to the 6 xHis-tag on the Cterminus of the scFv. Following dye incubation, $10 \mu$ aliquots of the labeled $\mathrm{H} 12$ scFv were taken and mixed with varying concentrations of MMP-12 protein (10 $\mu l)$ to make a dilution series. The resultant samples were loaded in microcapillaries and placed in the MST instrument for binding affinity determination.

\section{Synthesis of C'dot-scFv immunoconjugate}

The DFO-DBCO-PEG-Cy5-C' dots were synthesized and purified as previously described.(141-143) To conjugate scFv fragments to DFO-DBCOPEG-Cy5-C' dots, H12-scFv was first modified with NHS-PEG ${ }_{4}$-Azide. 2 mg of $\mathrm{H} 12-\mathrm{scFv}$ in PBS was incubated with 10 molar excess of NHS-PEG ${ }_{4}$-Azide (5 $\mathrm{mg} / \mathrm{ml}$ in anhydrous DMSO). The $\mathrm{pH}$ of the reaction was adjusted to 9.0 using $1 \mathrm{M}$ carbonate buffer and the reaction was carried out for 1 hour at room temperature with agitation. Azide modified H12-scFv was purified using a PD-10 gel filtration

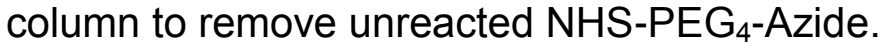

Next, 12.5 nmols of DFO-DBCO-PEG-Cy5-C' dots were mixed with 5 molar excess of azide modified H12-scFv fragments and incubated for 24 hours at room temperature with continuous mixing. Unconjugated scFv-azide fragments 
were removed by size-exclusion chromatography using HP Superdex 200 10/300 GL column. The purified C' dot-CFv containing fractions were pooled and concentrated using amicon-4 concentrator (10,000 Da MWCO) for further studies. The number of $\mathrm{H} 12-\mathrm{scFv}$ fragments on a single $\mathrm{C}^{\prime}$ dot particle was determined by measuring the absorbance at $280 \mathrm{~nm}$ (scFvs) and $640 \mathrm{~nm}$ ( ( ') dots).

\section{Radiolabeling}

To radiolabel $\mathrm{H} 12-\mathrm{scFv}$ with ${ }^{67} \mathrm{Ga}$ (Lantheus Medical Imaging,MA), antibody fragments were first conjugated with the bifunctional chelator NOTASCN. Briefly, $1 \mathrm{mg}$ of purified H12-scFv was incubated with 10 molar access of NOTA-SCN overnight at $4^{\circ} \mathrm{C}$. The $\mathrm{pH}$ of the reaction mixture was adjusted to 9.0 with carbonate buffer. After the overnight reaction, excess NOTA-SCN was removed using a PD-10 column. For radiolabeling, $100 \mu \mathrm{g}$ of scFv-NOTA was mixed with $1.0 \mathrm{mCi}$ of ${ }^{67} \mathrm{GaCl}_{3}$. The $\mathrm{pH}$ was adjusted to 6.0 and the reaction mixture was incubated at room temperature for 30 minutes. This was followed by addition of $50 \mu$ l of EDTA $(80 \mathrm{mM})$ and an additional incubation for 30 minutes at room temperature. The labeling yield was measured by instant thin layer chromatography (ITLC) using EDTA as a mobile phase. The unconjugated ${ }^{67} \mathrm{Ga}$ was removed by PD-10 column purification and radiochemical yield was measured by ITLC.

For ${ }^{89} \mathrm{Zr}$ labeling, $1.0 \mathrm{nmol}$ of DFO-C' dot-scFv immunoconjugate was mixed with $1 \mathrm{mCi}$ of ${ }^{89} \mathrm{Zr}$-oxalate (University of Wisconsin Cyclotron facility, WI) in HEPES buffer $(\mathrm{pH} 8)$ and incubated for 1 hour at $37^{\circ} \mathrm{C}$. The reaction $\mathrm{pH}$ was 
adjusted at 7.0-7.5. After 1 hour, $50 \mu$ of EDTA $(80 \mathrm{mM})$ was added and incubated for an additional 1 hour at $37^{\circ} \mathrm{C}$. The labeling yield was measured by ITLC using $10 \mathrm{mM}$ diethylenetriaminepentaacetic acid (DTPA) as a mobile phase. Free ${ }^{89} \mathrm{Zr}$-oxalate was removed using a PD-10 column and the radiochemical purity was measured by ITLC.

\section{A549 Lung Adenocarcinoma Xenograft Model}

All animal experiments were carried out in compliance with the Institutional Animal Care and Use committee in accordance with U.S. Public Health Service Guidelines. Athymic female BALB/C (nu/nu) mice were obtained from Envigo (USA) and inoculated with $1 \times 10^{7}$ A549 cells in the right shoulder subcutaneously. Tumors were allowed to grow for 3-4 weeks and mice were used when tumors were clearly visible, palpable, and measurable.

\section{In Vivo imaging}

For SPECT imaging, mice bearing A549 human lung adenocarcinoma xenografts were injected with $300 \mu \mathrm{Ci}$ of ${ }^{67} \mathrm{Ga}$-labeled $\mathrm{H} 12-\mathrm{scFv}$ via tail vein, and whole-body SPECT/CT images were taken 4 hours post injection. For ${ }^{89} \mathrm{Zr}$ PET/CT imaging, mice bearing A549 xenografts were injected with $300 \mu \mathrm{Ci}$ of ${ }^{89} \mathrm{Zr}$-DFO-scFv-C' dots via I.P. injection. Small-animal PET/CT images were acquired 4,24 , and 48 hours after the injection under isoflurane anesthesia. Images were reconstructed using an ordered-subset expectation maximization 2-

dimentional algorithm. For anatomical data fusion, small-animal CT was 
performed, and concurrent images were reconstructed with Fanbeam filteredbackprojection algorithm. 


\section{Results}

\section{Phage Display Selection}

The McCafferty scFv library, made up of $1.1 \times 10^{10}$ clones, was used for solid-phase affinity selection (panning) to identify MMP-12 specific ScFv fragments. To increase the stringency of the selection, the second round was carried out with a 10 times lower amount of MMP-12 than the first round. At the end of each round, the bulk of the output was spread on the agar plate and after overnight growth at $37^{\circ} \mathrm{C}$, single colonies were picked to calculate the selection output and the enrichment ratio. The selection output of round I and II was $3.1 \mathrm{x}$ $10^{4}$ and $1.95 \times 10^{5}$ colony forming units (cfus), respectively, with an estimated enrichment ratio of about 6.3. It may be possible to achieve higher enrichment by performing more rounds of selections, but that would also increase the chances of amplifying fast-growing phage clones which may have lost their plll-scFv fusion gene. Due to the use of trypsin-cleavable M13 helper phage in this study, only 2 rounds of selection were required instead of the usual 3-4 rounds. The use of this engineered helper phage and trypsin treatment greatly reduces the population of "bald" phages, which do not display antibodies on their surface.

\section{Phage ELISA}

Following two rounds of selections, 96 individual phage colonies were picked for the phage ELISA screening. The relative binding specificities of selected clones were determined by comparing phage-scFv binding to MMP-12 verses BSA. Out of 96 clones, 23 clones had MMP-12 : BSA binding ratios of $\geq$ 
5. These 23 clones with the highest MMP-12 specificities were selected and sequenced by Sanger sequencing (Fig. 3.1). The sequence alignment revealed that out of 23 selected clones, 8 clones had unique sequences and these $8 \mathrm{scFv}$ clones were chosen for further characterization (Table 3.1). 


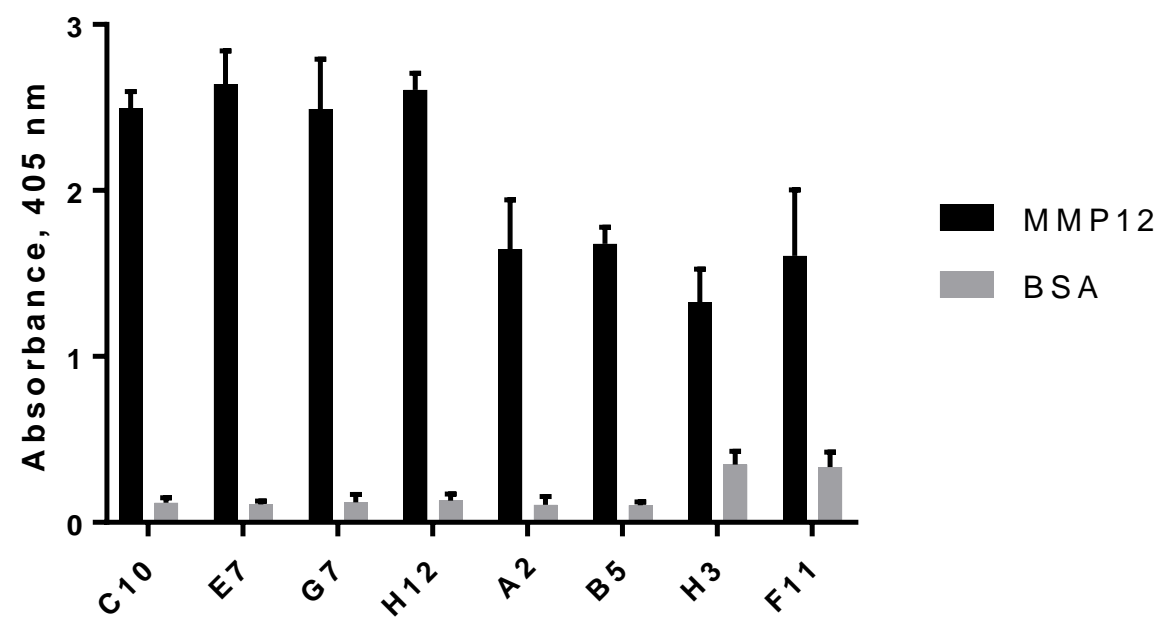

Figure 3.1: Phage ELISA: Following two rounds of selection against purified MMP-12 protein, the binding specificities of individual phage-scFv clones were determined by phage ELISA in a 96 well plate. The individual phage-scFv clones were added to 96 -well plates coated with MMP-12 or BSA. After washing nonspecific binders, the bound phage-scFvs were detected using an anti-M13-HRP conjugated secondary antibody. The 8 phage-scFv clones represented in the figure displayed highest specificities towards MMP-12 over BSA. Each bar represents average of 3 replicates. 
Table 3.1: Sequence analysis of MMP-12 specific antibody fragments

\begin{tabular}{|c|c|c|c|c|c|c|}
\hline ScFV clone & CDR-H1 & CDR-H2 & CDR-H3 & CDR-L1 & CDR-L2 & CDR-L3 \\
\hline & & & & & & \\
\hline H12 & SYTIS & IIPILGIANYAQK & GVVEGSGAFDI & TRSRGSIASHYVQ & LEDDQRP & QSYDSSNVV \\
\hline C10 & SYTIS & IIPILGIANYAQK & DRFEGAIFDY & TRSSGSIASNYVQ & FEDNQRP & QSYDSSNVV \\
\hline E7 & SYTIS & IIPILGIANYAQK & DRPYIYGMDV & KSSQNVLDSSNNMNYLG & YWASTRE & QQYYSPPVT \\
\hline G7 & SYTIS & IIPILGIANYAQK & AGYDSSGYSYFDY & RSSQSLVYVDGDTYLN & YRVSNRD & MQGTHWPPT \\
\hline A2 & SYTIS & IIPILGIANYAQK & DGGNDFDY & TGSSSNIGSTYDVH & FGNTNRP & QSYDDSLSAFV \\
\hline B5 & SYTIS & IIPILGIANYAQK & SQTTVTSGGAFI & RSSQSLVHSNGYTYLN & YKVSNRD & MQGTHWPPT \\
\hline H3 & SYTIS & IIPILGIANYAQK & ERTYDNYGMDV & TRSSGSIASNYVQ & YEDNQRP & QSYDSSNQV \\
\hline F11 & SYTIS & IIPILGIANYAQK & DGSSWHRYMDV & TRSQSISSYLN & YEDQNRP & QSYDSTTVVT \\
\hline
\end{tabular}




\section{ScFv Expression and Purification}

The McCafferty scFv library used in this study was constructed in the pSANG4 phagemid (Fig. 3.2A). Even though it is possible to express soluble scFvs from this phagemid, the yield is poor. Thus, to express large quantities of soluble scFvs, the antibody genes were subcloned into the pSANG10-3F PET expression vector. Here, expression of scFv gene is under the T7 promoter and it also fuses the scFv antibody to a C-terminal His-tag and a tri-FLAG tag for easy purification and detection. The pSANG10-3F expression vector also has an Nterminal pelB leader sequence which exports scFvs into the bacterial periplasm for disulfide bond formation and proper folding (Fig. 3.2B). Following the subcloning of scFv genes into the pSANG10-3F vector, resultant plasmids were transformed into the E.coli BL21 (DE3) cells and scFv fragments were expressed by IPTG induction. Osmotic shock was used to extract scFvs out of the periplasm, which were then purified using the Ni-affinity chromatography. The SDS-PAGE analysis showed a single band at around $30 \mathrm{kDa}$ for each scFv, which is the predicted mass of ScFv antibodies. The expression of scFvs was furthered verified by immunobloting using an anti-FLAG-HRP conjugated monoclonal antibody which confirmed the successful expression and purification of scFvs (Fig. 3.3). 
A)

pSANG4

Lac promoter

\begin{tabular}{|l|l|l|l|}
\multicolumn{3}{c}{ Ncol } & \multicolumn{2}{c}{ NotI } \\
\hline
\end{tabular}

B)

pSANG10

T7 promoter

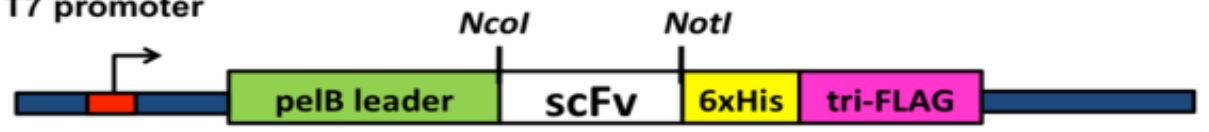

Figure 3.2: Expression vectors: Schematic representation of A) pSANG4 phagemid used for the McCafferty scFv library construction, and B) pSANG10-3F vector used to express soluble scFvs in E.coli. (Adopted and modified from Schofield et al., (2006)) 
A

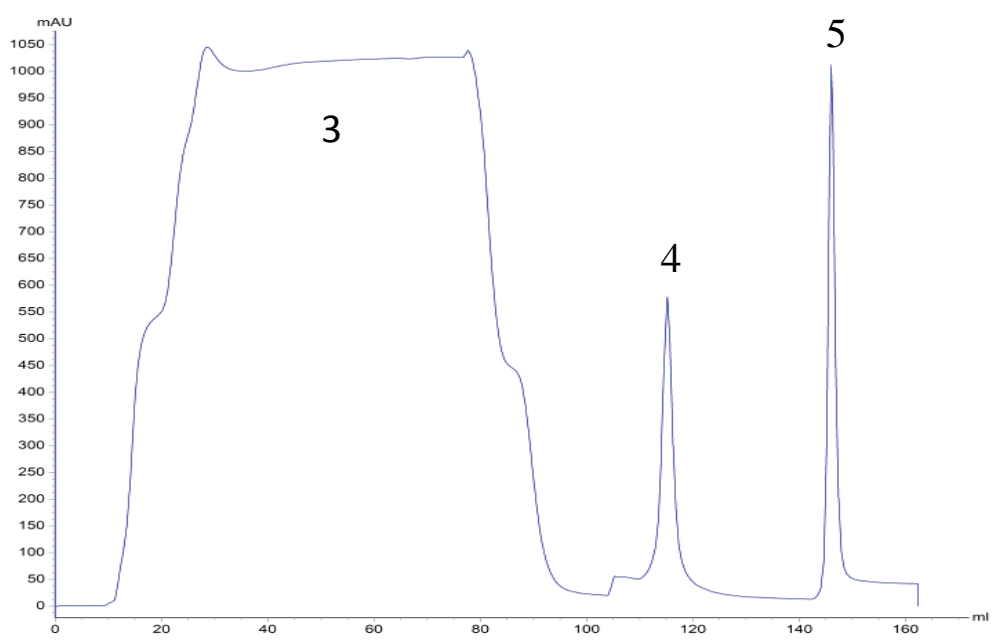

B

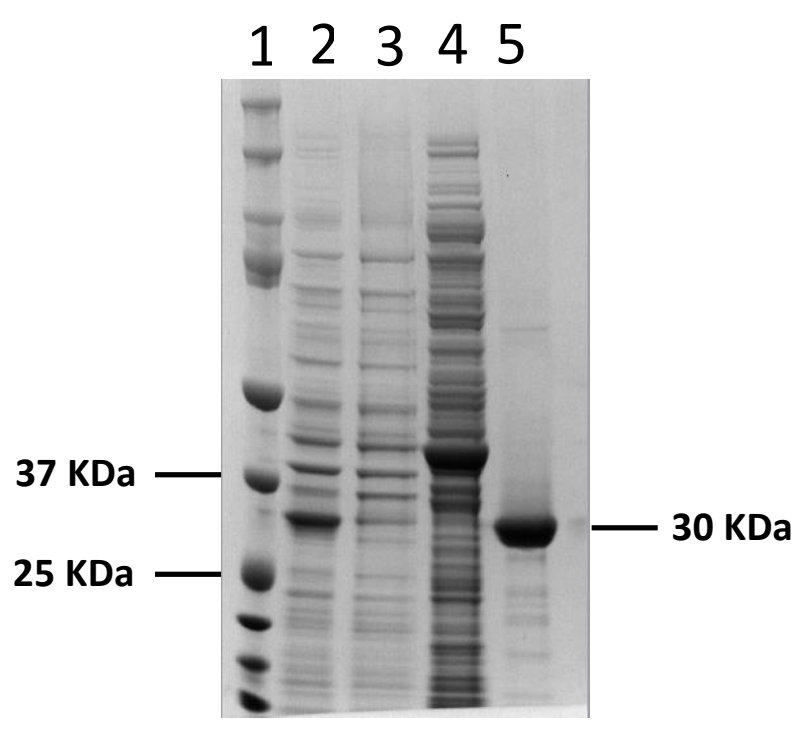

Figure 3.3: Expression and purification of the H12-scFv: The H12-scFv was expressed and purified from E.coli periplasm using a Ni-column. A) Chromatographic profile of the purification of H12-scFv using a Ni HiTrap column on AKTA Start system. B) Coomassie blue staining of SDA-PAGE gel; Lane 1Molecular weight markers, Lane 2- Loading sample, lane 3 - Flow through, lane 4 - Washing (40 mM Imidazole), and lane 5 - Elution (250 mM Imidazole) 


\section{ScFv-ELISA}

In order to confirm the results of the phage scFv ELISA and MMP-12 specificities of the selected clones, a secondary binding assay was performed with soluble scFv antibodies. Each of the 8 selected clones were subjected to ELISA with MMP-12 as a target antigen and BSA as a negative control. As shown in Fig. 3.4, all 8 scFv clones maintained their MMP-12 binding affinities and specificities with minimum binding to BSA. This assay illustrated that purified scFvs retained their MMP-12 specificities in their soluble form.

\section{In Vitro Cell Binding Studies}

A flow cytometry analysis was performed with MMP-12 expressing A549 human lung adenocarcinoma cells to determine the cell-binding characteristics of the selected ScFv fragments. The human breast cancer cell line MDA-MB-231 was used as a negative control. Cells were permeabilized by detergent treatment and incubated with FITC-conjugated H12-scFv antibody fragments. A total of 10,000 cells were counted for each cell line and the relative fluorescence intensities were measured by flow cytometry. As shown in Fig. 3.6, the mean

fluorescence intensity (MFI) of FITC-labeled H12-scFv with A549 cells was $153 \pm$ 68, while the MFIs for MDA-MB-231 and the unstained A549 cells were $4.0 \pm 1.0$ and $3 \pm 1$, respectively. These observations demonstrated that the selected $\mathrm{H} 12$ ScFv could specifically recognize MMP-12 on A549 lung carcinoma cells. Commercially available anti-MMP-12 antibody was used as a positive control which had the MFI of $55 \pm 14$ with A549 cells. 


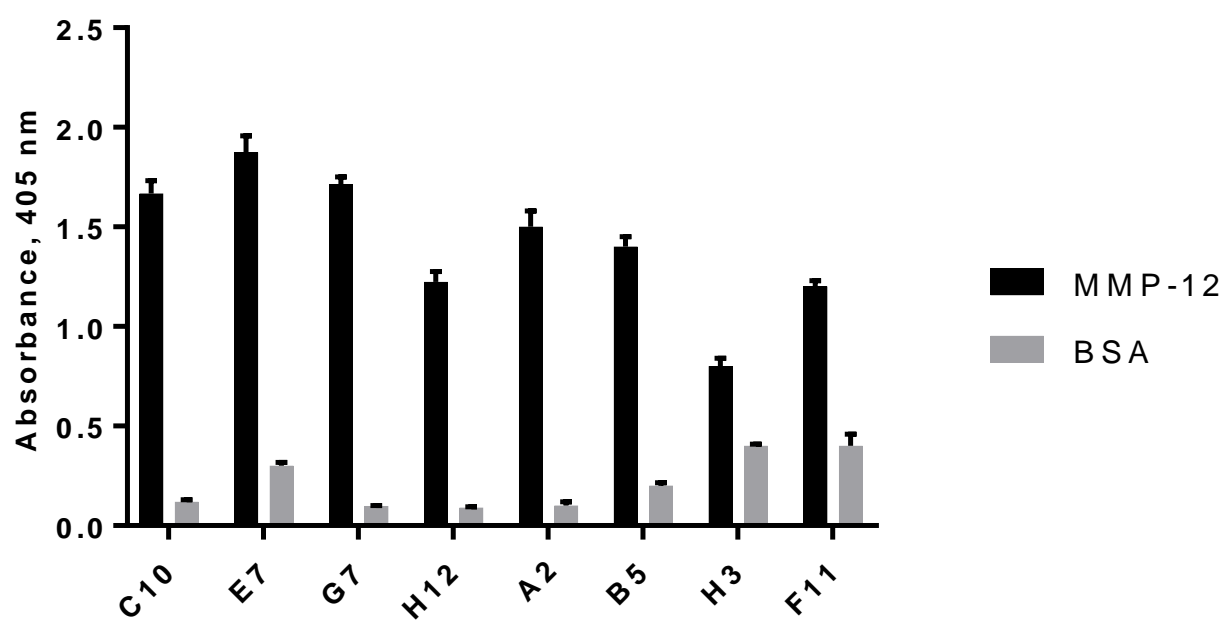

Figure 3.4: Soluble scFv ELISA: The binding specificities of soluble scFv fragments were determined by incubating $100 \mathrm{ng}$ of purified ScFv fragments in wells coated with either purified MMP-12 or BSA. After the washing step, wells were incubated with an anti-FLAG-HRP conjugated secondary antibody and the binding was detected by measuring absorbance at $405 \mathrm{~nm}$. Bars represent the average of 3 replicates. 


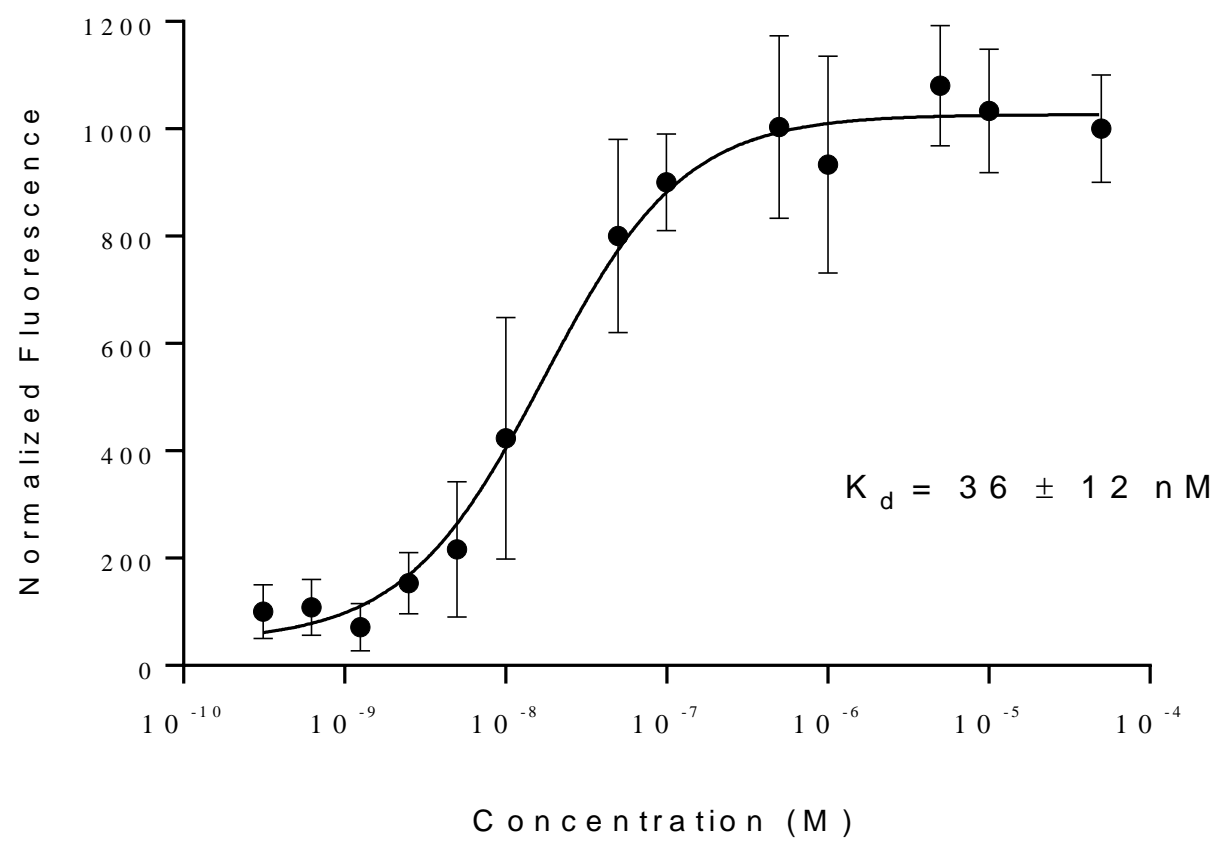

Figure 3.5: Binding affinity of the H12-scFv to purified MMP-12 protein was determined by the microscale thermophoresis (MST). The H12-scFv was fluorescently labeled with NTA-dye. Serial dilutions were prepared by keeping the concentration of the H12-scFv constant while changing the MMP-12 concentration. 


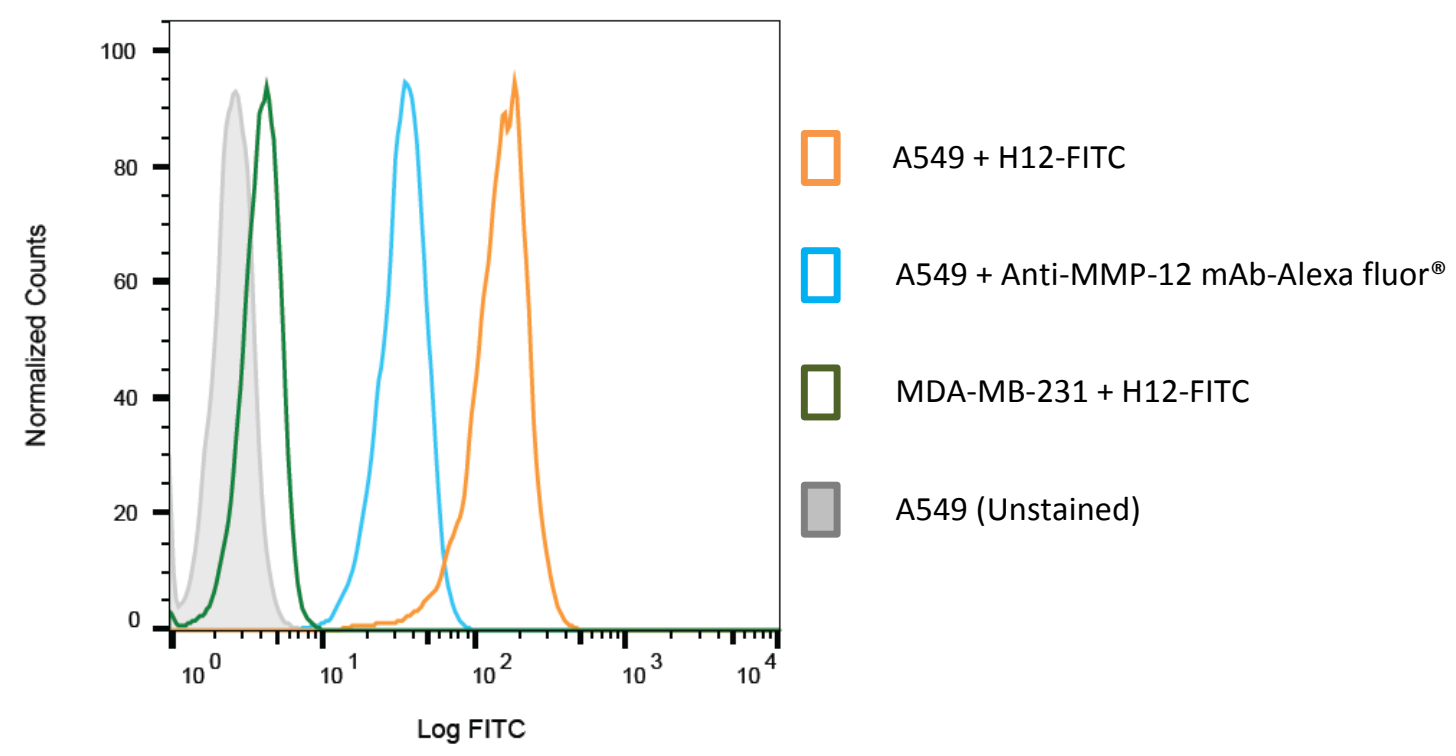

Figure 3.6: Flow cytometry analysis was carried out to assess the binding characteristics of the H12-scFv to MMP-12 overexpressing cell line A549. Cells $\left(1 \times 10^{5}\right)$ were fixed in $80 \%$ methanol and permeabilized with $0.1 \%$ TBST for 20 minutes. After blocking cells with $5 \%$ BSA/TBS for 1 hour, cells were incubated with FITC-conjugated H12-scFv for 1 hour on the ice. Next, cells were washed and binding was determined by counting 10,000 cells in CyAn ADP flow cytometer. MDA-MB-231 cells and unstained A549 cells were used as negative controls. An Anti-MMP-12 antibody conjugated to Alexa Fluor (ab200409, Abcam) was used as a positive control. 
To visualize ScFv binding and specificity to A549 cells, fluorescent microscopy was carried out using FITC-labeled H12-scFv. Similar to flow cytometry, FITC-labeled H12-scFv bound to MMP-12 positive A459 cells (Fig. 3.7).

\section{Synthesis of C'dot-scFv Immunoconjugates}

The C' dot nanopartilces have a silica core with embeded Cy5 dye. Their surface is coated with PEG chains to make them more hydophilic. A portion of these PEG chains can be modified furhther with different functional groups like DFO and DBCO. The DFO-DBCO-PEG-C' dots were synthesized in a multi-step procedure as described previously. $(141,142)$ The C' dot nanoparticles used in these studies had a hydrodynamic diameter (HD) of $5.3 \mathrm{~nm}$. (Fig. 3.8). The DFODBCO-PEG-C' dots were conjugated with azide-modified scFvs using azideDBCO click chemistry.(143) After incubating azide modified H12-scFv with DBCO functionalized C' dots for 24 hours at room temperature, the unconjugated scFvs were removed by size exclusion chromatography in 50 mM HEPES buffer. By measuring the UV absorbance of C' dots at $640 \mathrm{~nm}$ and of scFvs at $280 \mathrm{~nm}$, it was determined that there were an average of $2.4 \mathrm{scFv}$ molecules attached to each C' dot nanoparticle. 


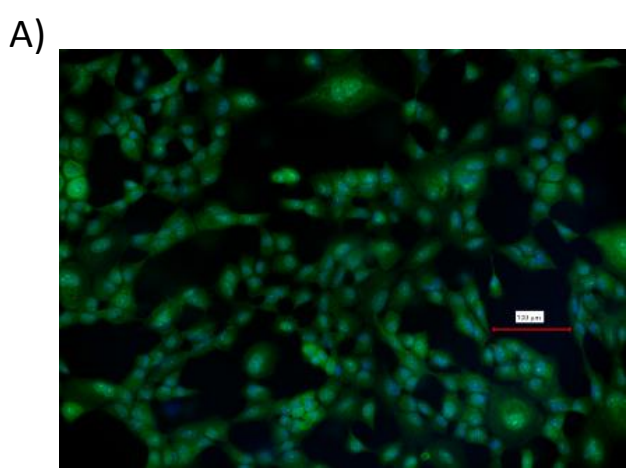

A549 + H12-FITC
B)

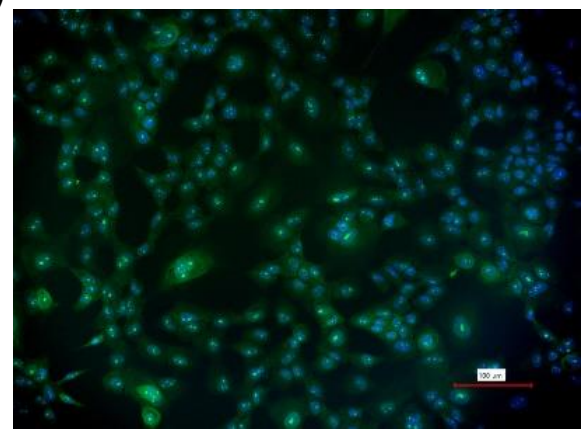

A549 + $\alpha$-MMP-12 mAb-Alexa fluor ${ }^{\circledR}$

Figure 3.7: Fluorescence microscopy analysis of cell binding: A549 cells were grown and fixed on the microscope slides. Cells were permeabilized with $0.1 \%$ Triton X-100 and blocked with 5\% BSA/TBS. This was followed by incubating cells $\mathrm{H} 12-\mathrm{FITC}$ scFv overnight at $4^{\circ} \mathrm{C}$. Images were taken the next day using a fluorescent microscope. A) An Image with H12-FITC scFv displaying the strong binding of the H12-scFv to MMP-12 positive A549 cells. B) An image with a commercially available anti-MMP-12 mAb binding to A549 cells as a positive control. 


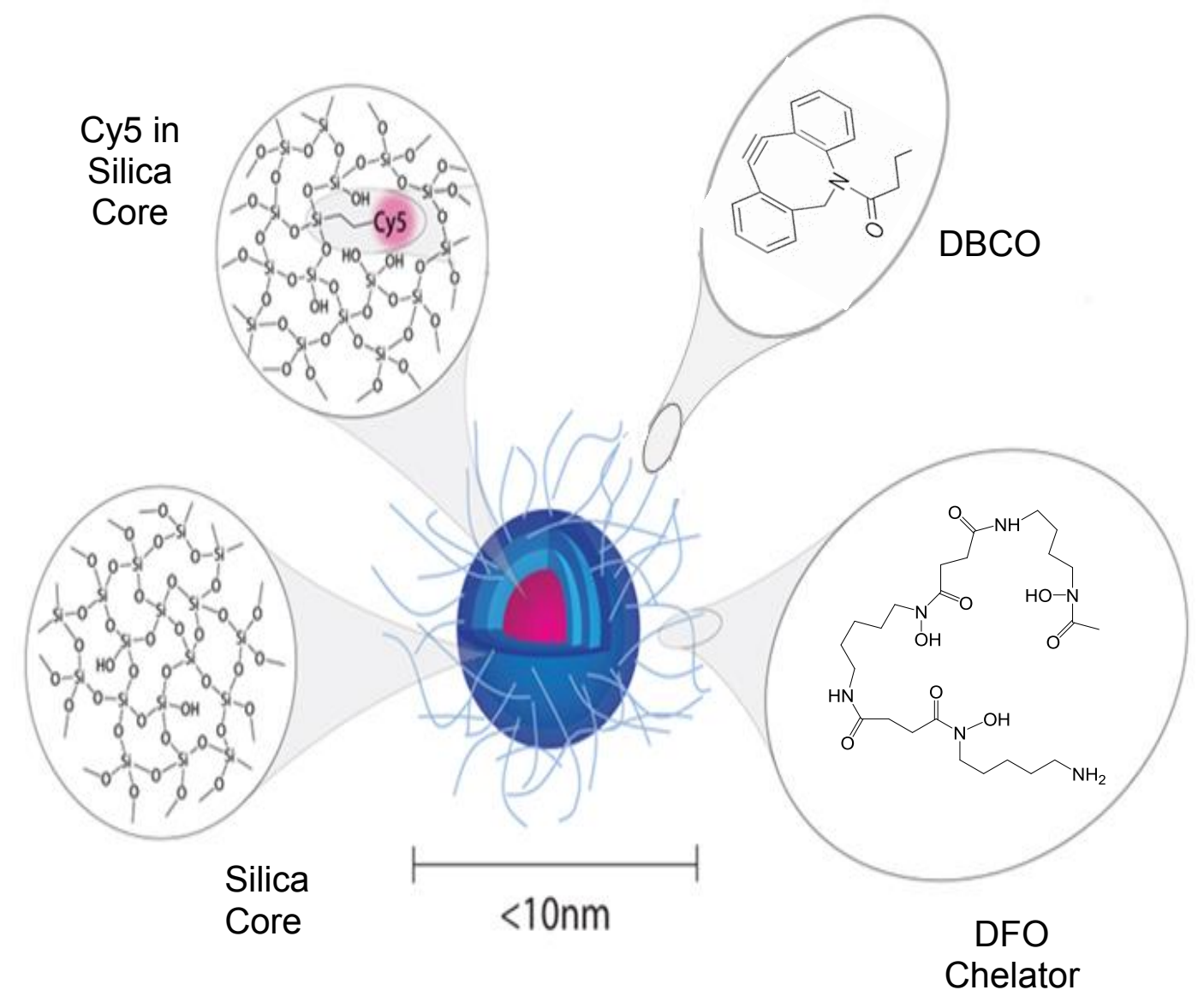

Figure 3.8: A schematic of the Cornell prime ( $C^{\prime}$ dot) nanoparticles: The $C^{\prime}$ dot nanoparticles have a silica core with embedded Cy5 fluorophore. The surface of the C' dot is covered with PEG chains to make C' dot particles more hydrophilic. The C' dot nanoparticles were further modified with DFO chelators and DBCO functional groups. The hydrodynamic diameter of DFO-DBCO-C' dot nanoparticle was $\sim 5.3 \mathrm{~nm}$. 


\section{In Vivo Imaging}

The imaging capability of the direct labeled ${ }^{67} \mathrm{Ga}-\mathrm{H} 12-\mathrm{scFv}$ was investigated in mice bearing A549 lung adenocarcinoma xenografts. Whole-body SPECT/CT images were acquired 4 hours following the injection of ${ }^{67} \mathrm{Ga}-\mathrm{H} 12$ scFv. Images revealed a clear tumor uptake of radiolabeled scFvs. Unfortunately, it also demonstrated high kidney and liver uptake. The high liver and kidney uptake of radiolabeled antibody fragments with $\mathrm{C}$-terminal $6 \mathrm{xH}$ is tag is consistent with previous studies (Fig. 3.9).(173-175)

To Investigate the tumor targeting efficiency of scFv-conjugated nanoparticles, the DFO-C' dot-scFv construct was radiolabeled with ${ }^{89} \mathrm{Zr}$ and injected in mice bearing A549 xenografts. PET/CT images were acquired 4, 24, and 48 hours after the injection of ${ }^{89} \mathrm{Zr}$-C'dot-H12-scFv nano-immunoconjugate. Images at 4 hours post injection showed that the radiolabeled particles were circulating throughout the body and there was no observable tumor uptake, however at 24 hours the specific tumor uptake of the particles was evident. There was still a significant amount of activity in the heart indicating that the particles were still circulating in the body. At 48 hours post injection, high accumulation of ${ }^{89}$ Zr-labeled C' dot-scF nanoparticles in the tumor was observed (Fig. 3.10). There was a little uptake in the liver which indicated that a small amount of ${ }^{89} \mathrm{Zr}$ C' dot-H12-scFv nanoparticle was getting cleared out of body via liver. There was no non-specific uptake in any other major body organ. Most importantly there was no kidney uptake at any time points. This result indicated that the high kidney and liver retention observed in ${ }^{67} \mathrm{Ga}-\mathrm{H} 12-\mathrm{scFv}$ SPECT/CT image was 
likely due to positively charged amino acid on the C-terminal tail of the scFv.(173175) 


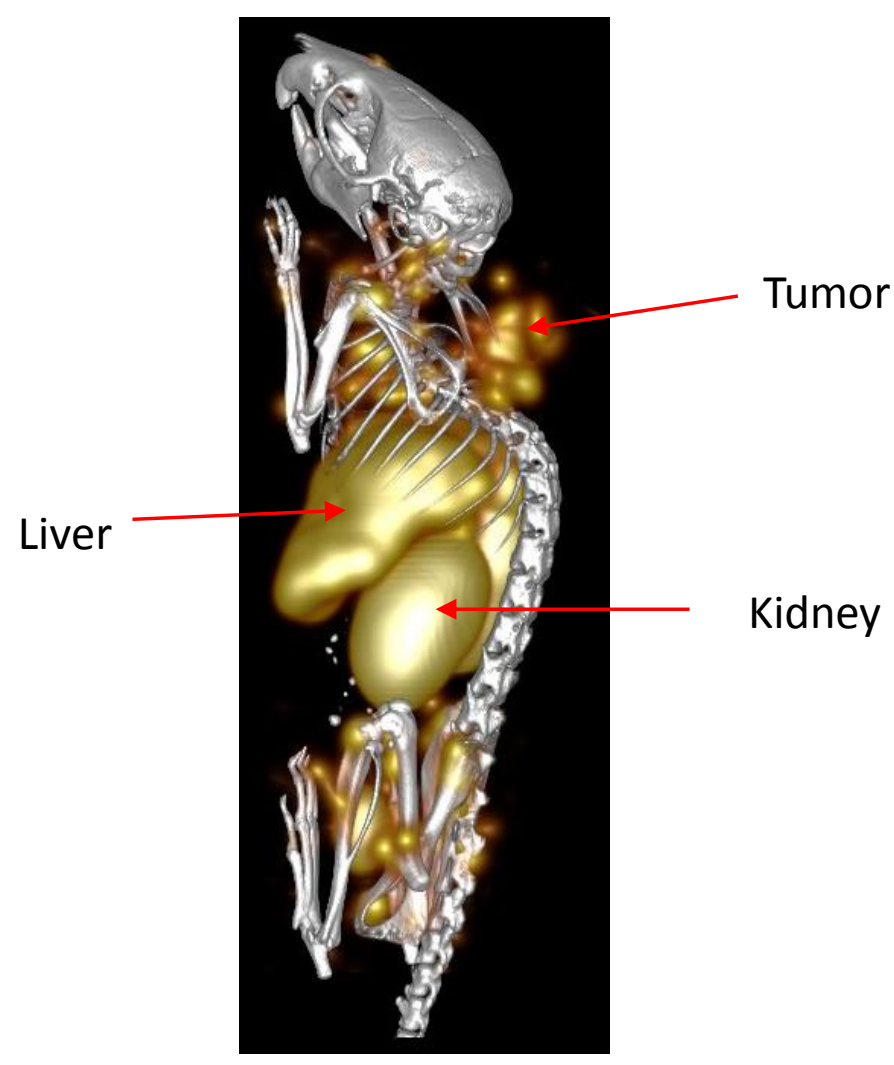

Figure 3.9: In vivo SPECT/CT imaging: An A549 tumor bearing mouse was injected with $300 \mu \mathrm{Ci}$ of ${ }^{67} \mathrm{Ga}$-labeled H12-scFv via tail vein injection. The whole body SPECT/CT image was acquired 4 hours post injection. An analysis of the image revealed that the radiolabeled H12-scFv bound to the tumor, however there was also a significant accumulation of $\mathrm{H} 12$-scFv in the liver and kidneys. 
4 hours post injection

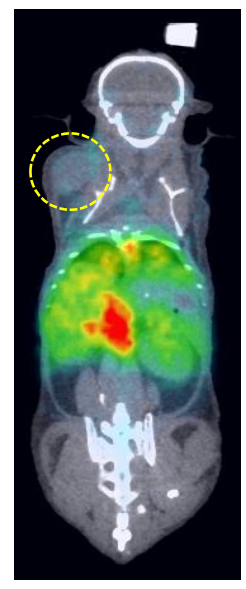

Dorsal

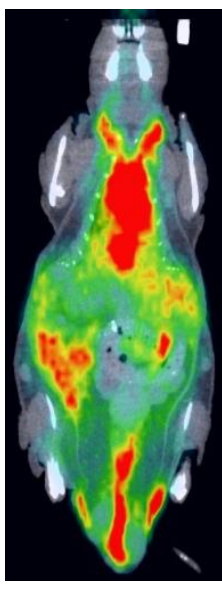

Ventral
24 hours post injection

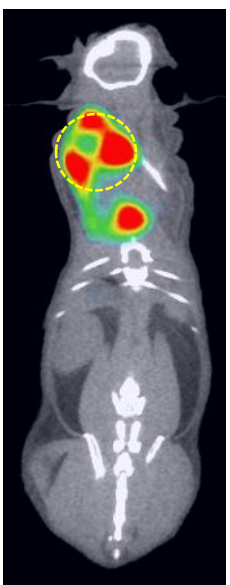

Dorsal

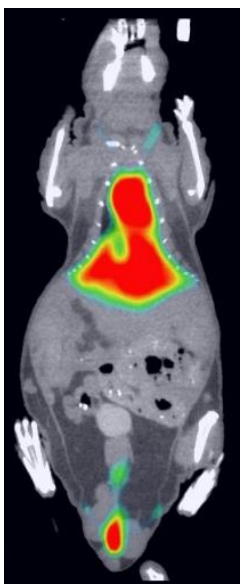

Ventral
48 hours post injection

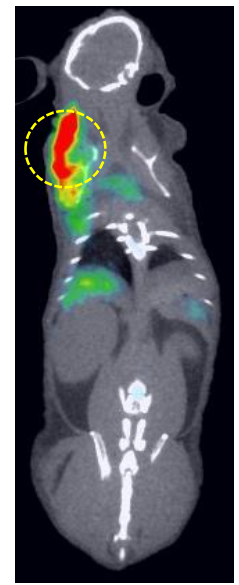

Dorsal

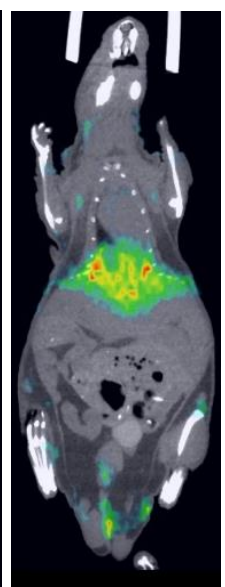

Ventral

Figure 3.10: In vivo PET/CT imaging: The H12-conjugated C' dot nanoparticles were radiolabeled with ${ }^{89} \mathrm{Zr}(300 \mu \mathrm{Ci})$ and injected in mice bearing $\mathrm{A} 549$ xenografts by I.P. Injection and whole-body PET/CT images were taken 4, 24, and 48 hours post injection. There was a significant accumulation of ${ }^{89} \mathrm{Zr}-\mathrm{C}^{\prime}$ dotscFvs in the tumor at 48 hours with no kidney retention and very minimal liver uptake. This image clearly demonstrated that the ultrasmall C' dot-H12 nanoimmunoconjugate exhibited higher tumor uptake and superior pharmacokinetics compared to the direct labeled-H12 scFvs. Dotted yellow circle indicates the tumor. 


\section{Discussion}

Lung cancer is by far the leading cancer killer in both men and women, accounting for nearly 1.7 million deaths word-wide. One of the main reasons for this high mortality rate is the lack of sensitive early diagnosis methods. It is critically important to detect lung cancer in its early stages, as the survival rate goes down drastically as the disease progresses to advanced stages. Here, we describe the development of a targeted imaging agent against MMP-12 for in vivo PET/CT imaging in A549 human lung adenocarcinoma tumor model. The MMP-12 specific construct would not only be used for initial diagnosis, but could also play an important role in treatment planning and post treatment response assessment. Various MMP-12 specific probes have been used for imaging aneurysms and atherosclerotic plaques, but to date MMP-12 has not been investigated as a molecular target for radioimaging in lung cancer. In this study, we successfully identified an antibody fragment that specifically targeted MMP-12 antigen in lung cancer. To the best of our knowledge, this is the first in vivo study establishing MMP-12 as a novel target for human lung adenocarcinoma using PET/CT imaging in a mouse xenograft model.

To identify MMP-12 specific antibody fragments (scFvs), phage display selections were carried out against MMP-12 protein. Using a standard affinityselection method, two rounds of selections were performed, and individual phage clones were picked at the end of the second round. A total 96 were selected and screened for MMP-12 specificity using BSA as a non-specific control target. Out of 96 phage-scFv clones, 23 clones displaying highest binding signals over BSA 
(MMP-12 : BSA $\geq 5$ ) were selected and sequenced by Sanger sequencing to identify duplicate clones. The sequencing analysis revealed that out of 23 clones, 8 clones had unique CDR sequences. Surprisingly, all 8 unique clones had the identical CDR-H1 and CDR-H2 sequences, but they all differed in their CDR-H3 regions (Table 3.1). No discernable pattern in their light chain CDR sequences was observed. This result indicated that the selection was convergent towards a common sequence motif and that the library was specifically enriched towards MMP-12. The selected phage-scFv clones were subsequently subcloned into pSANG10-3F vector for expression and purification of soluble scFvs. ELISA was carried out to ascertain that the purified scFvs in soluble form retained their MMP-12 specificity. In the phage ELISA binding studies, the scFv is connected to a huge phage particle that might bind non-specifically to the target resulting in false positives. By repeating the ELISA with soluble scFvs, we can confirm that the binding signal observed was due to specific interaction between scFvs and the target protein. ELISA performed with soluble scFvs confirmed that all selected 8 clones were MMP-12 specific, as the binding signal for MMP-12 was at least 5 times higher than that of the negative control BSA (Fig. 3.3).

Based on the specificity towards MMP-12 as well as the purification yield, scFv clone $\mathrm{H} 12$ was selected for further characterization. The microscale thermophoresis analysis revealed that H12-scFv bound to purified MMP-12 protein with the binding affinity $\left(\mathrm{K}_{\mathrm{d}}\right)$ of $36 \pm 12 \mathrm{nM}$ (Fig. 3.5). The H12-scFv was further characterized in vitro to determine if it could detect MMP-12 in A549 human lung adenocarcinoma cells. The A549 cell line was reported to 
overexpress MMP-12 and was used as a target cancer cell line, while human breast cancer cell line MDA-MB-231 was used as a negative cell line since it does not express MMP-12. Also, MDA-MB-231 cells overexpress membrane bound MMP-14 (MT-1 MMP). Therefore, not only does MDA-MB-231 serve as a negative control for MMP-12 expression, but it also helps to determine if $\mathrm{H} 12$ scFv can discriminate between MMP-12 and MMP-14. The flow cytometry analysis showed that H12-scFv bound specifically to MMP-12 expressing A549 cells and did not bind to MDA-MB-231 cells (Fig. 3.6). Surprisingly H12-scFv showed a much higher binding signal to A549 cells than the commercially available anti-MMP-12 antibody. The specific biding of H12-scFv to A549 cell was furthered confirmed by fluorescent microscopy. Again, the H12-scFv did not bind to the MDA-MB-231 cells, which affirmed that H12-scFv could recognize MMP-12 in cell binding assays and also distinguish between MMP-12 and MMP14 (Fig. 3.7). The specificity of H12-scFv towards MMP-12 and its nanomolar affinity were sufficient to further investigate its usefulness as an in vivo radioimaging agent.

Radiolabeling of $\mathrm{H} 12-\mathrm{scFv}$ for in vivo imaging was accomplished by conjugating scFvs with bifunctional chelator $p$-SCN-Bn-NOTA and subsequently labeling with ${ }^{67} \mathrm{Ga}$. The ${ }^{67} \mathrm{Ga}-\mathrm{H} 12-\mathrm{scFv}$ was injected in $\mathrm{A} 549$ tumor bearing mice. The in vivo SPECT/CT images showed that there was a moderate tumor uptake for the ${ }^{67} \mathrm{Ga}$-labeled $\mathrm{H} 12 \mathrm{scFv}$ at 4 hours post injection. Unfortunately, there was also a significant non-tumor uptake of $\mathrm{H} 12-\mathrm{scFv}$ in the liver and kidneys (Fig. 3.9). Because of their smaller size and rapid body clearance via kidneys, scFvs 
usually have a higher kidney uptake compared to the full length antibodies. This problem was compounded by the fact that scFvs expressed using pSANG10 vector has a C-terminal 6xHis-tag. At a physiological $\mathrm{pH}$, these histidine residues are positively charged and bind to negatively charged proximal tubule cells of the kidneys resulting in high kidney uptake. The presence of 6 histidine residues as well as lysine residues in the tri-FLAG tag also lead to higher liver uptake as observed in the in vivo SPECT image with ${ }^{67} \mathrm{Ga}-\mathrm{H} 12-\mathrm{scFv} .(173-175)$ There are various ways to reduce the liver and kidney uptakes of vectors with histidine tags. It has been shown that modifying the $\mathrm{HHHHHH}$ tag to the HEHEHE tag leads to considerable less uptake in kidney and liver. $(175,176)$ So does the administration of positively charged amino acids like lysine or arginine just before the injection of radiolabeled vector with 6xHis-tag. $(179,180)$ In this study, we conjugated scFvs to the ultrasmall silica nanoparticles which resulted in no kidney uptake and significantly lower liver retention.

Cornell prime ( $C^{\prime}$ dot) ultrasmall nanoparticles were designed with a Cy5 fluorophore embedded silica core. These particles have a hydrodynamic diameter in the rage of 5-7 $\mathrm{nm}$. The silica core particles are coated with PEG chains to make them more hydrophilic which in turn reduce non-specific uptake in liver, spleen, and other body organs. Because of their small size and hydrophilic properties, the C' dot nanoparticles excrete through the body via kidneys with no kidney retention.(141-143) These C' dot nanoparticles have been functionalized with various tumor targeting peptides for successful in vivo tumor imaging with superior tumor targeting and high tumor-to-background ratios. (144- 
146) Because of their non-toxic nature, favorable biodistribution profile, and higher tumor targeting, the $C^{\prime}$ dot nanoparticles are approved by the FDA for clinical trials and have been used successfully for in vivo PET imaging in patients with metastatic melanoma.(147)

The C' dot nanoparticles used in this study were synthesized and provided by the Michelle Bradbury and Ulrich Wiesner groups.(143) These nanoparticles were functionalized with DBCO and DFO groups and had hydrodynamic diameter of $5.3 \mathrm{~nm}$ (Fig. 3.8). Using azide-DBCO click-chemistry, H12-scFv was conjugated to the C' dot particles with approximately 2.4 scFvs per particle. The scFv-conjugated C' dots were radiolabeled with ${ }^{89} \mathrm{Zr}$ and injected in mice bearing A549 xenografts. The in vivo PET/CT imaging demonstrated a high tumor specific uptake for ${ }^{89} \mathrm{Zr}-\mathrm{C}$ ' dot-H12-scFv nano-immunoconjugates at 48 hours post injection (Fig. 3.10). Unlike the direct labeled ${ }^{67} \mathrm{Ga}-\mathrm{scFv}$ construct, there was no kidney uptake and a very little to moderate liver uptake. This clearly demonstrated that the ultrasmall silica nanoparticles functionalized with singlechain antibody fragments could be used successfully as an in vivo imaging agent with superior tumor targeting and efficient renal clearance. Also, this study established MMP-12 as a novel target for lung adenocarcinoma diagnosis with the potential be explored as a therapeutic target. 


\section{Conclusion}

In summary, this project was aimed at discovering MMP-12 specific antibody fragments for in vivo radioimaging. The growing evidence suggests that MMP-12 is involved in lung adenocarcinoma tumor growth and metastasis. Given the lack of a MMP-12 specific tumor targeting probes, we decided to investigate if MMP-12 has the potential as a novel biomarker for lung cancer diagnosis. Using the McCafferty scFv library, MMP-12 specific antibody fragments were selected and characterized in vitro. The in vivo SPECT/CT imaging using direct labeled ${ }^{67} \mathrm{Ga}-\mathrm{scFv}$ demonstrated moderate tumor uptake. Even though this construct showed promise, it had a limited feasibility as potential imaging agent due to very high kidney and liver uptake. In sharp

contrast, PET/CT imaging with ${ }^{89} \mathrm{Zr}$-labeled C' dot-scFv construct displayed a very high MMP-12 specific tumor uptake and no kidney retention in the A549 xenograft model. Additionally, there was no non-specific binding of the probe in any other major organ except for a little uptake in the liver. The C' dot-scFv nanoimmnunoconjugates provided a better imaging tool due to their higher tumor retention and better pharmacokinetic profile than the direct labeled antibody fragments. These observations clearly demonstrated that MMP-12 is an attractive new target for lung adenocarcinoma diagnosis as well as therapy. 


\section{Future Studies}

Since the in vivo PET/CT imaging with ${ }^{89} \mathrm{Zr}$-labeled $\mathrm{C}^{\prime}$ dot-scFv nanoimmunoconjugates yielded positive results, the next step would be to study the biodistribution profile of this construct to quantify the uptake in the tumor and normal organs and tissues. For this experiment, mice bearing A549 xenografts will be injected with $5 \mu \mathrm{Ci}$ of ${ }^{89} \mathrm{Zr}-\mathrm{C}^{\prime}$ dot-scFv probe. Mice will be sacrificed at various time points $(4,24,48$, and 72 hours) and individual organs will be collected to measure radioactivity. The biodistribution data will establish the pharmacokinetics of the C' dot-scFv conjugates and will also be used to calculate dosimetry. Also, the specificity of ${ }^{89} \mathrm{Zr}$-labeled $\mathrm{C}^{\prime}$ dot-scFv probe can be further confirmed by carrying out a blocking PET imaging study where ${ }^{89} \mathrm{Zr}$-labeled C' dot-scFv is co-injected in mice in the presence of excess MMP-12 specific scFv fragments (100 fold excess). Because of their high molar concentration, the nonradioactive scFvs should block the access of ${ }^{89} \mathrm{Zr}$-labeled nanoparticles to the tumor resulting in significant reduction in tumor uptake. In addition, MMP-12 specific C' dot-scFv nanoparticles can be radiolabeled with therapeutic radionuclides such as ${ }^{177} \mathrm{Lu}$ to explore the possibility of radioimmunotherapy in a lung cancer model. 


\section{CHAPTER 4}

Phage Display Selection of Single-Chain Antibody Fragments Against Thomsen-Friedenreich Antigen (TF-Antigen) 


\section{Introduction}

Thomsen-Friedenreich (TF) antigen is a disaccharide, galactose $\beta 1-3 \mathrm{~N}-$ acetylgalactosamine alpha, which is also referred to as core-1 structure.(148) It is an O-linked mucin associated type glycan. In normal cells, the TF epitope is masked either by sialic acid or by other carbohydrate moieties. However, in cancer cells, the TF antigen is exposed on the surface due to aberrant glycosylation.(149) The presence of TF has been detected on the surface of $90 \%$ of all carcinomas and thus TF is also known as a 'pancarcinoma antigen'. The expression of TF antigen has been shown in various types of cancers including breast, colon, liver, prostate, and ovary.(150) There may be numerous reasons for this increased exposure of TF antigen on the surface of tumor cells such as over expression of TF antigen, reduced level of enzymes that further glycosylate the core-1 structure, or increased synthesis of neuraminidase or other glycosidase enzymes that would strip more complex carbohydrates revealing this simple disaccharide.(151) TF expression on tumor cells is correlated with poor prognosis and tumor propagation. TF antigen is also involved in cell to cell adhesion and metastasis. $(152,153)$ TF antigen is a major ligand for cell surface adhesion molecules like galactin-3. TF-expressing malignant cells bind to the endothelium through TF and galactin-3 interactions, which support tumor cell metastasis.(154) The phage display derived peptide (P30), discovered by the Quinn group, selectively bound to the TF antigen and was able to block TF mediated cell to cell adhesion of breast cancer cells. $(155,156)$ On a related line, the Deutscher group demonstrated that 
galactin-3 specific peptides inhibited metastasis associated cancer cell adhesion by blocking the TF and galactine-3 interaction.(157) A second generation TF specific peptide (P30-1) was used successfully for in vivo PET/CT imaging in a tumor mouse model.(158) Taken together, these studies suggest that TF antigen is a promising target for tumor imaging and therapeutic probe development.

Over the years, numerous attempts have been made to discover TF specific antibodies.(159-161) However, most of these antibodies are of the IgM class. Due to their large molecular weight and poor in vivo pharmacokinetic properties, the IgM class of antibodies are not suitable for in vivo applications.(162) The group of Kate Rittenhouse-Olson identified a mouse monoclonal $\lg G_{3}$ antibody JAA-F11, which specifically bound to the tumor associated TF antigen alpha linkage.(163) This antibody has been shown to inhibit cancer cell growth, decrease metastasis, and improve survival in tumor breast cancer models.(164,165). Antibody fragments in either monovalent or multivalent forms have also been isolated for development of TF targeting molecular probes.(166-168) So far, there have been no reports of utilizing singlechain antibody fragments for in vivo imaging targeting TF antigen.

The aim of this project was to identify TF antigen specific scFv fragments for development of in vivo tumor imaging agents. To accomplish this goal, two rounds of phage display selection were carried out using the McCafferty scFv antibody library. A total of 96 clones were screened for their TF binding specificity. One selected TF scFv specific scFv clone was further characterized in vitro for its ability to recognize TF antigen on the MDA-MB-231 human breast 
cancer cell line. The TF-specific 9C-scFv was expressed with C-terminal 6xHistag which allowed them to be radiolabeled directly with $\left[{ }^{99 m} \mathrm{Tc}(\mathrm{CO})_{3}\right]^{+} .{ }^{99 m} \mathrm{Tc}$ is one of the most commonly used radioisotopes for molecular imaging due to its favorable half-life $\left(t_{1 / 2}=6 h\right)$, low cost, and availability. Antibody fragments radiolabeled with ${ }^{99 m} \mathrm{Tc}$ by the $6 \mathrm{xHis}$-tag sequence would yield scFvs with defined radionuclide coordination that would not interfere with the antigen recognition. The radiolabeled ${ }^{99 \mathrm{~m}} \mathrm{Tc}-\mathrm{scFv}$ was evaluated for in vitro cell binding using TF displaying human breast cancer cell line MDA-MB-231. The ${ }^{99 m} \mathrm{Tc}-$ labeled ScFv was investigated in vivo for its tumor binding ability by SPECT/CT imaging. 


\section{Materials and Methods}

\section{Phage Display Selection}

Phage display selection was carried out using the McCafferty scFv library as described in Chapter 3. Briefly, 2 rounds of selections were performed using a standard affinity-selection method. For the first round, $10 \mathrm{ng}$ of asialoglycophorin was adsorbed on the well of Nunc Maxisorb ${ }^{\text {TM }}$ 96-well plate. For the second round, $10 \mathrm{ng}$ of TF-conjugated human serum albumin (TF-HSA) was used. At the end of the second round, 96 individual colonies were picked for the phage ELISA screening.

\section{Primary Screening by Individual Phage ELISA}

Phage ELISA was carried out to identify the phage-scFv clones with high binding specificity towards the TF epitope. Two Nunc Maxisorb ${ }^{\text {TM }}$ 96-well plates were coated with $10 \mu \mathrm{g} / \mathrm{ml}(100 \mu \mathrm{l})$ of asialoglycophorin and asialofetuin. Both of these proteins display TF antigen on their surface and serve as target plates. While two additional plates coated with glycophorin and fetuin were used as negative control as these proteins do not display TF. Plates were blocked with Rockland blocking buffer (Rockland Inc., PA) and incubated with individual phage-scFv clones. After 1 hour incubation at room temperature, plates were washed 5 times with $0.1 \%$ TBST and an anti-M13-HRP conjugated antibody (1:2000 dilution) was added to wells. To detect binding, $100 \mu \mathrm{l}$ of 2,2'-Azinobis(3-ethylbenzothiazoline-6-sulfonic acid) (ABTS) was added and the absorbance was measured at $405 \mathrm{~nm}$ using UV-Vis spectrophotometer plate 
reader. Clones which displayed highest signal-to-noise ratios were picked for further analysis.

\section{Sequence Analysis of Positive Clones}

A total of 5 phage clones with the highest binding ratios of asialoglycophorin-to-glycophorin and asialofetuin-to-fetuin in phage ELISA were selected for sequence analysis. These clones in the pSANG4 phagemid were sequenced using the forward primer M13 LeadSeq (5'AAATTATTATTCGCAATTCCTTTGGTTGTTCCT) and the reverse primer NotMycSeq (5'-GGCCCCATTCAGATCCTCTTCTGAGATGAG). These clones were analyzed for the presence of full-length scFv gene inserts and their sequence similarities using Serial Cloner $^{\mathrm{TM}}$ software. Clones missing either heavy chain or light chain domains were removed. The clone which had the highest signal:noise ratio in ELISA and had intact $\mathrm{VH}$ and $\mathrm{VL}$ domains was selected for large scale expression.

\section{Expression and Purification of The Selected scFv Fragment}

The selected ScFv gene was subcloned into the pSANG10-3F expression vector using Ncol/Notl restriction enzymes as described in Chapter 3. The ligated plasmid was transformed into the chemically competent E.coli BL21 (DE3) cells for expression. A single colony of the scFv clone was grown in $30 \mathrm{ml}$ of 2xTYKG media (2xTY media with kanamycin and $2 \%$ glucose) at $37^{\circ} \mathrm{C}$ overnight (250 rpm). The next day, 3L of 2xTYKG media was inoculated with the $30-\mathrm{ml}$ of overnight culture and incubated at $37^{\circ} \mathrm{C}$ for $2.5-3.0$ hours until the $\mathrm{OD}_{600}$ reached 
0.5-0.7. To induce the scFv expression, cells were pelleted at $4500 \times \mathrm{g}$ for 20 minutes, resuspended in 2xTY media (containing kanamycin and 1mM IPTG), and incubated at $37^{\circ} \mathrm{C}$ for 4 hours with shaking. The cell pellet was obtained by spinning down the culture at $4500 \times \mathrm{g}$ for 25 minutes. The pellet was resuspended in lysis buffer containing $20 \mathrm{mM}$ Tris-HCL (pH 8.0), $500 \mathrm{mM} \mathrm{NaCl}$, benzonase, and protease inhibitor cocktail. Cells were lysed by sonication and cell debris was pelleted at $27000 \times \mathrm{g}$ for 30 minutes. The supernatant was collected and filtered through $0.22 \mu \mathrm{m}$ filter.

For the purification of the scFv, filtered supernatant was loaded onto a 5-ml HisTrap ${ }^{\mathrm{TM}} \mathrm{HP}$ Ni-column. The column was washed with 10 column volumes of washing buffer $(20 \mathrm{mM}$ Tris- $\mathrm{HCl}, 500 \mathrm{mM} \mathrm{NaCl}$, and $40 \mathrm{mM}$ Imidazole; $\mathrm{pH}$ 8.0). The bound scFv was eluted with elution buffer (20 mM Tris$\mathrm{HCl}, 500 \mathrm{mM} \mathrm{NaCl}$, and $250 \mathrm{mM}$ Imidazole; $\mathrm{pH}$ 8.0). ScFv containing fractions were pooled and the purity of the scFv was analyzed by SDS-PAGE and immunoblot.

\section{ScFv-ELISA}

To determine the binding of purified scFv, wells of nunc MaxiSorp ${ }^{\text {TM }}$ plates were coated with $100 \mu \mathrm{l}(10 \mu \mathrm{g} / \mathrm{ml})$ of asialoglycophorin and asialofetuin overnight. Wells coated with glycophorin, fetuin, and BSA were used as negative controls. Next day, plates were blocked with Rockland blocking buffer for 1 hour at room temperature. The purified scFv fragment (100 ng) was added to blocked wells and incubated for 1 hour at room temperature. Plates were washed 5 times 
with $0.1 \%$ TBST before incubating with an anti-FLAG-HRP conjugated antibody for 1 hour at room temperature. After washing 5 times with $0.1 \%$ TBST, the binding was detected by addition of ABTS substrate and measuring the absorbance at $405 \mathrm{~nm}$ using a UV-Visible plate reader.

\section{In Vitro Cell Binding Studies}

The binding characteristics of the purified 9C-scFv to the TF epitope was determined by flow cytometry using MDA-MB-231 human breast cancer cell line. MDA-MB-231 cells over expresses TF on their surface, while TF negative mouse melanoma cell line B10F16 was used as a negative control cell line. Cells $(2 \mathrm{x}$ $10^{5}$ cells/ tube) were fixed with $4 \%$ paraformaldehyde for 10 minutes, followed by blocking with $5 \%$ BSA/TBS for 1 hour at room temperature. After washing 3 times with $1 \% \mathrm{BSA} / \mathrm{TBS}$ solution, cells were incubated with purified $9 \mathrm{C}$-scFv at $4^{\circ} \mathrm{C}$ for 1 hour in the dark. After washing 3 times with 1\% BSA/TBS, cells were incubated with an anti-FLAG-FITC secondary antibody. The binding was determined by measuring relative fluorescence intensity of stained cells by CyAn ADP flow cytometer (Beckman Coulter) using the FITC channel.

\section{Microscale Thermophoresis}

To determine the binding affinity of selected $9 \mathrm{C}$-scFv towards the TF epitope, microscale thermophoresis technique was used. The binding affinities of the scFv were calculated against TF expressing proteins asialoglycophorin and asialofetuin as described in Chapter 3. 


\section{Radiolabeling}

The selected $9 \mathrm{C}$-scFv was radiolabeled directly with ${ }^{99 m} \mathrm{Tc}$ using the 6xHis-tag on the C-terminus. Briefly, $5 \mathrm{mCi}$ of ${ }^{99 \mathrm{~m}} \mathrm{TcO}_{4}{ }^{-}$generator eluent was added directly into an IsoLink kit. The mixture was heated for $100^{\circ} \mathrm{C}$ for 20 minutes. The resultant $\left[{ }^{99 \mathrm{~m}} \mathrm{Tc}(\mathrm{CO})_{3}\right]^{+}$was mixed with $100 \mu \mathrm{g}$ of purified $9 \mathrm{C}$-scFv in PBS. The $\mathrm{pH}$ was adjusted to 7.4 and labeling reaction was carried out at $37^{\circ} \mathrm{C}$ for 90 minutes. The labeling yield was calculated by ITLC using 200 mM EDTA as a mobile phase. The ${ }^{99 \mathrm{~m}} \mathrm{Tc}$-labeled $9 \mathrm{C}$-scFv was purified using a PD-10 gelfilteration column and the radiochemical yield was measured by ITLC.

To evaluate the stability of ${ }^{99 \mathrm{~m}} \mathrm{Tc}$-labeled $9 \mathrm{C}-\mathrm{scFv}$, a histidine challenge was performed. The ${ }^{99 \mathrm{~m}} \mathrm{Tc}$-labeled $9 \mathrm{C}$-scFv was incubated with 5000 molar excess of histidine for $1 \mathrm{~h}, 2 \mathrm{~h}$, and 4 hours. After the incubation, stability was determined by ITLS as described above.

\section{Cell Binding Analysis}

${ }^{99 \mathrm{~m}} \mathrm{Tc}$-labeled $9 \mathrm{C}$-scFv $(100 \mu \mathrm{L})$ was diluted to 100,000 counts per minute (CPM) aliquots and added to MDA-MB-231 cells or TF-negative B16F10 cells. After 1 hour of incubation, cells were washed three times with ice-cold $1 \%$ BSA/PBS buffer. Cells were centrifuged at $14000 \times \mathrm{g}$ for 5 minutes and supernatant was discarded. The pellet was collected and used for determining the binding by counting the radioactivity in a gamma counter. 


\section{A549 Lung Adenocarcinoma Xenograft Model}

All animal experiments were carried out in compliance with the Institutional Animal Care and Use committee in accordance with U.S. Public Health Service Guidelines. Athymic female BALB/C (nu/nu) mice were obtained from Envigo (USA) and inoculated with $1 \times 10^{7}$ MDA-MB-231 cells in right shoulder subcutaneously. Tumors were allowed to grow for 3-4 weeks and mice were used when tumors were clearly visible, palpable, and measurable.

\section{In Vivo Imaging}

For SPECT imaging, mice bearing MDA-MB-231 xenograft were injected with $300 \mu \mathrm{Ci}$ of ${ }^{99 \mathrm{~m}} \mathrm{Tc}$-labeled $9 \mathrm{C}-\mathrm{scFv}$ via tail vein. Whole-body SPECT/CT images were taken 4 hours post injection. For anatomical data fusion, smallanimal CT was performed, and concurrent images were reconstructed with Fanbeam filtered-backprojection algorithm. 


\section{Results}

\section{Phage Display Selection}

To isolate TF specific antibodies, two rounds of affinity selections were carried out using the McCafferty scFv library (diversity of $1.1 \times 10^{10}$ ). To increase the stringency of the selection process and to avoid selecting antibodies against carrier proteins, each round of selection was performed using a different TF displaying carrier protein. The selection output of first round against asialoglycophorin was $2.9 \times 10^{4} \mathrm{cfu}$, while the output of second round against TFHSA was $1.3 \times 10^{5}$ cfu with the enrichment of 4.48 times between two rounds. Since the helper phage with trypsin cleavable plll protein was used for superinfection, only two rounds of selections were necessary.

\section{Phage ELISA}

Phage ELISA was carried out with 96-colonies picked at the end of the second round of selection. The binding specificity against the TF antigen was determined by measuring binding signal for asialogycophorin over glycophorin and asialofetuin over fetuin. There were 5 clones which had signal-to-noise ratio of $\geq 3$. (Fig. 4.1) These 5 clones were selected and sequenced by Sanger sequencing. The sequence analysis revealed that out of 5 clones, only one clone (9C) had the full scFv sequence with both heavy and light chain domains intact. The clone 9C was selected for large scale expression and downstream characterization. 
A

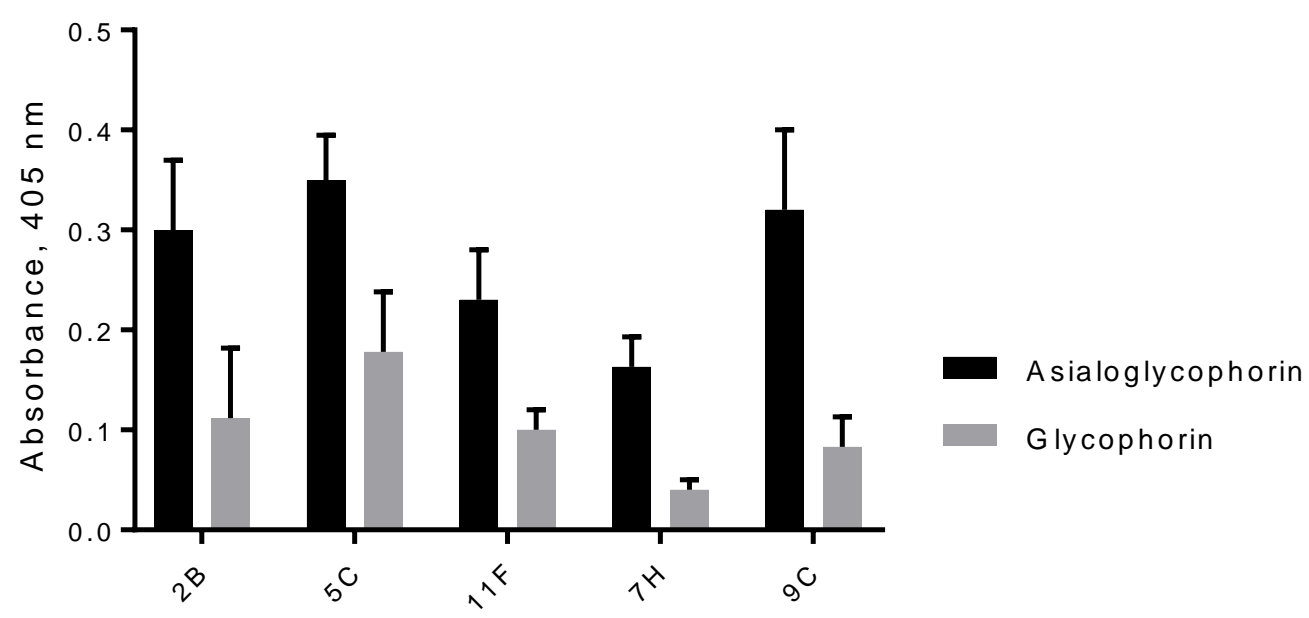

B

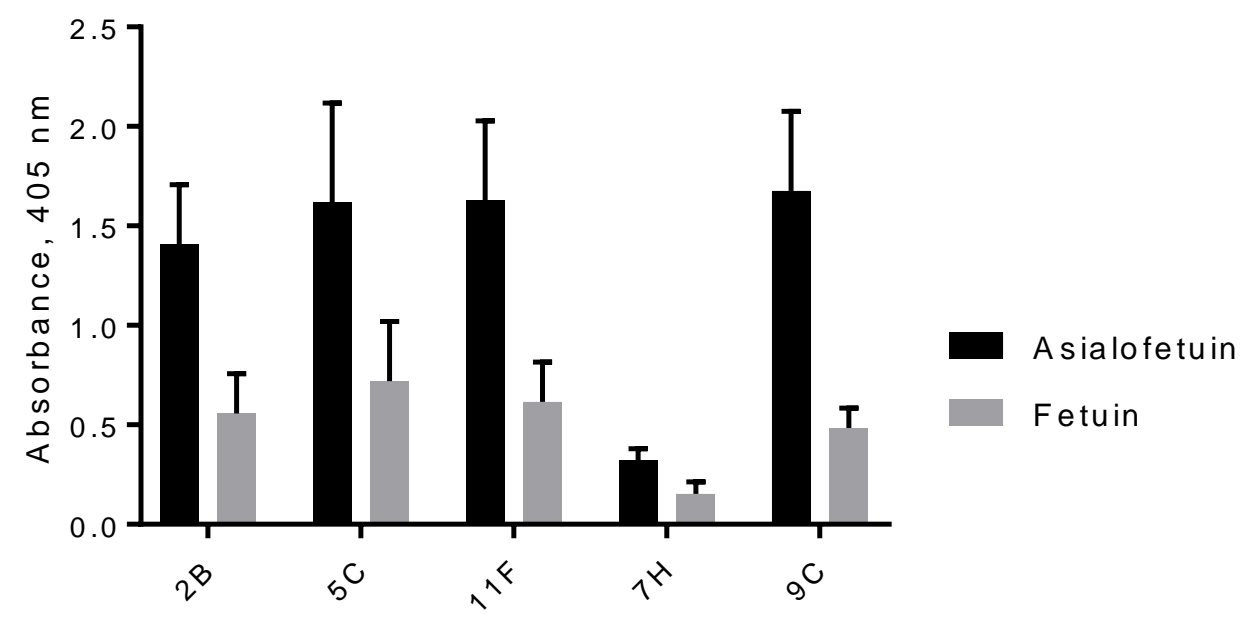

Figure 4.1: Phage ELISA: At the end of the second round, 96 random phage clones were selected and screened for TF binding specificity. Individual phagescFv clones were incubated with asialoglycophorin and asialofetuin coated 96well plates and binding was detected using an anti-M13-HRP conjugated secondary antibody. Glycophorin and fetuin coated plates were used as negative control. 


\section{ScFv Expression and Purification}

The 9C-scFv gene was subcloned into the pSANG10-3F expression vector. Expression of $9 \mathrm{C}$-scFv was induced by IPTG induction and purified by affinity chromatography using Ni-column as described in Chapter 3. The expression and purity of the 9C-scFv was verified by SDS-PAGE and immunoblot analysis (Fig. 4.2).

\section{ScFv-ELISA}

In order to confirm binding specificity of the purified 9C-scFv towards the TF epitope, a secondary binding assay was performed with soluble 9C-scFv. The ELISA demonstrated that $9 \mathrm{C}$-scFv retained its binding affinity towards TF displaying proteins asialoglycophorin and asialofetuin with minimal binding to TF negative glycophorin, fetuin, and BSA (Fig. 4.3). This assay proved that purified 9c-scFv in soluble form bound to the TF epitope and not to the carrier proteins. 

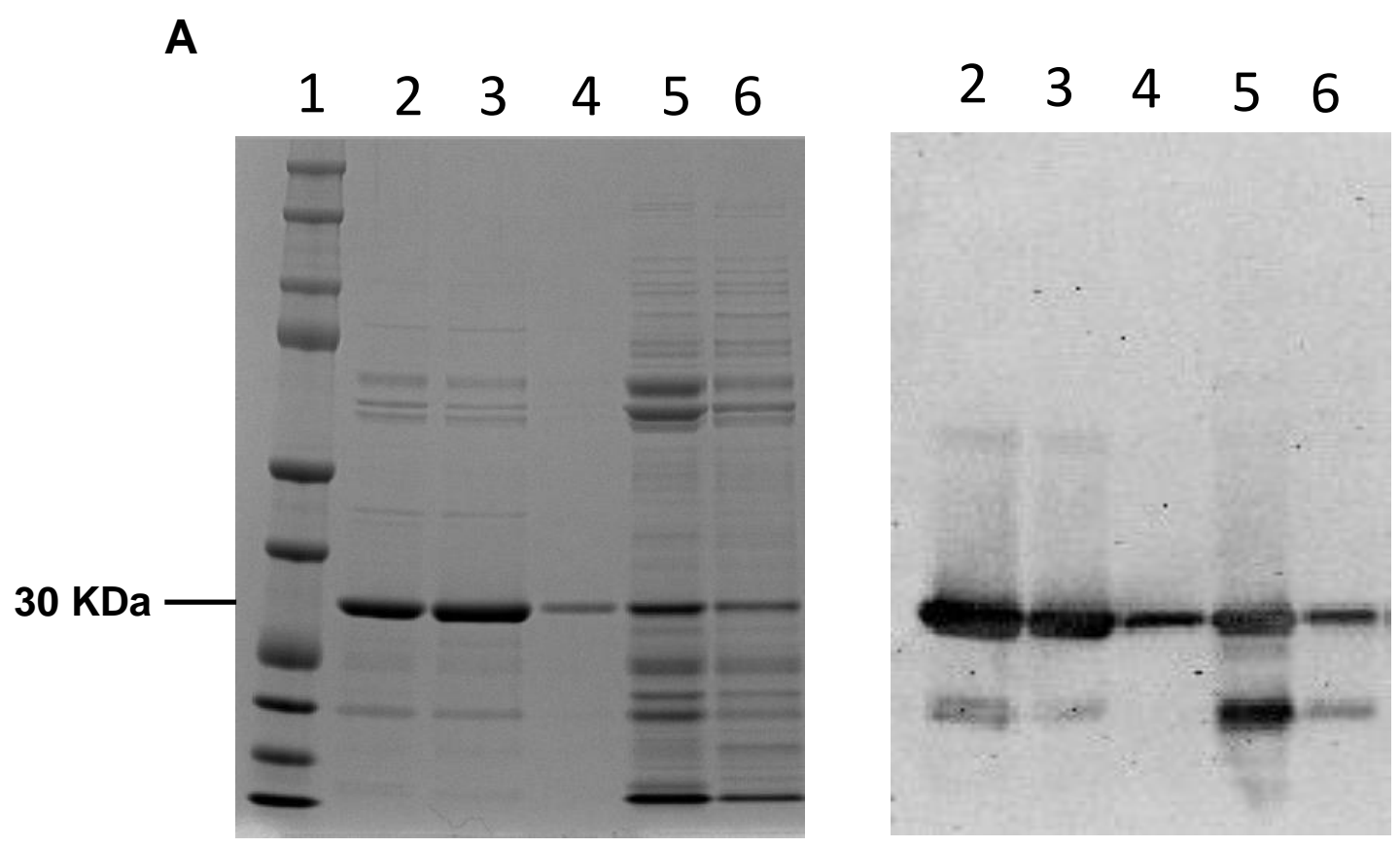

Figure 4.2: Expression and purification of 9C-scFv. The scFv was expressed by IPTG induction in E.coli BL21 cells and purified using a Ni-column. The purity of the eluted $9 \mathrm{C}$-scFv was detected by A) SDS-PAGE gel, and B) Immunoblot analysis using anti-FLAG-HRP conjugated secondary antibody. Lane 1- Molecular weight markers, lane 2, 3, and 4- Eluted fractions containing purified 9C-scFv, lane 5- Loading sample, lane 6- Flow through. 
A

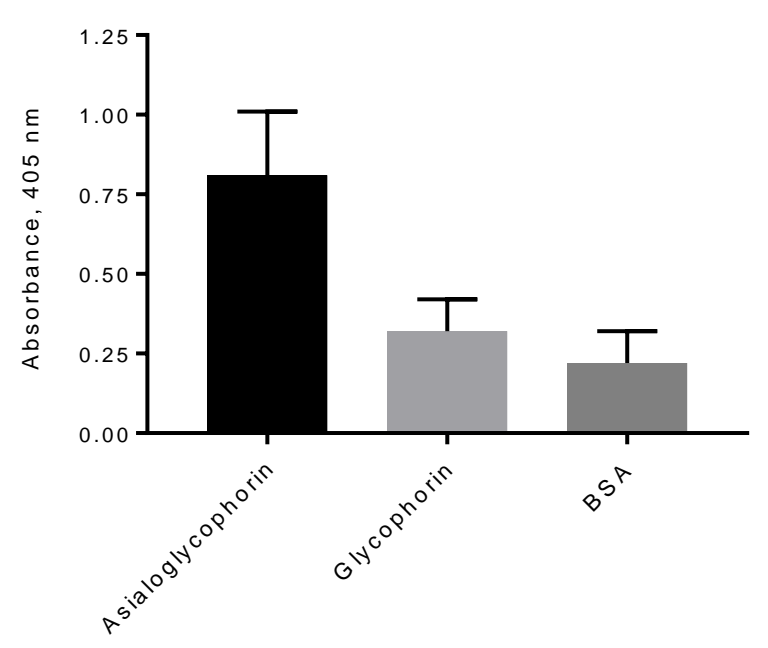

B

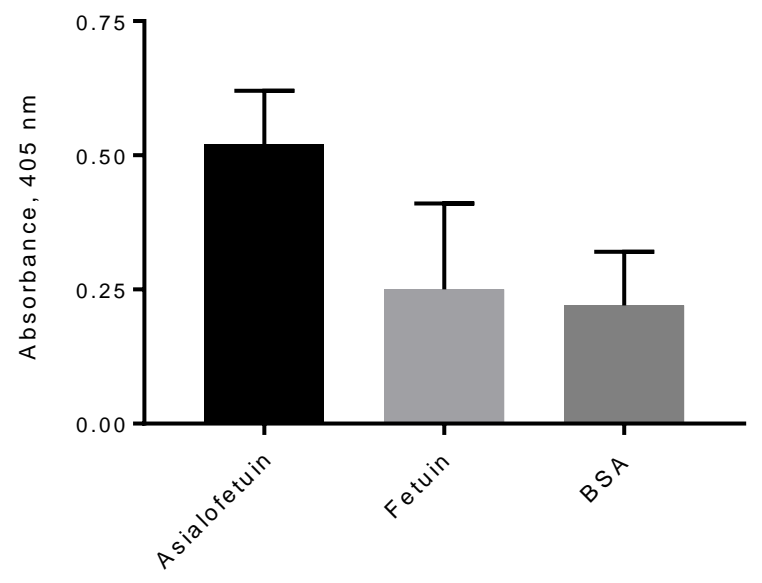

Figure 4.3: Soluble scFv ELISA. The binding specificity of purified 9C-scFvs was determined by incubating $100 \mathrm{ng}$ of purified $9 \mathrm{C}-\mathrm{scFv}$ fragments in wells coated with asialoglycophorin and asialofetuin. After the washing step, the wells were incubated with an anti-FLAG-HRP conjugated secondary antibody and the binding was detected by measuring absorbance at $405 \mathrm{~nm}$. Bars represent the average of 3 replicates. Glycophorin, fetuin, and BSA were used as negative controls. 
A

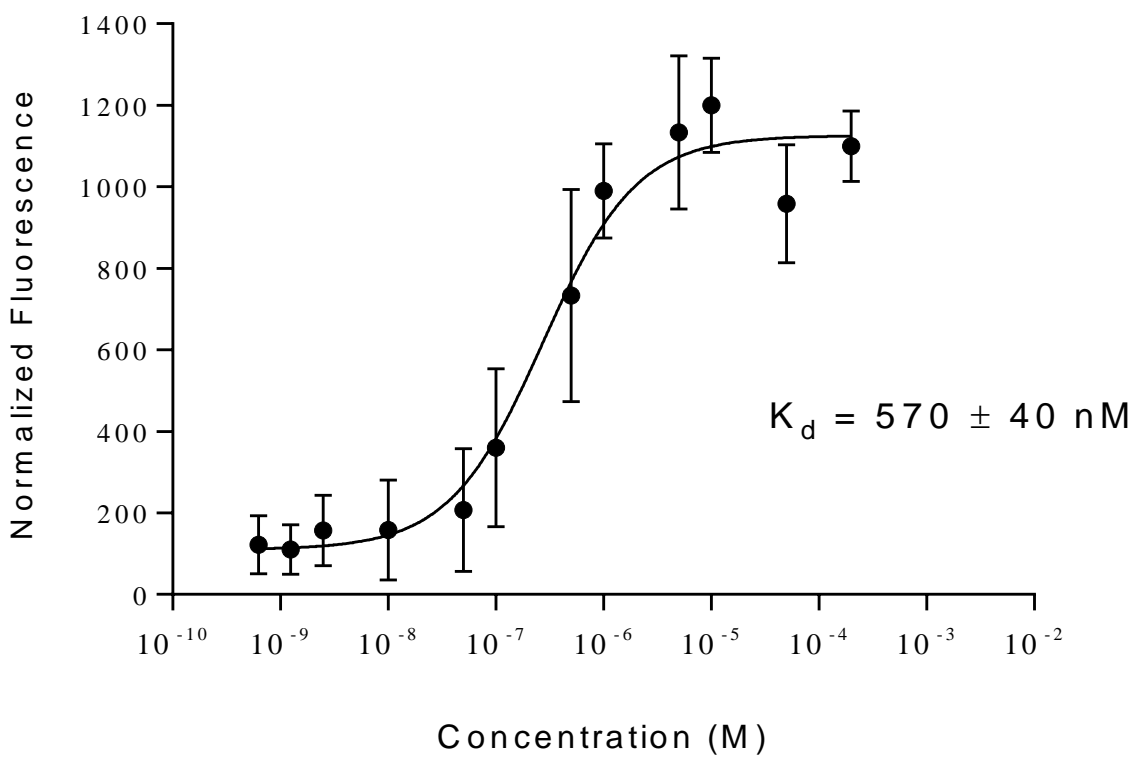

B

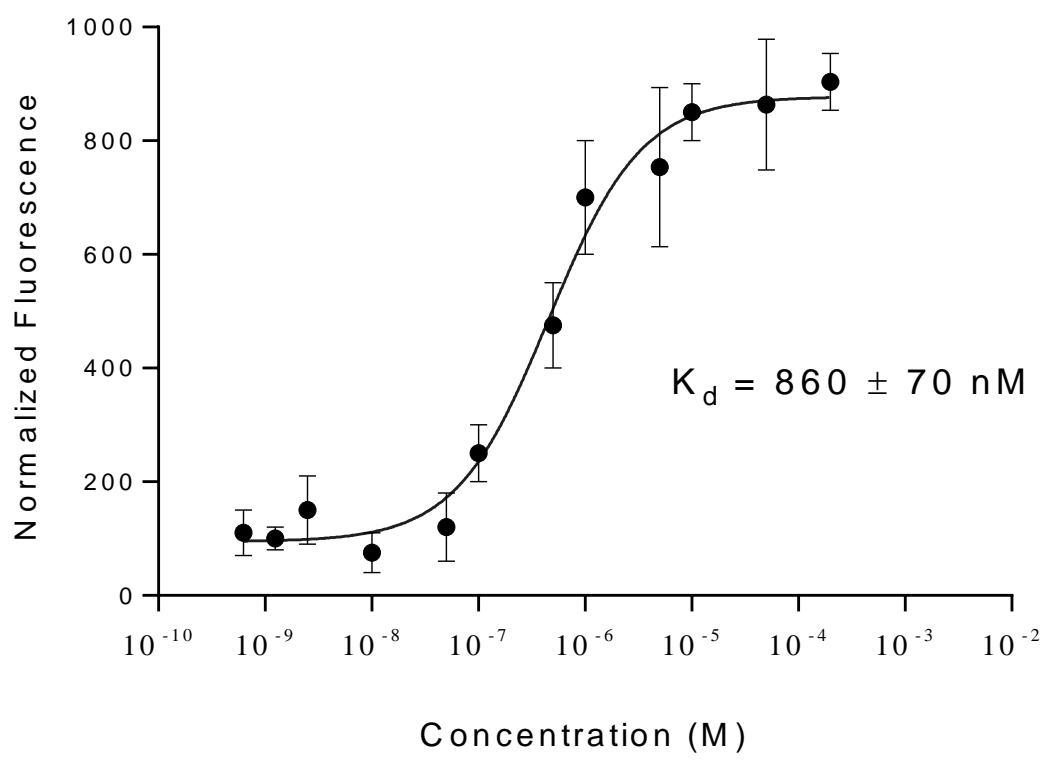

Figure 4.4: Binding affinity of the TF-specific 9C-scFv clone was determined for A) Asialogyclophorin and B) Asialofetuin by microscale thermophoresis. 


\section{Cell Binding Analysis}

Cell binding analysis was carried out by flow cytometry using MDA-MB231 and B16F10 cells. As shown in Fig. 4.5, 9C-scFv bound to TF expressing MDA-MB-231 cells with higher specificity (MFI of $16 \pm 4$ ) while the signal with TF negative cell line B16F10 was negligible (MFI of $2 \pm 3$ ). Peanut agglutinin (PNA) was used as a positive control for TF binding (MFI of $21 \pm 6$ ). The binding signal for selected 9C-scFv against MDA-MB-231 cells was very similar to PNA while the signal against B16F10 was similar to unstained negative control. These results confirmed that the $9 \mathrm{C}-\mathrm{scFv}$ specifically bound to the TF epitope on the human breast cancer cell line.

\section{Radiolabeling and Cell Binding Analysis}

The TF specific 9C-scFv was radiolabeled with ${ }^{99 \mathrm{~m}} \mathrm{Tc}$ using the IsoLink kit as previously described. A radiolabeling yield of $93 \%$ was achieved, while the radiochemical purity was found to be $>99 \%$. The ${ }^{99 m} \mathrm{Tc}$-labeled $9 \mathrm{C}$-scFv remained stable with $99 \%$ of the radiolabeled conjugate remaining intact after 4 hours at $37^{\circ} \mathrm{C}$ in human serum. The radiolabeled $9 \mathrm{C}-\mathrm{scFv}$ was also remarkably stable during histidine challenge as $98 \%$ of ${ }^{99 \mathrm{~m}} \mathrm{Tc}$-labeled $9 \mathrm{C}$-scFv remained intact (Table 4.1).

In order to confirm the specificity of ${ }^{99 \mathrm{~m}} \mathrm{Tc}$-labeled $9 \mathrm{C}$-scFv towards TF epitope, an in vitro cell binding assay was performed. As shown in Fig. 4.6, the

${ }^{99 \mathrm{~m}}$ Tc-labeled 9C-scFv demonstrated higher binding signal (7247 $\left.\pm 152 \mathrm{CPM}\right)$ to MDA-MB-231 cells, while the signal for TF-negative B16F10 cells was much 
lower (856 $\pm 51 \mathrm{CPM})$. These cell binding assays demonstrated the specificity of ${ }^{99 m}$ Tc-labeled $9 \mathrm{C}$-scFv towards the TF antigen. 


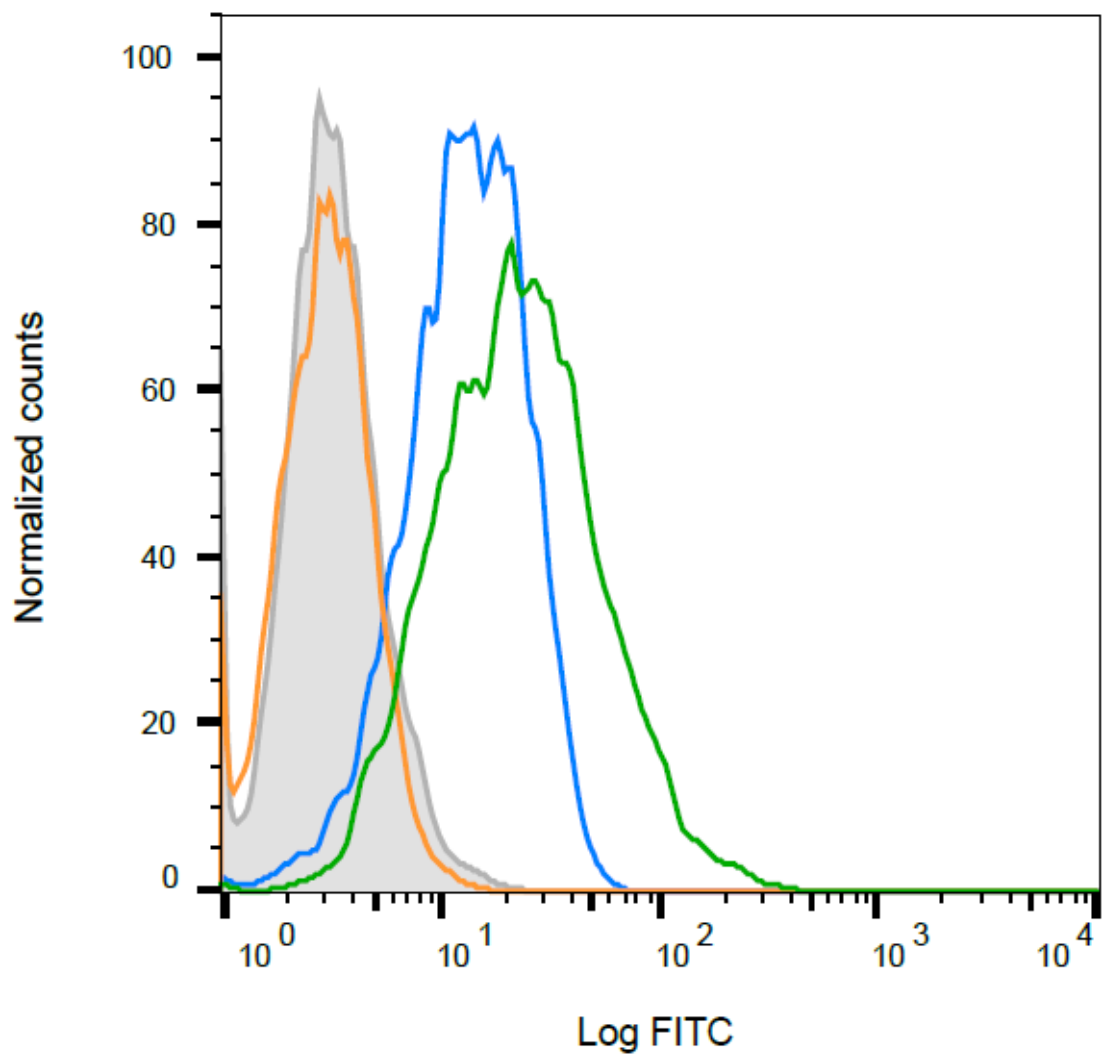

Figure 4.5: Flow cytometry analysis of $9 \mathrm{C}-\mathrm{scFv}$. The TF specific 9C-scFv was incubated with MDA-MB-231 ( $\square$ ) or B16F10 cells $(\square)$. Following 1 hour incubation on ice, cells were washed and incubated for additional 1 hour with an anti-FLAG-FITC conjugated secondary antibody. Binding was determined by counting 10,000 cells in a CyAn ADP flow cytometer. Peanut agglutinin ( $\square$ ) and unstained MDA-MB-231 cells $(\square)$ were used as negative control. 
Table 4.1: Stability of ${ }^{99 \mathrm{~m}} \mathrm{Tc}$-labeled $9 \mathrm{C}-\mathrm{scFv}$

\begin{tabular}{|c|c|c|}
\hline Stability at $37^{\circ} \mathrm{C}$ & Human Serum (\%) & $\begin{array}{c}5000 \text { fold Histidine } \\
\text { solution (\%) }\end{array}$ \\
\hline 1 Hour & 99.8 & 98.1 \\
\hline 2 Hours & 99.3 & 97.6 \\
\hline 4 Hours & 99.1 & 97.9 \\
\hline
\end{tabular}

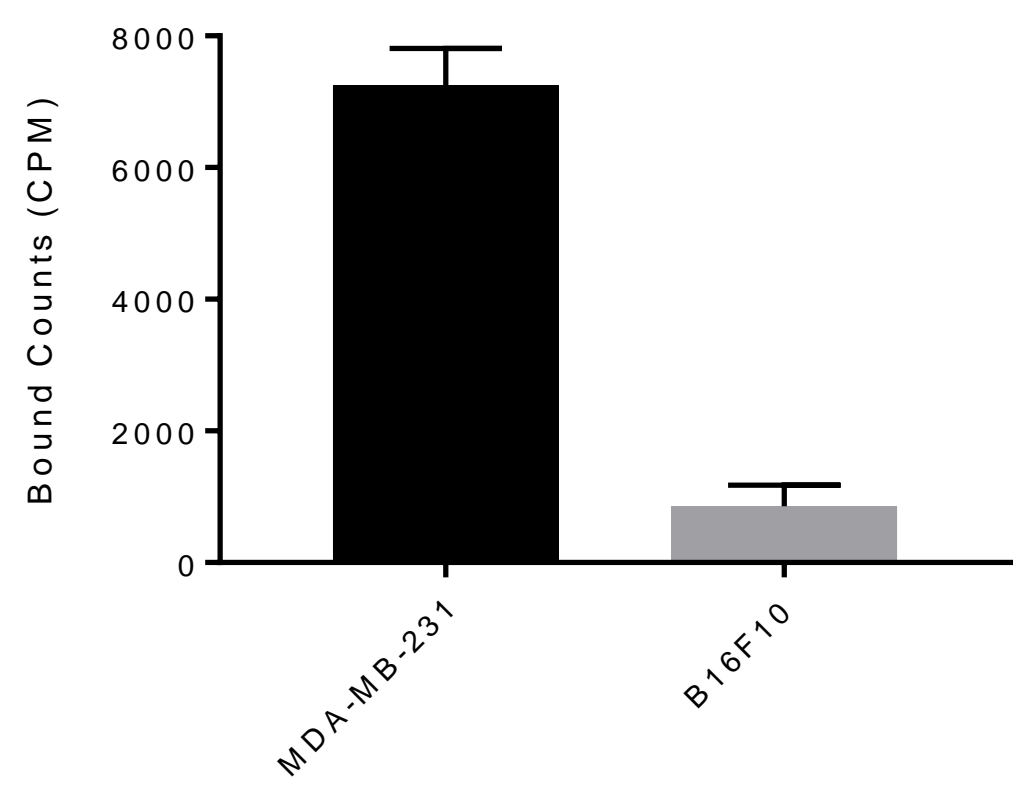

Figure 4.6: In vitro cell binding assay. The MDA-MB-231 human breast cancer and B16F10 mouse melanoma cells were incubated with 100,000 counts (cpm) of ${ }^{99 \mathrm{~m}} \mathrm{Tc}-9 \mathrm{C}$ labeled $\mathrm{scFv}$ for 1 hour. Following washing, bound ScFv was detected by gamma counter. Bars represent the mean of 3 replicates with standard deviation. 


\section{In vivo SPECT Imaging}

The binding capability of the ${ }^{99 \mathrm{~m}} \mathrm{Tc}$-labeled $9 \mathrm{C}$-scFv was explored in mice bearing MDA-MB-231 tumors. Full-body SPECT/CT images were acquired 4 hours after the i.v. injection of ${ }^{99 m} \mathrm{Tc}-\mathrm{scFv}$ via tail vein. The image revealed a moderate tumor uptake and significant accumulation in the liver and kidneys (Fig. 4.7). 


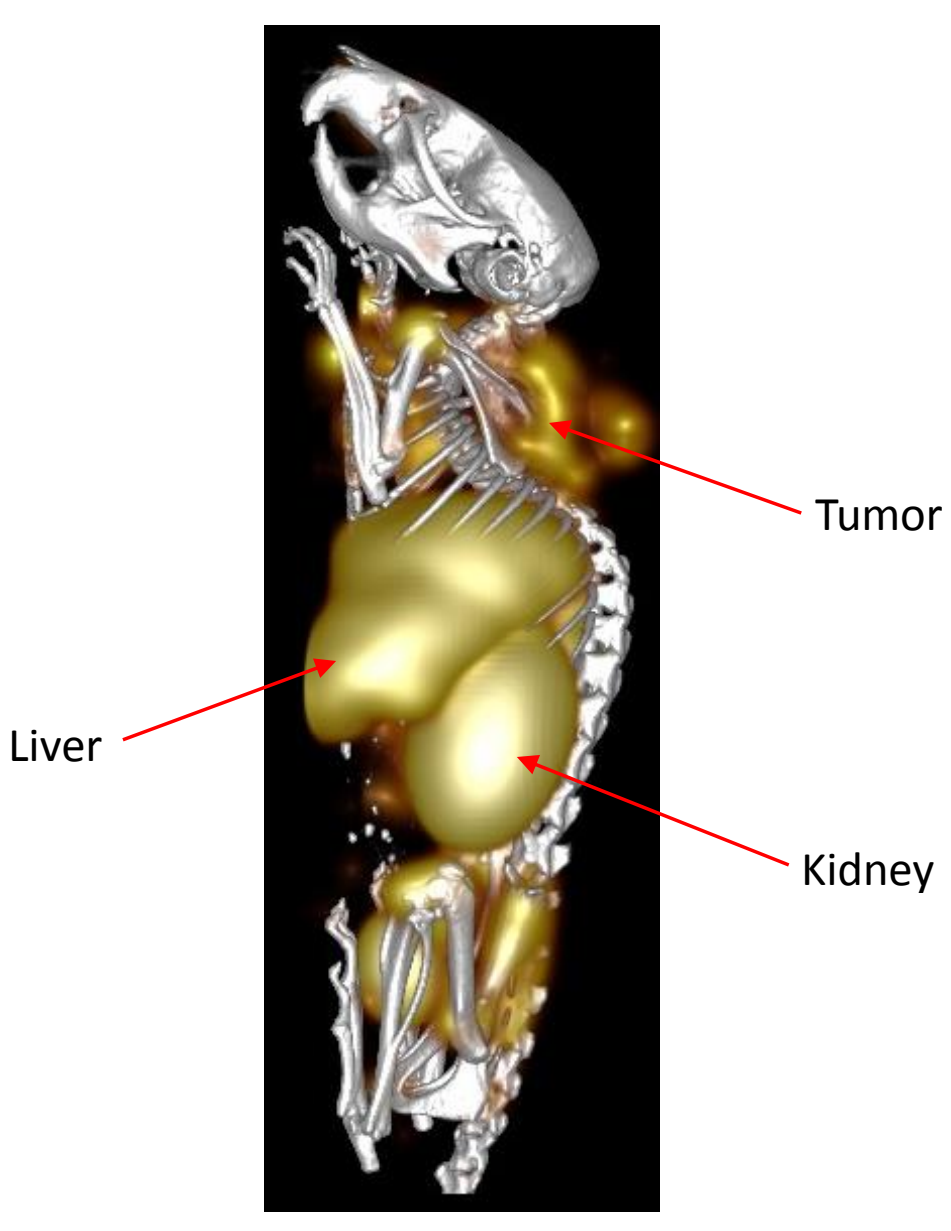

Figure 4.7: In vivo SPECT/CT imaging. A MDA-MB-231 tumor bearing mouse was injected with $300 \mu \mathrm{Ci}$ of ${ }^{99 \mathrm{~m}} \mathrm{Tc}-9 \mathrm{C}-\mathrm{scF} v$ via tail vein injection. The SPECT/CT image was acquired 4 hours post injection. 


\section{Discussion}

In this project, we described the selection and isolation of ThomsenFriedenreich (TF) specific scFv antibodies by phage display methodology. Two rounds of phage display selections were carried out using the McCafferty antibody library. In order to enrich the library towards the TF epitope, and not protein backbone, the library was exposed to two different TF presenting proteins during the selection process. Asialoglycophorin, which has 6 TF epitopes on its surface, was chosen for the first round as it displays TF in its natural conformation. The second round was carried out using TF-HSA, in which 20 TF molecules were chemically conjugated to human serum albumin. A total of 96 clones were randomly picked for the initial screening to identify TF-specific scFvs by phage ELISA. From these 96 clones, 5 clones were identified that displayed higher binding towards TF presenting targets (asialoglycophorin and asialofetuin)

over their non-TF presenting counterparts (glycophorin and fetuin). Because asialofetuin, which has 3 TF epitopes, was not used during the selection process, the higher signal-to-background ratios for asialofetuin over fetuin indicated that the selected antibodies were indeed recognizing the TF antigen and not binding to protein backbone. The Sanger sequence analysis of these 5 clones revealed that only one clone (9C) had an intact ScFv gene with both VH and VL domains present. The 9C-scFv clone was selected for large scale protein expression and further characterization.

The TF-specific 9C-scFv was expressed in E.coli and purified using a Nicolumn. The binding specificity of the purified $9 \mathrm{C}-\mathrm{scFv}$ was confirmed by ELISA 
using asialoglycophorin and asialofetuin as targets. The signal-to-background ratios of $>2$ confirmed that $9 \mathrm{C}$-scFv specifically recognized the TF epitope. The lower than expected signal-to-noise ratios in ELISA was likely due to monovalent scFv binding and the fact that TF is a very small epitope and there are only a few TF disaccharide molecules on the carrier protein molecule (6 per asialoglycophorin and 3 per asialofetuin molecule). The binding constant of 9CscFv was measured by microscale thermophoresis analysis. The 9C-scFv bound to the asialogycophorin with the binding affinity $\left(K_{d}\right)$ of $570 \pm 40 \mathrm{nM}$, while the $K_{d}$ for asialofetuin was found to be $860 \pm 70 \mathrm{nM}$ (Fig. 4.4). These values are consistent with previously published binding affinities for antibodies/peptides against carbohydrate antigens. $(155,163,166)$ In vitro cell binding analysis by flow cytometry asserted that $9 \mathrm{C}-\mathrm{scFv}$ recognized the TF antigen on the human breast cancer cell line MDA-MB-231, while it displayed minimal binding to the TFnegative B16F10 cells (Fig. 4.5)

The $9 \mathrm{C}-\mathrm{scFv}$ was radiolabeled with ${ }^{99 \mathrm{~m}} \mathrm{Tc}$ by directly conjugating ${ }^{99 \mathrm{~m}} \mathrm{Tc}$ to the C-terminal 6xHis-tag. Previously published reports suggested that every other histidine molecule in 6xHis-tag is involved in coordinating the ${ }^{99 \mathrm{~m}} \mathrm{Tc}$. (169171) Using this direct labeling approach, the $9 \mathrm{C}$-scFv was radiolabeled with a high labeling yield (> 93\%) and with high serum stability (> $98 \%$ after 4 hours). The in vitro cell binding analysis revealed that ${ }^{99 \mathrm{~m}} \mathrm{Tc}$-labeled $9 \mathrm{C}-\mathrm{scFv}$ bound to the TF displaying MDA-MB-231 cells significantly better than the B16F10, asserting that radiolabeling with ${ }^{99 \mathrm{~m}} \mathrm{Tc}$ did not affect the ability of the ${ }^{99 \mathrm{~m}} \mathrm{Tc}$ labeled 9C-scFv to recognize and bind to the TF antigen (Fig. 6). The ${ }^{99 m} \mathrm{Tc}$ - 
labeled 9C-scFv was administered in mice bearing MDA-MB-231 xenografts via tail vein and whole-body SPECT/CT images were acquired 4 hours post injection (Fig. 4.7). The SPECT images revealed that there was a moderate tumor uptake of ${ }^{99 \mathrm{~m}} \mathrm{Tc}$-labeled $9 \mathrm{C}$-scFv in vivo. However, images also showed a significant non-target accumulation in other body organs such as kidneys, liver, and stomach. The high kidney uptake can be attributed to the fact that scFv fragments clear out of body via kidneys.(51) The presence of positively charged histidine residues in the C-terminal tail of scFvs may also lead to non-specific binding of scFvs to the negatively charged kidney tubules.(173-175) Previously published reports also suggested that the $\mathrm{N}$-terminus His-tag and its subsequent radiolabeling with ${ }^{99 m} \mathrm{Tc}$ have been associated with significantly high liver uptake.(175-178) Taken together, these results demonstrated that even though 9C-scFv bound specifically to the TF epitope in vitro, it did not result in high contrast in vivo SPECT/CT images. There are number of strategies that may be utilized to improve the pharmacokinetics of these scFv fragments. To remove the influence of His-tag in high liver and kidney retentions, scFvs can be expressed and purified without any tags or with other tags such as FLAG tag or enzymatic removal of tag post purification. Alternatively, as described in Chapter 3, we can conjugate 9C-scFv to the ultrasmall silica particles and assess the difference in the biodistribution profile of the resulting nano-immunoconjugates.

In conclusion, here we described the identification of a ThomsenFriedenreich specific scFv fragment using phage display technology. The TF specific 9C-scFv clone was characterized in vitro for its Tf-specificity. The 9C- 
scFv was radiolabeled with ${ }^{99 \mathrm{~m}} \mathrm{Tc}$ and investigated in vivo for its SPECT/CT imaging properties in mice bearing human breast cancer xenografts. Even though ${ }^{99 m}$ Tc-labeled $9 \mathrm{C}-\mathrm{scFv}$ showed moderate tumor accumulation, there was also a significant non-specific retention in other major body organs. More work needs to be performed to alter the pharmacokinetics of the TF-specific $9 \mathrm{C}$-scFv to achieve high-contrast in vivo images. 


\section{REFERENCES}

1. Hussain, T.; Nguyen, Q. T., Molecular imaging for cancer diagnosis and surgery. Advanced drug delivery reviews 2014, 66, 90-100.

2. Weissleder, R., Molecular imaging in cancer. Science 2006, 312, 11681171.

3. Del Vecchio, S.; Zannetti, A.; Fonti, R.; Pace, L.; Salvatore, M., Nuclear imaging in cancer theranostics. The Quarterly Journal of Nuclear Medicine and Molecular Imaging 2007, 51, 152.

4. Kurdziel, K.; Ravizzini, G.; Croft, B.; Tatum, J.; Choyke, P.; Kobayashi, H., The evolving role of nuclear molecular imaging in cancer. Expert opinion on medical diagnostics 2008, 2, 829-842.

5. Mariani, G.; Bruselli, L.; Kuwert, T.; Kim, E. E.; Flotats, A.; Israel, O.; Dondi, M.; Watanabe, N., A review on the clinical uses of SPECT/CT. European journal of nuclear medicine and molecular imaging 2010, 37, 1959-1985.

6. Banerjee, S.; Pillai, M. R. A.; Ramamoorthy, N. In Evolution of Tc-99m in diagnostic radiopharmaceuticals, Seminars in nuclear medicine, Elsevier: 2001; pp 260-277.

7. Zolle, I., Technetium-99m pharmaceuticals. Springer: 2007.

8. Bailey, D. L.; Willowson, K. P., An evidence-based review of quantitative SPECT imaging and potential clinical applications. J Nucl Med 2013, 54, 83-89. 
9. Reddy, S.; Robinson, M. K. In Immuno-positron emission tomography in cancer models, Seminars in nuclear medicine, Elsevier: 2010; pp 182-189.

10. Alauddin, M. M., Positron emission tomography (PET) imaging with 18Fbased radiotracers. American journal of nuclear medicine and molecular imaging 2012, 2, 55.

11. Gambhir, S. S., Molecular imaging of cancer with positron emission tomography. Nature Reviews Cancer 2002, 2, 683.

12. Vaquero, J. J.; Kinahan, P., Positron emission tomography: current challenges and opportunities for technological advances in clinical and preclinical imaging systems. Annual review of biomedical engineering $2015,17,385-414$.

13. Wu, A. M.; Senter, P. D., Arming antibodies: prospects and challenges for immunoconjugates. Nature biotechnology 2005, 23, 1137.

14. Freise, A. C.; Wu, A. M., In vivo imaging with antibodies and engineered fragments. Molecular immunology 2015, 67, 142-152.

15. Wu, A. M., Engineered antibodies for molecular imaging of cancer. Methods 2014, 65, 139-147.

16. Gordon, L. I.; Witzig, T.; Molina, A.; Czuczman, M.; Emmanouilides, C.; Joyce, R.; Vo, K.; Theuer, C.; Pohlman, B.; Bartlett, N., ${ }^{90}$ Yttrium-labeled ibritumomab tiuxetan radioimmunotherapy produces high response rates and durable remissions in patients with previously treated B-cell lymphoma. Clinical lymphoma 2004, 5, 98-101.

17. Kaminski, M. S.; Tuck, M.; Estes, J.; Kolstad, A.; Ross, C. W.; Zasadny, 
K.; Regan, D.; Kison, P.; Fisher, S.; Kroll, S., ${ }^{131}$ I-tositumomab therapy as initial treatment for follicular lymphoma. New England Journal of Medicine 2005, 352, 441-449.

18. Boerman, O. C.; van Schaijk, F. G.; Oyen, W. J.; Corstens, F. H., Pretargeted radioimmunotherapy of cancer: progress step by step. Journal of Nuclear Medicine 2003, 44, 400.

19. Bailly, C.; Bodet-Milin, C.; Rousseau, C.; Faivre-Chauvet, A.; KraeberBodéré, F.; Barbet, J., Pretargeting for imaging and therapy in oncological nuclear medicine. EJNMMI radiopharmacy and chemistry 2017, 2, 6.

20. Knight, J. C.; Cornelissen, B., Bioorthogonal chemistry: implications for pretargeted nuclear (PET/SPECT) imaging and therapy. American journal of nuclear medicine and molecular imaging 2014, 4, 96.

21. Sletten, E. M.; Bertozzi, C. R., From mechanism to mouse: a tale of two bioorthogonal reactions. Accounts of chemical research 2011, 44, 666676.

22. Marik, J.; Sutcliffe, J. L., Click for PET: rapid preparation of [18F] fluoropeptides using Cul catalyzed 1, 3-dipolar cycloaddition. Tetrahedron Letters 2006, 47, 6681-6684.

23. Hausner, S. H.; Marik, J.; Gagnon, M. K. J.; Sutcliffe, J. L., In vivo positron emission tomography (PET) imaging with an av $\beta 6$ specific peptide radiolabeled using ${ }^{18} \mathrm{~F}$-"click" chemistry: evaluation and comparison with the corresponding 4-[18F] fluorobenzoyl-and 2-[18F] fluoropropionylpeptides. Journal of medicinal chemistry 2008, 51, 5901-5904. 
24. Li, Z.-B.; Wu, Z.; Chen, K.; Chin, F. T.; Chen, X., Click chemistry for ${ }^{18} \mathrm{~F}-$ labeling of RGD peptides and microPET imaging of tumor integrin $a v \beta 3$ expression. Bioconjugate chemistry 2007, 18, 1987-1994.

25. Lin, F. L.; Hoyt, H. M.; van Halbeek, H.; Bergman, R. G.; Bertozzi, C. R., Mechanistic investigation of the Staudinger ligation. Journal of the American Chemical Society 2005, 127, 2686-2695.

26. Vugts, D. J.; Vervoort, A.; Stigter-van Walsum, M.; Visser, G. W.; Robillard, M. S.; Versteegen, R. M.; Vulders, R. C.; Herscheid, J. D.; van Dongen, G. A., Synthesis of phosphine and antibody-azide probes for in vivo Staudinger ligation in a pretargeted imaging and therapy approach. Bioconjugate chemistry 2011, 22, 2072-2081.

27. Rossin, R.; Robillard, M. S., Pretargeted imaging using bioorthogonal chemistry in mice. Current opinion in chemical biology 2014, 21, 161-169.

28. Lee, S. B.; Kim, H. L.; Jeong, H. J.; Lim, S. T.; Sohn, M. H.; Kim, D. W., Mesoporous silica nanoparticle pretargeting for PET imaging based on a rapid bioorthogonal reaction in a living body. Angewandte Chemie 2013, $125,10743-10746$.

29. Blackman, M. L.; Royzen, M.; Fox, J. M., Tetrazine ligation: fast bioconjugation based on inverse-electron-demand Diels- Alder reactivity. Journal of the American Chemical Society 2008, 130, 13518-13519.

30. Rossin, R.; Renart Verkerk, P.; van den Bosch, S. M.; Vulders, R. C.; Verel, I.; Lub, J.; Robillard, M. S., In vivo chemistry for pretargeted tumor imaging in live mice. Angewandte Chemie 2010, 122, 3447-3450. 
31. Zeglis, B. M.; Sevak, K. K.; Reiner, T.; Mohindra, P.; Carlin, S. D.; Zanzonico, P.; Weissleder, R.; Lewis, J. S., A pretargeted PET imaging strategy based on bioorthogonal Diels-Alder click chemistry. Journal of nuclear medicine: official publication, Society of Nuclear Medicine 2013, $54,1389$.

32. Houghton, J. L.; Membreno, R.; Abdel-Atti, D.; Cunanan, K. M.; Carlin, S.; Scholz, W. W.; Zanzonico, P. B.; Lewis, J. S.; Zeglis, B. M., Establishment of the in vivo efficacy of pretargeted radioimmunotherapy utilizing inverse electron demand Diels-Alder click chemistry. Molecular cancer therapeutics 2017, 16, 124-133.

33. Wang, C. H.; Willis, D. L.; Loveland, W. D., Radiotracer methodology in the biological environmental, and physical sciences. 1975.

34. Kim, Y.-S.; Brechbiel, M. W., An overview of targeted alpha therapy. Tumor biology 2012, 33, 573-590.

35. Couturier, O.; Supiot, S.; Degraef-Mougin, M.; Faivre-Chauvet, A.; Carlier, T.; Chatal, J.-F.; Davodeau, F.; Cherel, M., Cancer radioimmunotherapy with alpha-emitting nuclides. European journal of nuclear medicine and molecular imaging 2005, 32, 601-614.

36. McDevitt, M. R.; Ma, D.; Lai, L. T.; Simon, J.; Borchardt, P.; Frank, R. K.; Wu, K.; Pellegrini, V.; Curcio, M. J.; Miederer, M., Tumor therapy with targeted atomic nanogenerators. Science 2001, 294, 1537-1540.

37. Su, F.-M.; Beaumier, P.; Axworthy, D.; Atcher, R.; Fritzberg, A., Pretargeted radioimmunotherapy in tumored mice using an in vivo 
212Pb/212Bi generator. Nuclear medicine and biology 2005, 32, 741-747.

38. Milenic, D. E.; Garmestani, K.; Brady, E. D.; Albert, P. S.; Ma, D.; Abdulla, A.; Brechbiel, M. W., a-Particle radioimmunotherapy of disseminated peritoneal disease using a ${ }^{212} \mathrm{~Pb}$-labeled radioimmunoconjugate targeting HER2. Cancer biotherapy \& radiopharmaceuticals 2005, 20, 557-568.

39. Miao, Y.; Hylarides, M.; Fisher, D. R.; Shelton, T.; Moore, H.; Wester, D. W.; Fritzberg, A. R.; Winkelmann, C. T.; Hoffman, T.; Quinn, T. P., Melanoma therapy via peptide-targeted a-radiation. Clinical cancer research 2005, 11, 5616-5621.

40. Tan, Z.; Chen, P.; Schneider, N.; Glover, S.; Cui, L.; Torgue, J.; Rixe, O.; Spitz, H. B.; Dong, Z., Significant systemic therapeutic effects of high-LET immunoradiation by ${ }^{212} \mathrm{~Pb}$-trastuzumab against prostatic tumors of androgen-independent human prostate cancer in mice. International journal of oncology 2012, 40, 1881-1888.

41. Chappell, L. L.; Dadachova, E.; Milenic, D. E.; Garmestani, K.; Wu, C.; Brechbiel, M. W., Synthesis, characterization, and evaluation of a novel bifunctional chelating agent for the lead isotopes ${ }^{203} \mathrm{~Pb}$ and ${ }^{212} \mathrm{~Pb}$. Nuclear medicine and biology 2000, 27, 93-100.

42. Milenic, D. E.; Garmestani, K.; Brady, E. D.; Albert, P. S.; Abdulla, A.; Flynn, J.; Brechbiel, M. W., Potentiation of high-LET radiation by gemcitabine: targeting HER2 with trastuzumab to treat disseminated peritoneal disease. Clinical Cancer Research 2007, 13, 1926-1935.

43. Milenic, D. E.; Garmestani, K.; Brady, E. D.; Baidoo, K. E.; Albert, P. S.; 
Wong, K. J.; Flynn, J.; Brechbiel, M. W., Multimodality therapy: potentiation of high linear energy transfer radiation with paclitaxel for the treatment of disseminated peritoneal disease. Clinical Cancer Research $2008,14,5108-5115$.

44. Meredith, R. F.; Torgue, J. J.; Rozgaja, T. A.; Banaga, E. P.; Bunch, P. W.; Alvarez, R. D.; Straughn Jr, J. M.; Dobelbower, M. C.; Lowy, A. M., Safety and outcome measures of first-in-human intraperitoneal $\alpha$ radioimmunotherapy with ${ }^{212} \mathrm{~Pb}-\mathrm{TCMC}$-trastuzumab. American journal of clinical oncology 2018, 41, 716.

45. Meredith, R.; Torgue, J.; Shen, S.; Fisher, D. R.; Banaga, E.; Bunch, P.; Morgan, D.; Fan, J.; Straughn Jr, J. M., Dose escalation and Dosimetry of first in human alpha radioimmunotherapy with ${ }^{212} \mathrm{~Pb}-\mathrm{TCMC}$-trastuzumab. Journal of nuclear medicine: official publication, Society of Nuclear Medicine 2014, 55, 1636.

46. Köhler, G.; Milstein, C., Continuous cultures of fused cells secreting antibody of predefined specificity. Nature 1975, 256, 495.

47. Schroeder Jr, H. W.; Cavacini, L., Structure and function of immunoglobulins. Journal of Allergy and Clinical Immunology 2010, 125, S41-S52.

48. Strohl, W. R., Optimization of Fc-mediated effector functions of monoclonal antibodies. Current opinion in biotechnology 2009, 20, 685691.

49. Holliger, P.; Hudson, P. J., Engineered antibody fragments and the rise of 
single domains. Nature biotechnology 2005, 23, 1126.

50. Nelson, A. L. In Antibody fragments: hope and hype, MAbs, Taylor \& Francis: 2010; pp 77-83.

51. Monnier, P.; Vigouroux, R.; Tassew, N., In vivo applications of single chain Fv (variable domain)(scFv) fragments. Antibodies 2013, 2, 193-208.

52. Reilly, R.; Maiti, P.; Kiarash, R.; Prashar, A.; Fast, D.; Entwistle, J.; Dan, M.; Narang, S.; Foote, S.; Kaplan, H., Rapid imaging of human melanoma xenografts using an scFv fragment of the human monoclonal antibody H11 labelled with ${ }^{111}$ In. Nuclear medicine communications 2001, 22, 587595.

53. Kobayashi, K.; Sasaki, T.; Takenaka, F.; Yakushiji, H.; Fujii, Y.; Kishi, Y.; Kita, S.; Shen, L.; Kumon, H.; Matsuura, E., A novel PET imaging using ${ }^{64} \mathrm{Cu}$-labeled monoclonal antibody against mesothelin commonly expressed on cancer cells. Journal of immunology research 2015, 2015.

54. Ueda, M.; Hisada, H.; Temma, T.; Shimizu, Y.; Kimura, H.; Ono, M.; Nakamoto, Y.; Togashi, K.; Saji, H., Gallium-68-labeled anti-HER2 singlechain Fv fragment: development and in vivo monitoring of HER2 expression. Molecular imaging and biology 2015, 17, 102-110.

55. Berndorff, D.; Borkowski, S.; Moosmayer, D.; Viti, F.; Muller-Tiemann, B.; Sieger, S.; Friebe, M.; Hilger, C. S.; Zardi, L.; Neri, D., Imaging of Tumor Angiogenesis Using ${ }^{99 m}$ Tc-Labeled Human Recombinant Anti-ED-B Fibronectin Antibody Fragments. Journal of nuclear medicine 2006, 47, 1707. 
56. Smith, G. P., Filamentous fusion phage: novel expression vectors that display cloned antigens on the virion surface. Science 1985, 228, 13151317.

57. McCafferty, J.; Griffiths, A. D.; Winter, G.; Chiswell, D. J., Phage antibodies: filamentous phage displaying antibody variable domains. nature 1990, 348, 552.

58. Scarselli, E.; Esposito, G.; Traboni, C., Receptor phage: display of functional domains of the human high affinity $\operatorname{lgE}$ receptor on the $\mathrm{M} 13$ phage surface. FEBS letters 1993, 329, 223-226.

59. McCafferty, J.; Jackson, R. H.; Chiswell, D. J., Phage-enzymes: expression and affinity chromatography of functional alkaline phosphatase on the surface of bacteriophage. Protein Engineering, Design and Selection 1991, 4, 955-961.

60. Crameri, R.; Suter, M., Display of biologically active proteins on the surface of filamentous phages: a cDNA cloning system for selection of functional gene products linked to the genetic information responsible for their production. Gene 1993, 137, 69-75.

61. Barbas, C. F.; Kang, A. S.; Lerner, R. A.; Benkovic, S. J., Assembly of combinatorial antibody libraries on phage surfaces: the gene III site. Proceedings of the National Academy of Sciences 1991, 88, 7978-7982.

62. Clackson, T.; Hoogenboom, H. R.; Griffiths, A. D.; Winter, G., Making antibody fragments using phage display libraries. Nature 1991, 352, 624.

63. Griffiths, A. D.; Williams, S. C.; Hartley, O.; Tomlinson, I.; Waterhouse, P.; 
Crosby, W. L.; Kontermann, R.; Jones, P.; Low, N.; Allison, T. a., Isolation of high affinity human antibodies directly from large synthetic repertoires. The EMBO journal 1994, 13, 3245-3260.

64. Hoogenboom, H. R.; de Bruïne, A. P.; Hufton, S. E.; Hoet, R. M.; Arends, J.-W.; Roovers, R. C., Antibody phage display technology and its applications. Immunotechnology 1998, 4, 1-20.

65. Schofield, D. J.; Pope, A. R.; Clementel, V.; Buckell, J.; Chapple, S. D.; Clarke, K. F.; Conquer, J. S.; Crofts, A. M.; Crowther, S. R.; Dyson, M. R., Application of phage display to high throughput antibody generation and characterization. Genome biology 2007, 8, R254.

66. Goletz, S.; Christensen, P. A.; Kristensen, P.; Blohm, D.; Tomlinson, I.; Winter, G.; Karsten, U., Selection of large diversities of antiidiotypic antibody fragments by phage display1. Journal of molecular biology 2002, $315,1087-1097$.

67. Kristensen, P.; Winter, G., Proteolytic selection for protein folding using filamentous bacteriophages. Folding and Design 1998, 3, 321-328.

68. Vaughan, T. J.; Williams, A. J.; Pritchard, K.; Osbourn, J. K.; Pope, A. R.; Earnshaw, J. C.; McCafferty, J.; Hodits, R. A.; Wilton, J.; Johnson, K. S., Human antibodies with sub-nanomolar affinities isolated from a large nonimmunized phage display library. Nature biotechnology 1996, 14, 309-314.

69. Sheets, M. D.; Amersdorfer, P.; Finnern, R.; Sargent, P.; Lindqvist, E.; Schier, R.; Hemingsen, G.; Wong, C.; Gerhart, J. C.; Marks, J. D., Efficient construction of a large nonimmune phage antibody library: the production 
of high-affinity human single-chain antibodies to protein antigens. Proceedings of the National Academy of Sciences 1998, 95, 6157-6162.

70. Pavoni, E.; Flego, M.; Dupuis, M. L.; Barca, S.; Petronzelli, F.; Anastasi, A. M.; D'Alessio, V.; Pelliccia, A.; Vaccaro, P.; Monteriù, G., Selection, affinity maturation, and characterization of a human scFv antibody against CEA protein. BMC cancer 2006, 6, 41 .

71. Nagase, H.; Visse, R.; Murphy, G., Structure and function of matrix metalloproteinases and TIMPs. Cardiovascular research 2006, 69, 562573.

72. Itoh, Y.; Nagase, H., Matrix metalloproteinases in cancer. Essays in biochemistry 2002, 38, 21-36.

73. Page-McCaw, A.; Ewald, A. J.; Werb, Z., Matrix metalloproteinases and the regulation of tissue remodelling. Nature reviews Molecular cell biology 2007, 8, 221.

74. Newby, A. C., Dual role of matrix metalloproteinases (matrixins) in intimal thickening and atherosclerotic plaque rupture. Physiological reviews 2005, $85,1-31$.

75. Shah, P. K., Inflammation, metalloproteinases, and increased proteolysis: an emerging pathophysiological paradigm in aortic aneurysm. Circulation $1997,96,2115-2117$.

76. Burrage, P. S.; Mix, K. S.; Brinckerhoff, C. E., Matrix metalloproteinases: role in arthritis. Front Biosci 2006, 11, 529-543.

77. Gialeli, C.; Theocharis, A. D.; Karamanos, N. K., Roles of matrix 
metalloproteinases in cancer progression and their pharmacological targeting. The FEBS journal 2011, 278, 16-27.

78. Jabłońska-Trypuć, A.; Matejczyk, M.; Rosochacki, S., Matrix metalloproteinases (MMPs), the main extracellular matrix (ECM) enzymes in collagen degradation, as a target for anticancer drugs. Journal of enzyme inhibition and medicinal chemistry 2016, 31, 177-183.

79. Yadav, L.; Puri, N.; Rastogi, V.; Satpute, P.; Ahmad, R.; Kaur, G., Matrix metalloproteinases and cancer-roles in threat and therapy. Asian Pac $J$ Cancer Prev 2014, 15, 1085-1091.

80. Werb, Z.; Gordon, S., Elastase secretion by stimulated macrophages. Characterization and regulation. Journal of Experimental Medicine 1975, 142, 361-377.

81. Johnson, J. L.; Devel, L.; Czarny, B.; George, S. J.; Jackson, C. L.; Rogakos, V.; Beau, F.; Yiotakis, A.; Newby, A. C.; Dive, V., A selective matrix metalloproteinase-12 inhibitor retards atherosclerotic plaque development in apolipoprotein E-knockout mice. Arteriosclerosis, thrombosis, and vascular biology 2011, 31, 528-535.

82. Hunninghake, G. M.; Cho, M. H.; Tesfaigzi, Y.; Soto-Quiros, M. E.; Avila, L.; Lasky-Su, J.; Stidley, C.; Melén, E.; Söderhäll, C.; Hallberg, J., MMP12, lung function, and COPD in high-risk populations. New England Journal of Medicine 2009, 361, 2599-2608.

83. Wang, X.; Liang, J.; Koike, T.; Sun, H.; Ichikawa, T.; Kitajima, S.; Morimoto, M.; Shikama, H.; Watanabe, T.; Sasaguri, Y., Overexpression 
of human matrix metalloproteinase-12 enhances the development of inflammatory arthritis in transgenic rabbits. The American journal of pathology 2004, 165, 1375-1383.

84. Longo, G. M.; Buda, S. J.; Fiotta, N.; Xiong, W.; Griener, T.; Shapiro, S.; Baxter, B. T., MMP-12 has a role in abdominal aortic aneurysms in mice. Surgery 2005, 137, 457-462.

85. Ella, E.; Harel, Y.; Abraham, M.; Wald, H.; Benny, O.; Karsch-Bluman, A.; Vincent, D.; Laurent, D.; Amir, G.; Izhar, U., Matrix metalloproteinase 12 promotes tumor propagation in the lung. The Journal of thoracic and cardiovascular surgery 2018, 155, 2164-2175. e2161.

86. Lv, F.; Wang, J.; Wu, Y.; Chen, H.; Shen, X., Knockdown of MMP12 inhibits the growth and invasion of lung adenocarcinoma cells. International journal of immunopathology and pharmacology 2015, 28, 7784.

87. Heller, T.; Hennecke, M.; Baumann, U.; Gessner, J. E.; zu Vilsendorf, A. M.; Baensch, M.; Boulay, F.; Kola, A.; Klos, A.; Bautsch, W., Selection of a C5a receptor antagonist from phage libraries attenuating the inflammatory response in immune complex disease and ischemia/reperfusion injury. The Journal of Immunology 1999, 163, 985-994.

88. Choudhry, V.; Zhang, M.-Y.; Sidorov, I. A.; Louis, J. M.; Harris, I.; Dimitrov, A. S.; Bouma, P.; Cham, F.; Choudhary, A.; Rybak, S. M., Cross-reactive HIV-1 neutralizing monoclonal antibodies selected by screening of an immune human phage library against an envelope glycoprotein (gp140) 
isolated from a patient (R2) with broadly HIV-1 neutralizing antibodies. Virology 2007, 363, 79-90.

89. Jung, S.; Honegger, A.; PluÈckthun, A., Selection for improved protein stability by phage display1. Journal of molecular biology 1999, 294, 163180.

90. Frenzel, A.; Schirrmann, T.; Hust, M. In Phage display-derived human antibodies in clinical development and therapy, MAbs, Taylor \& Francis: 2016; pp 1177-1194.

91. Turner, S. Humira: the highs and lows of the world's best-selling drug. https://www.pharmaceutical-technology.com/features/humira-abbvie-drug/ (accessed November 12, 2018).

92. Sharkey, R. M.; Goldenberg, D. M., Cancer radioimmunotherapy. Immunotherapy 2011, 3, 349-370.

93. Larson, S. M.; Carrasquillo, J. A.; Cheung, N.-K. V.; Press, O. W., Radioimmunotherapy of human tumours. Nature Reviews Cancer 2015, 15, 347.

94. Wang, W.; Wang, E.; Balthasar, J., Monoclonal antibody pharmacokinetics and pharmacodynamics. Clinical Pharmacology \& Therapeutics 2008, 84, $548-558$.

95. Pouget, J.-P.; Navarro-Teulon, I.; Bardiès, M.; Chouin, N.; Cartron, G.; Pèlegrin, A.; Azria, D., Clinical radioimmunotherapy-the role of radiobiology. Nature reviews Clinical oncology 2011, 8, 720.

96. Boswell, C. A.; Brechbiel, M. W., Development of radioimmunotherapeutic 
and diagnostic antibodies: an inside-out view. Nuclear medicine and biology 2007, 34, 757-778.

97. Patra, M.; Zarschler, K.; Pietzsch, H.-J.; Stephan, H.; Gasser, G., New insights into the pretargeting approach to image and treat tumours. Chemical Society Reviews 2016, 45, 6415-6431.

98. Goldenberg, D. M.; Sharkey, R. M.; Paganelli, G.; Barbet, J.; Chatal, J.-F., Antibody pretargeting advances cancer radioimmunodetection and radioimmunotherapy. Journal of Clinical Oncology 2006, 24, 816.

99. Stickney, D. R.; Anderson, L. D.; Slater, J. B.; Ahlem, C. N.; Kirk, G. A.; Schweighardt, S. A.; Frincke, J. M., Bifunctional antibody: a binary radiopharmaceutical delivery system for imaging colorectal carcinoma. Cancer research 1991, 51, 6650-6655.

100. Kalofonos, H.; Rusckowski, M.; Siebecker, D.; Sivolapenko, G.; Snook, D.; Lavender, J.; Epenetos, A.; Hnatowich, D., Imaging of tumor in patients with indium-111-labeled biotin and streptavidin-conjugated antibodies: preliminary communication. Journal of nuclear medicine: official publication, Society of Nuclear Medicine 1990, 31, 1791-1796.

101. Weiden, P. L.; Breitz, H. B.; Press, O.; Appelbaum, J. W.; Bryan, J. K.; Gaffigan, S.; Stone, D.; Axworthy, D.; Fisher, D.; Reno, J., Pretargeted radioimmunotherapy (PRIT ${ }^{\mathrm{TM}}$ ) for treatment of non-Hodgkin's lymphoma (NHL): initial phase I/II study results. Cancer biotherapy \& radiopharmaceuticals 2000, 15, 15-29.

102. Liu, G.; Dou, S.; Liu, Y.; Wang, Y.; Rusckowski, M.; Hnatowich, D. J., 90Y 
labeled phosphorodiamidate morpholino oligomer for pretargeting radiotherapy. Bioconjugate chemistry 2011, 22, 2539-2545.

103. Bagshawe, K. D., Antibody-directed enzyme prodrug therapy (ADEPT) for cancer. Expert review of anticancer therapy 2006, 6, 1421-1431.

104. Sletten, E. M.; Bertozzi, C. R., Bioorthogonal chemistry: fishing for selectivity in a sea of functionality. Angewandte Chemie International Edition 2009, 48, 6974-6998.

105. Rossin, R.; Lappchen, T.; van den Bosch, S. M.; Laforest, R.; Robillard, M. S., Diels-Alder reaction for tumor pretargeting: in vivo chemistry can boost tumor radiation dose compared with directly labeled antibody. J Nucl Med 2013, 54, 1989-1995.

106. Rossin, R.; van den Bosch, S. M.; ten Hoeve, W.; Carvelli, M.; Versteegen, R. M.; Lub, J.; Robillard, M. S., Highly reactive transcyclooctene tags with improved stability for Diels-Alder chemistry in living systems. Bioconjugate chemistry 2013, 24, 1210-1217.

107. Rossin, R.; van Duijnhoven, S. M.; Läppchen, T.; van den Bosch, S. M.; Robillard, M. S., Trans-Cyclooctene tag with improved properties for tumor pretargeting with the Diels-Alder reaction. Molecular pharmaceutics 2014, 11, 3090-3096.

108. Houghton, J. L.; Zeglis, B. M.; Abdel-Atti, D.; Sawada, R.; Scholz, W. W.; Lewis, J. S., Pretargeted immuno-PET of pancreatic cancer: overcoming circulating antigen and internalized antibody to reduce radiation doses. Journal of nuclear medicine: official publication, Society of Nuclear 
Medicine 2016, 57, 453.

109. Gulston, M.; de Lara, C.; Jenner, T.; Davis, E.; O’Neill, P., Processing of clustered DNA damage generates additional double-strand breaks in mammalian cells post-irradiation. Nucleic acids research 2004, 32, $1602-$ 1609.

110. Yong, K. J.; Milenic, D. E.; Baidoo, K. E.; Brechbiel, M. W., ${ }^{212} \mathrm{~Pb}-$ Radioimmnotherapy induces G2 cell cycle arrest and delays DNA damage repair in tumor xenografts in a model for disseminated intraperitoneal disease. Molecular cancer therapeutics 2012, molcanther. 0671.2011.

111. Yong, K.; Brechbiel, M. W., Towards translation of ${ }^{212} \mathrm{~Pb}$ as a clinical therapeutic; getting the lead in! Dalton Transactions 2011, 40, 6068-6076.

112. Milenic, D. E.; Garmestani, K.; Brady, E. D.; Albert, P. S.; Ma, D.; Abdulla, A.; Brechbiel, M. W., a-Particle radioimmunotherapy of disseminated peritoneal disease using a 212Pb-labeled radioimmunoconjugate targeting HER2. Cancer biotherapy \& radiopharmaceuticals 2005, 20, 557-568.

113. Horak, E.; Hartmann, F.; Garmestani, K.; Wu, C.; Brechbiel, M.; Gansow, O. A.; Landolfi, N. F.; Waldmann, T. A., Radioimmunotherapy targeting of HER2/neu oncoprotein on ovarian tumor using lead-212-DOTA-AEl. Journal of Nuclear Medicine 1997, 38, 1944-1950.

114. Price, E. W.; Orvig, C., Matching chelators to radiometals for radiopharmaceuticals. Chemical Society Reviews 2014, 43, 260-290.

115. Mirzadeh, S.; Kumar, K.; Gansow, O. A., The chemical fate of ${ }^{212} \mathrm{Bi}$-DOTA formed by $\beta$-decay of ${ }^{212} \mathrm{~Pb}$ (DOTA) 2. Radiochimica Acta 1993, 60, 1-10. 
116. Beatty, B. G.; Kuhn, J. A.; Edmond Hui, T.; Fisher, D. R.; Williams, L. E.; David Beatty, J., Application of the cross-organ beta dose method for tissue dosimetry in tumor-bearing mice treated with a ${ }^{90} \mathrm{Y}$-labeled immunoconjugate. Cancer 1994, 73, 958-965.

117. Howell, R. W.; Goddu, S. M.; Narra, V. R.; Fisher, D. R.; Schenter, R. E.; Rao, D. V., Radiotoxicity of gadolinium-148 and radium-223 in mouse testes: relative biological effectiveness of alpha-particle emitters in vivo. Radiation research 1997, 147, 342-348.

118. Shen, S.; Forero, A.; LoBuglio, A. F.; Breitz, H.; Khazaeli, M.; Fisher, D. R.; Wang, W.; Meredith, R. F., Patient-specific dosimetry of pretargeted radioimmunotherapy using CC49 fusion protein in patients with gastrointestinal malignancies. Journal of Nuclear Medicine 2005, 46, 642651.

119. Pagel, J. M.; Kenoyer, A. L.; Bäck, T.; Hamlin, D. K.; Wilbur, D. S.; Fisher, D. R.; Park, S. I.; Frayo, S.; Axtman, A.; Orgun, N., Anti-CD45 pretargeted radioimmunotherapy using bismuth-213: high rates of complete remission and long-term survival in a mouse myeloid leukemia xenograft model. Blood 2011, blood-2011-2004-347039.

120. Orozco, J. J.; Bäck, T.; Kenoyer, A.; Balkin, E. R.; Hamlin, D. K.; Wilbur, D. S.; Fisher, D. R.; Frayo, S. L.; Hylarides, M. D.; Green, D. J., Anti-CD45 radioimmunotherapy using $211 \mathrm{At}$ with bone marrow transplantation prolongs survival in a disseminated murine leukemia model. Blood 2013, blood-2012-2011-467035. 
121. American Cancer Societry. Cancer Facts \& Figures 2018. ; American Cancer Society: 2018.

122. Werb, Z.; Gordon, S., Elastase secretion by stimulated macrophages. Characterization and regulation. Journal of Experimental Medicine 1975, 142, 361-377.

123. Chen, Y. E., MMP-12, an old enzyme plays a new role in the pathogenesis of rheumatoid arthritis? The American journal of pathology 2004, 165, 1069-1070.

124. Gronski, T. J.; Martin, R. L.; Kobayashi, D. K.; Walsh, B. C.; Holman, M. C.; Huber, M.; Van Wart, H. E.; Shapiro, S. D., Hydrolysis of a broad spectrum of extracellular matrix proteins by human macrophage elastase. Journal of Biological Chemistry 1997, 272, 12189-12194.

125. ASHWORTH, J. L.; MURPHY, G.; SHERRATT, M. J.; SHAPIRO, S. D.; SHUTTLEWORTH, C. A.; KIELTY, C. M., Fibrillin degradation by matrix metalloproteinases: implications for connective tissue remodelling. Biochemical Journal 1999, 340, 171-181.

126. Ohbayashi, H., Matrix metalloproteinases in lung diseases. Current Protein and Peptide Science 2002, 3, 409-421.

127. Johnson, J. L.; Devel, L.; Czarny, B.; George, S. J.; Jackson, C. L.; Rogakos, V.; Beau, F.; Yiotakis, A.; Newby, A. C.; Dive, V., A selective matrix metalloproteinase-12 inhibitor retards atherosclerotic plaque development in apolipoprotein E-knockout mice. Arteriosclerosis, thrombosis, and vascular biology 2011, 31, 528-535. 
128. Razavian, M.; Bordenave, T.; Georgiadis, D.; Beau, F.; Zhang, J.; Golestani, R.; Toczek, J.; Jung, J.-J.; Ye, Y.; Kim, H.-Y., Optical imaging of MMP-12 active form in inflammation and aneurysm. Scientific reports $2016,6,38345$.

129. Lim, N. H.; Meinjohanns, E.; Bou-Gharios, G.; Gompels, L. L.; Nuti, E.; Rossello, A.; Devel, L.; Dive, V.; Meldal, M.; Nagase, H., In vivo imaging of matrix metalloproteinase 12 and matrix metalloproteinase 13 activities in the mouse model of collagen-induced arthritis. Arthritis \& Rheumatology $2014,66,589-598$.

130. Bordenave, T.; Helle, M.; Beau, F.; Georgiadis, D.; Tepshi, L.; Bernes, M.; Ye, Y.; Levenez, L.; Poquet, E.; Nozach, H., Synthesis and in vitro and in vivo evaluation of MMP-12 selective optical probes. Bioconjugate chemistry 2016, 27, 2407-2417.

131. Shah, S. A.; Spinale, F. G.; Ikonomidis, J. S.; Stroud, R. E.; Chang, E. I.; Reed, C. E., Differential matrix metalloproteinase levels in adenocarcinoma and squamous cell carcinoma of the lung. The Journal of thoracic and cardiovascular surgery 2010, 139, 984-990.

132. KerkelaĖ, E.; Ala-aho, R.; Jeskanen, L.; Rechardt, O.; Grénman, R.; Shapiro, S. D.; KaĖhaÈri, V.-M.; Saarialho-Kere, U., Expression of human macrophage metalloelastase (MMP-12) by tumor cells in skin cancer. Journal of Investigative Dermatology 2000, 114, 1113-1119.

133. Kerkelä, E.; Ala-aho, R.; Klemi, P.; Grénman, S.; Shapiro, S. D.; Kähäri, V. M.; Saarialho-Kere, U., Metalloelastase (MMP-12) expression by tumour 
cells in squamous cell carcinoma of the vulva correlates with invasiveness, while that by macrophages predicts better outcome. The Journal of pathology 2002, 198, 258-269.

134. Hofmann, H.-S.; Hansen, G.; Richter, G.; Taege, C.; Simm, A.; Silber, R.E.; Burdach, S., Matrix metalloproteinase-12 expression correlates with local recurrence and metastatic disease in non-small cell lung cancer patients. Clinical Cancer Research 2005, 11, 1086-1092.

135. Cho, N. H.; Hong, K. P.; Hong, S. H.; Kang, S.; Chung, K. Y.; Cho, S. H., MMP expression profiling in recurred stage IB lung cancer. Oncogene $2004,23,845$.

136. Qu, P.; Du, H.; Wang, X.; Yan, C., Matrix metalloproteinase 12 overexpression in lung epithelial cells plays a key role in emphysema to lung bronchioalveolar adenocarcinoma transition. Cancer research 2009, $69,7252-7261$.

137. Yu, M. K.; Park, J.; Jon, S., Targeting strategies for multifunctional nanoparticles in cancer imaging and therapy. Theranostics 2012, 2, 3.

138. Byrne, J. D.; Betancourt, T.; Brannon-Peppas, L., Active targeting schemes for nanoparticle systems in cancer therapeutics. Advanced drug delivery reviews 2008, 60, 1615-1626.

139. Yao, V. J.; D'angelo, S.; Butler, K. S.; Theron, C.; Smith, T. L.; Marchiò, S.; Gelovani, J. G.; Sidman, R. L.; Dobroff, A. S.; Brinker, C. J., Ligandtargeted theranostic nanomedicines against cancer. Journal of Controlled Release 2016, 240, 267-286. 
140. Bahrami, B.; Hojjat-Farsangi, M.; Mohammadi, H.; Anvari, E.; Ghalamfarsa, G.; Yousefi, M.; Jadidi-Niaragh, F., Nanoparticles and targeted drug delivery in cancer therapy. Immunology letters 2017, 190, 64-83.

141. Ma, K.; Mendoza, C.; Hanson, M.; Werner-Zwanziger, U.; Zwanziger, J.; Wiesner, U., Control of ultrasmall sub-10 nm ligand-functionalized fluorescent core-shell silica nanoparticle growth in water. Chemistry of Materials 2015, 27, 4119-4133.

142. Ma, K.; Wiesner, U., Modular and Orthogonal Post-Pegylation Surface Modifications by Insertion Enabling Penta-Functional Ultrasmall OrganicSilica Hybrid Nanoparticles. Chemistry of Materials 2017, 29, 6840-6855.

143. Chen, F.; Ma, K.; Madajewski, B.; Zhuang, L.; Zhang, L.; Rickert, K.; Marelli, M.; Yoo, B.; Turker, M. Z.; Overholtzer, M., Ultrasmall targeted nanoparticles with engineered antibody fragments for imaging detection of HER2-overexpressing breast cancer. Nature communications 2018, 9, 4141.

144. Chen, F.; Zhang, X.; Ma, K.; Madajewski, B.; Benezra, M.; Zhang, L.; Phillips, E.; Turker, M. Z.; Gallazzi, F.; Penate-Medina, O., Melanocortin-1 receptor-targeting ultrasmall silica nanoparticles for dual-modality human melanoma imaging. ACS applied materials \& interfaces 2018, 10, 43794393.

145. Benezra, M.; Penate-Medina, O.; Zanzonico, P. B.; Schaer, D.; Ow, H.; Burns, A.; DeStanchina, E.; Longo, V.; Herz, E.; lyer, S., Multimodal silica 
nanoparticles are effective cancer-targeted probes in a model of human melanoma. The Journal of clinical investigation 2011, 121, 2768-2780.

146. Bradbury, M. S.; Phillips, E.; Montero, P. H.; Cheal, S. M.; Stambuk, H.; Durack, J. C.; Sofocleous, C. T.; Meester, R. J.; Wiesner, U.; Patel, S., Clinically-translated silica nanoparticles as dual-modality cancer-targeted probes for image-guided surgery and interventions. Integrative Biology $2013,5,74-86$.

147. Phillips, E.; Penate-Medina, O.; Zanzonico, P. B.; Carvajal, R. D.; Mohan, P.; Ye, Y.; Humm, J.; Gönen, M.; Kalaigian, H.; Schöder, H., Clinical translation of an ultrasmall inorganic optical-PET imaging nanoparticle probe. Science translational medicine 2014, 6, 260ra149-260ra149.

148. David, L.; Nesland, J.; Clausen, H.; Carneiro, F.; Sobrinho-Simoes, M., Simple mucin-type carbohydrate antigens ( $T n$, sialosyl-Tn and $T)$ in gastric mucosa, carcinomas and metastases. APMIS. Supplementum 1992, 27, 162-172.

149. Baldus, S. E.; Zirbes, T. K.; Hanisch, F. G.; Kunze, D.; Shafizadeh, S. T.; Nolden, S.; Mönig, S. P.; Schneider, P. M.; Karsten, U.; Thiele, J., Thomsen-Friedenreich antigen presents as a prognostic factor in colorectal carcinoma: A clinicopathologic study of 264 patients. Cancer $2000,88,1536-1543$.

150. Yu, L.-G., The oncofetal Thomsen-Friedenreich carbohydrate antigen in cancer progression. Glycoconjugate journal 2007, 24, 411-420.

151. Almogren, A.; Abdullah, J.; Ghapure, K.; Ferguson, K.; Glinsky, V. V.; 
Rittenhouse-Olson, K., Anti-Thomsen-Friedenreich-Ag (anti-TF-Ag) potential for cancer therapy. Front Biosci (Schol Ed) 2012, 4, 840-863.

152. Cazet, A.; Julien, S.; Bobowski, M.; Burchell, J.; Delannoy, P., Tumourassociated carbohydrate antigens in breast cancer. Breast cancer research 2010, 12, 204.

153. Glinsky, V. V.; Glinsky, G. V.; Rittenhouse-Olson, K.; Huflejt, M. E.; Glinskii, O. V.; Deutscher, S. L.; Quinn, T. P., The role of ThomsenFriedenreich antigen in adhesion of human breast and prostate cancer cells to the endothelium. Cancer research 2001, 61, 4851-4857.

154. Glinsky, V. V.; Glinsky, G. V.; Glinskii, O. V.; Huxley, V. H.; Turk, J. R.; Mossine, V. V.; Deutscher, S. L.; Pienta, K. J.; Quinn, T. P., Intravascular metastatic cancer cell homotypic aggregation at the sites of primary attachment to the endothelium. Cancer research 2003, 63, 3805-3811.

155. Peletskaya, E. N.; Glinsky, V. V.; Glinsky, G. V.; Deutscher, S. L.; Quinn, T. P., Characterization of peptides that bind the tumor-associated Thomsen-Friedenreich antigen selected from bacteriophage display libraries 1. Journal of molecular biology 1997, 270, 374-384.

156. Glinsky, V. V.; Huflejt, M. E.; Glinsky, G. V.; Deutscher, S. L.; Quinn, T. P., Effects of Thomsen-Friedenreich antigen-specific peptide P-30 on $\beta$ galactoside-mediated homotypic aggregation and adhesion to the endothelium of MDA-MB-435 human breast carcinoma cells. Cancer research 2000, 60, 2584-2588.

157. Landon, L. A.; Peletskaya, E. N.; Glinsky, V. V.; Karasseva, N.; Quinn, T. 
P.; Deutscher, S. L., Combinatorial evolution of high-affinity peptides that bind to the Thomsen-Friedenreich carcinoma antigen. Journal of protein chemistry 2003, 22, 193-204.

158. Kumar, S. R.; Gallazzi, F. A.; Quinn, T. P.; Deutscher, S. L., 64Cu-labeled peptide for PET of breast carcinomas expressing the thomsen-friedenreich carbohydrate antigen. Journal of Nuclear Medicine 2011, 52, 1819.

159. Karsten, U.; BUTSCHAK, G.; Cao, Y.; GOLETZ, S.; HANISCH, F.-G., A New Monoclonal Antibody (A78-G/A7) to the Thomsen-Friedenreich Pan-Tumor Antigen. Hybridoma 1995, 14, 37-44.

160. Butschak, G.; Karsten, U., Isolation and characterization of ThomsenFriedenreich-specific antibodies from human serum. Tumor biology 2002, 23, 113-122.

161. Dahlenborg, K.; Hultman, L.; Carlsson, R.; Jansson, B., Human monoclonal antibodies specific for the tumour associated ThomsenFriedenreich antigen. International journal of cancer 1997, 70, 63-71.

162. Jain, R. K., Delivery of novel therapeutic agents in tumors: physiological barriers and strategies. JNCl: Journal of the National Cancer Institute $1989,81,570-576$.

163. Rittenhouse-Diakun, K.; Xia, Z.; Pickhardt, D.; Morey, S.; Baek, M.-G.; Roy, R., Development and Characterization of Monoclonal Antibody to TAntigen:(Galßl—3GalNAc-a-O). Hybridoma 1998, 17, 165-173.

164. Heimburg, J.; Yan, J.; Morey, S.; Glinskii, O. V.; Huxley, V. H.; Wild, L.; Klick, R.; Roy, R.; Glinsky, V. V.; Rittenhouse-Olson, K., Inhibition of 
Spontaneous Breast Cancer Metastasis by Anti-Thomsen-Friedenreich Antigen Monoclonal Antibody JAA-F11. Neoplasia 2006, 8, 939-948.

165. Rittenhouse-Olson, K., Therapeutic use of anti-TF-Antigen antibody. Google Patents: 2008.

166. Matsumoto-Takasaki, A.; Horie, J.; Sakai, K.; Furui, Y.; Sato, R.; Kawakami, H.; Toma, K.; Takayanagi, A.; Shimizu, N.; Fujita-Yamaguchi, Y., Isolation and characterization of anti-T-antigen single chain antibodies from a phage library. Bioscience trends 2009, 3.

167. Yuasa, N.; Koyama, T.; Subedi, G. P.; Yamaguchi, Y.; Matsushita, M.; Fujita-Yamaguchi, Y., Expression and structural characterization of anti-Tantigen single-chain antibodies (scFvs) and analysis of their binding to Tantigen by surface plasmon resonance and NMR spectroscopy. The Journal of Biochemistry 2013, 154, 521-529.

168. Ravn, P.; Danielczyk, A.; Jensen, K. B.; Kristensen, P.; Christensen, P. A.; Larsen, M.; Karsten, U.; Goletz, S., Multivalent scFv display of phagemid repertoires for the selection of carbohydrate-specific antibodies and its application to the Thomsen-Friedenreich antigen. Journal of molecular biology 2004, 343, 985-996.

169. Waibel, R.; Alberto, R.; Willuda, J.; Finnern, R.; Schibli, R.; Stichelberger, A.; Egli, A.; Abram, U.; Mach, J.-P.; Plückthun, A., Stable one-step technetium-99m labeling of His-tagged recombinant proteins with a novel Tc (I)-carbonyl complex. Nature biotechnology 1999, 17, 897.

170. Badar, A.; Williams, J.; de Rosales, R. T.; Tavaré, R.; Kampmeier, F.; 
Blower, P. J.; Mullen, G. E., Optimising the radiolabelling properties of technetium tricarbonyl and His-tagged proteins. EJNMMI research 2014, $4,14$.

171. Novak-Hofer, I.; Waibel, R.; Zimmermann, K.; Grünberg, J.; Chester, K. A.; Murray, A.; Lo, B. K.; Perkins, A. C.; Schubiger, P. A., Radiometal labeling of antibodies and antibody fragments for imaging and therapy. In Antibody Engineering, Springer: 2004; pp 481-494.

172. Schneider, D. W.; Heitner, T.; Alicke, B.; Light, D. R.; McLean, K.; Satozawa, N.; Parry, G.; Yoo, J.; Lewis, J. S.; Parry, R., In Vivo Biodistribution, PET Imaging, and Tumor Accumulation of $86 \mathrm{Y}$-and ${ }^{111} \mathrm{In}$ Antimindin/RG-1, Engineered Antibody Fragments in LNCaP TumorBearing Nude Mice. Journal of nuclear medicine: official publication, Society of Nuclear Medicine 2009, 50, 435.

173. D'huyvetter, M.; Vincke, C.; Xavier, C.; Aerts, A.; Impens, N.; Baatout, S.; De Raeve, H.; Muyldermans, S.; Caveliers, V.; Devoogdt, N., Targeted radionuclide therapy with $A{ }^{177}$ Lu-labeled anti-HER2 nanobody. Theranostics 2014, 4, 708.

174. Chatalic, K.; Veldhoven-Zweistra, J.; Bolkestein, M.; Hoeben, S.; Koning, G. A.; Boerman, O. C.; de Jong, M.; van Weerden, W. M., A novel ${ }^{111} \mathrm{In}$ labeled anti-prostate-specific membrane antigen nanobody for targeted SPECT/CT imaging of prostate cancer. J Nucl Med 2015, 56, 1094-1099.

175. Hofström, C.; Altai, M.; Honarvar, H.; Strand, J.; Malmberg, J.; Hosseinimehr, S. J.; Orlova, A.; Gräslund, T. r.; Tolmachev, V., HAHAHA, 
HEHEHE, HIHIHI, or HKHKHK: influence of position and composition of histidine containing tags on biodistribution of $\left[{ }^{99 m} \mathrm{Tc}(\mathrm{CO})_{3}\right]^{+}$-labeled affibody molecules. Journal of medicinal chemistry 2013, 56, 4966-4974.

176. Tolmachev, V.; Hofström, C.; Malmberg, J.; Ahlgren, S.; Hosseinimehr, S. J.; Sandström, M.; Abrahmsén, L.; Orlova, A.; Gräslund, T. r., HEHEHEtagged affibody molecule may be purified by IMAC, is conveniently labeled with $\left.{ }^{99 \mathrm{~m}} \mathrm{Tc}(\mathrm{CO})_{3}\right]^{+}$, and shows improved biodistribution with reduced hepatic radioactivity accumulation. Bioconjugate chemistry 2010, 21, 2013-2022.

177. Elvas, F.; Vangestel, C.; Rapic, S.; Verhaeghe, J.; Gray, B.; Pak, K.; Stroobants, S.; Staelens, S., Characterization of $\left[{ }^{99 m} \mathrm{Tc}\right]$ duramycin as a SPECT imaging agent for early assessment of tumor apoptosis. Molecular Imaging and Biology 2015, 17, 838-847.

178. Huang, L.; Gainkam, L. O. T.; Caveliers, V.; Vanhove, C.; Keyaerts, M.; De Baetselier, P.; Bossuyt, A.; Revets, H.; Lahoutte, T., SPECT imaging with ${ }^{99 \mathrm{~m}} \mathrm{Tc}$-labeled EGFR-specific nanobody for in vivo monitoring of EGFR expression. Molecular imaging and biology 2008, 10, 167-175.

179. Behr, T. M.; Sharkey, R. M.; Juweid, M. E.; Blumenthal, R. D.; Dunn, R. M.; Griffiths, G. L.; Bair, H.-J.; Wolf, F. G.; Becker, W. S.; Goldenberg, D. M., Reduction of the renal uptake of radiolabeled monoclonal antibody fragments by cationic amino acids and their derivatives. Cancer research $1995,55,3825-3834$.

180. Barone, R.; Pauwels, S.; De Camps, J.; Krenning, E. P.; Kvols, L. K.; 
Smith, M. C.; Bouterfa, H.; Devuyst, O.; Jamar, F., Metabolic effects of amino acid solutions infused for renal protection during therapy with radiolabelled somatostatin analogues. Nephrology Dialysis Transplantation 2004, 19, 2275-2281.

181. Pinsky, P. F.; Bellinger, C. R.; Miller Jr, D. P., False-positive screens and lung cancer risk in the National Lung Screening Trial: Implications for shared decision-making. Journal of medical screening 2018, 25, 110-112. 


\section{VITA}

Manankumar Shah was born on April 27, 1988 in Vadodara, India. He is the son of Anilkumar and Darshnaben Shah. He graduated from high school from Bright English Medium High School in 2005. Manankumar attended Sardar Patel University in Vallabh Vidhyanagar in Gujarat province, India and received Bachelor of Pharmacy degree in 2009. Manankumar moved to the United States of America in 2009 to pursue Master of Science (M.S.) in Pharmaceutical Chemistry from New Jersey Institute of Technology, New Jersey. He graduated with M.S. degree in 2011 and worked in industry for two years before starting the Ph.D. program at University of Missouri in 2013. He joined the group of Dr. Thomas Quinn in Biochemistry department in May 2014 and is expected to complete his Ph.D. in Biochemistry in December 2018. 